\title{
The micro/nano-PCMs for thermal energy storage systems: A state of art review
}

\author{
Adeel Arshad ${ }^{\mathrm{a}, *}$, Mark Jabbal $^{\mathrm{a}}$, Yuying Yan $^{\mathrm{a}, \mathrm{b}, *}$, Jo Darkwa $^{\mathrm{c}}$ \\ ${ }^{a}$ Fluids $\& 3$ Thermal Engineering (FLUTE) Research Group, Faculty of Engineering, University of Nottingham, \\ Nottingham NG7 2RD, UK \\ ${ }^{b}$ Research Centre for Fluids and Thermal Engineering, University of Nottingham Ningbo China, Ningbo 315100, China \\ ${ }^{c}$ Building, Energy and Environment (BEE) Research Group, Faculty of Engineering, University of Nottingham, \\ Nottingham NG7 2RD, UK
}

\begin{abstract}
With advancement in technology, the nanotechnology, various thermal energy storage (TES) materials have been invented and modified with promising thermal transport properties. The solid-liquid phase change materials (PCMs) have been extensively used as TES materials for various energy applications due to their highly favourable and potential thermal properties. The class of PCMs, organic phase change materials (OPCMs) have more potential and advantages over the class, inorganic phase change materials (IPCMs) having high phase change enthalpy (positive advantage). However, the OPCMs possess low thermal conductivity as well as density and suffer leakage during the melting phase. The encapsulation technologies (i.e. micro and nano) of PCMs, with organic and inorganic materials, have a tendency to enhance the thermal conductivity, effective heat transfer, and leakage issues as TES materials. The encapsulation of PCMs involves several technologies to develop at both micro and nano levels, called micro-encapsulated PCMs (micro-PCM) and nano-encapsulated PCMs (nano-PCM) respectively. This study covers a wide range of preparation methods, thermal and morphological characteristics, their stability, applications and future perspective of micro/nano-PCMs as TES materials. The potential applications such as solar-to-thermal, electrical-to-thermal, thermal management, building, textile, foam, medical industry of micro- and nano-PCMs are reviewed critically. Finally, this review paper highlights the emerging future research paths of the mico/nano-PCMs for the researchers who are working in the area of thermal energy storage.
\end{abstract}

Keywords: Nanotechnology, Thermal energy storage, Phase change materials, Micro-encapsulated, Nano-encapsulated, Micro-PCM, Nano-PCM, Encapsulation technologies

\footnotetext{
* Correspondence authors

Email addresses: adeel.arshad@nottingham.ac.uk, adeel_kirmani@hotmail.com (Adeel Arshad), yuying.yan@nottingham.ac.uk (Yuying Yan)
} 


\section{Introduction}

After energy crisis of the 1970s, the world is facing worse shortage of energy resources and facing economic decline cumulatively. Researchers are looking forward towards different energy storage technologies based on renewable and sustainable resources to meet the future energy requirements [1]. The phase change thermal energy storage (TES) technology using phase change materials (PCMs) ensures the storage, transportation and wider domestic and industrial applications of thermal energy. The TES technology has the high heat capacity and enthalpy of fusion with capability of absorbing and releasing extensive amount of thermal energy while phase transition. The thermal performance of phase change TES technology employing PCMs which are also known as latent heat storage materials (LHSMs), solely depends on the properties of PCMs. On the bases of chemical composition, PCMs are classified in to major categories, organic phase change materials (OPCMs) and inorganic phase change materials (IPCMs). The positive advantage of PCMs especially, OPCMs which includes paraffins (n-alkanes) and non-paraffins (n-alkenes) materials, are more stable and high energy storage density and no segregation, non-toxic, self nucleation (super-cooling), non corrosiveness and non-reactive 2]. Contrarily, IPCMs have the high volumetric energy storage density, relatively high thermal conductivity and flame retardancy. In spite of this, IPCMs possess the sub-cooling and phase separation which reduce their instant release and utilization of thermal energy for large-scale TES applications. The OPCMs have the lower thermal conductivity [3] also they suffer the leakage problem and sub-cooling phenomenon during phase transition 4]. The lower thermal conductivity of OPCMs materials reduces the rate of heat transfer which causes increase in temperature gradient and insensitivity to temperature changes across the system boundaries. The OPCMs with potential advantage as TES materials are being under applications of air conditioning i.e. natural air cooling [5], cold thermal storage and absorption refrigeration 6, 7], waste heat recovery 8, 9], solar energy storage [10, 11], thermal regulating fabric [12, 13], passive heating of building [14, 15, 16. 17], heat pipes [18], desalination [19], thermal management of electronic devices and electric vehicle batteries $20,21,22,23,24,25,26,27,28,29$, space craft 30,31 , and other integrated thermal control systems such as trombe wall, PCM filled wallboards, shutter, concrete, under floor heating systems, ceiling boards and hot water supply [32, 33]. However, the leakage issue and lower thermal conductivity of OPCMs causes harm with interacting medium and losses the energy efficiency of the thermal system.

In the past, to solve the aforementioned challenges related with both types of PCMs efforts have been made. Various conventional approaches such as the adding up of more water, nucleating agents, thickeners and stirring of the salt solution have been employed to control the predicaments of IPCMs in their constant dissolution and crystallization procedure 34]. In contrary, the addition of conductive fillers and flame-retardants has reduced the disadvantages of OPCMs. On the other hand, these efforts would certainly lessen the energy storage density of PCMs due to the presence of inactive mass [35. At present, nanoconfinement technologies have attracted a lot of interest and present a new opportunity for considerable refinement in the thermophysical properties of PCMs while sustaining their energy storage capacity 36, 37. There are several advantages associated with nanoconfinement like small domain size, large surface area, diverse surface functionalities, controlled volume expansion, reduced reactivity with the external environment and high heat transfer rate. 
Confinement is the procedure of enclosing liquid or solid PCMs within supporting materials to fabricate a type of composite PCM. The main function of confinement is to stop the contact of the liquid phase of PCMs with the surrounding environment 38. The surface chemistry occupied at the interfaces of two phases such as solid-liquid or liquid-gas, has a considerable effect on the thermodynamic properties of composite PCMs. So, confinement technology can be applied to control the phase change parameters by a new mechanistic way by heterogeneous nucleation, large contact area and associated surface energy in a confined environment. Therefore, confinement is useful to reduce the drawbacks of PCMs as well as to enhance the thermophysical properties. For example, the confinement of salt hydrates inside packaging materials not only restrains the loss of water of crystallization during the phase transition to resolve the phase dissociation and supercooling phenomena but also enhances the heat transfer duration. Depending on the size, confinement technology can be classify into macro-confinement, micro-confinement and nano-confinement. Different kind of physical properties like adhesion forces, Van der Waals interactions, capillary actions and surface chemistries are more effective at the nanoscale while confinement. For that reason, nano-confinement technology has proven to more valuable than macro and micro-confinement 39, 40. Additionally, nano-confinement provide better heat transfer, and accommodates dimensional changes related with the phase transition of PCMs. According to material designs and dimensions, confinement strategies can be classified into as:

1. Core-shell confinement $(0 D)$

2. Longitudinal confinement $(1 D)$

- Tubular confinement

- Fibrous confinement

3. Interfacial or Layer confinement $(2 D)$

4. Porous confinement $(3 D)$

In core-shell confinement, a small particle of liquid or solid PCMs is coated with shell material exhibits the zero-dimensionality. longitudinal confinement is also similar to core-shell confinement but it has the one-dimensional $(1 D)$. According to shell materials, longitudinal confinement is further achieved either by infiltrating the melted PCM into the inner cavity of nanotubes (tubular confinement) such as CNTs or by restraining the PCMs within the internal diameter of nanofibers (fibrous confinement) employing coaxial electrospinning technique. Interfacial or layer confinement technology cover the confinement of PCMs at the interface of nanomaterials by the interaction between PCM molecules and the surface of nanomaterials such as graphene oxide. In nanoporous confinement, the PCMs are impregnated into the nanopores of the supporting materials through a vacuum develop infiltration method, shown in Figure 1. In term of size, the term core-shell nano-confinement is used if the size of the capsules vary between $1-1000 \mathrm{~nm}$ and for longitudinal confinement, the diameter of nanotubes or nanofibers should vary from $1-1000 \mathrm{~nm}$.

Here in current study, the core-shell confinement of PCMs is further reviewed in detail. PCMs are encapsulated in a capsule of a core-shell composite construction called encapsulated phase change materials (EPCMs) 42, 43, 44]. The EPCMs are tiny capsules or containers, consisting of two parts: (i) 


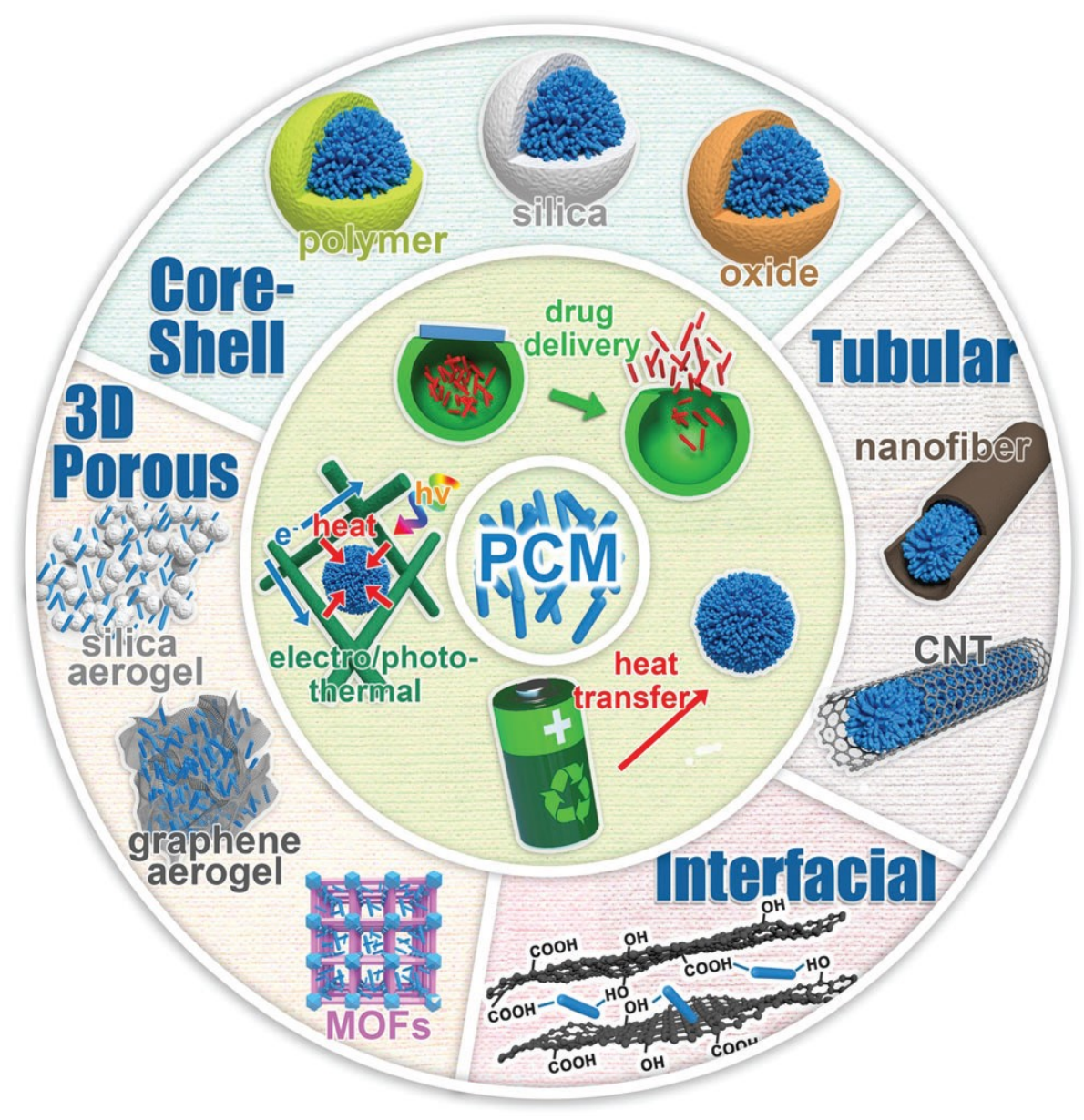

Figure 1: Confinement strategies and potential applications of PCMs. Reused from Ref. [41] with permission from The Royal Society of Chemistry.

core of PCMs and (ii) shell of polymer or inorganic materials which may have core-shell, multi-shell and polynuclear structure depending on the synthesis technique, as shown in 2 . These capsules are both in regular (e.g. spherical, tubular, and oval) and irregular shapes. Additionally, the structural arrangement of the capsule depends on the core material and deposition process of the shell 45 . The material of coating shell has a very significant importance in terms to provide structural integrity and stability. Particularly, to gain the heat transfer rate, the encapsulated PCMs need mechanically strong and thermally conductive shell materials. The proportion of core and shell materials therefore is a key parameter to enhance the TES capability and structural stability applied both in non-flow and flowing system. Weight percentage of both core and shell materials are relatively depends on each other which defines the TES performance. A high weight percentage of shell material reduces the heat storage capacity of core PCM but alternatively increases the structural stability and vice versa $46,47,48$. Therefore, the mass of coating material needs to be optimized to obtain the desired thermophysical properties. Various coating materials such as organic polymers, silica, metal oxides and hydroxides have been utilized. Furthermore, the selection of the shell material is based on encapsulation technique and type of PCM. Generally, polymers are used as a traditional coating materials for encapsulation of PCMs. The positive features of using polymers as shell materials are that they are cheap, lightweight, mechanically stable, easily processable and compatible 
with PCMs [49]. In addition, as the polymers have the flexible nature which compensate the expanded volume of PCM while phase transition resulting ease the melting and keep the shape in stable of prepared NCs. Such promising physical properties of polymers prefer them to use as shell material for PCM encapsulation. Heretofore, polystyrene (PS), polyurea (PU), poly(urethene), polyacrylates, poly-amide (PA), polymethyl methacrylate (PMMA), polyethly methacrylate (PEMA) and formaldehyde resins have been utilized as shell materials to encapsulate OPCMS. So far many encapsulation technologies have been introduced as (i) micro and nano encapsulation, (ii) shape-stabilized composite, and (iii) intercalation. The encapsulation of the PCMs are classified into three major categories based on the particle size under core-shell confinement strategy:

- Macro-encapsulated PCM (Macro-PCM) (1mm)

- Micro-encapsulated PCM (Micro-PCM) $(1-1000 \mu m)$

- Nano-encapsulated PCM (Nano-PCM) $(1-1000 \mathrm{~nm})$
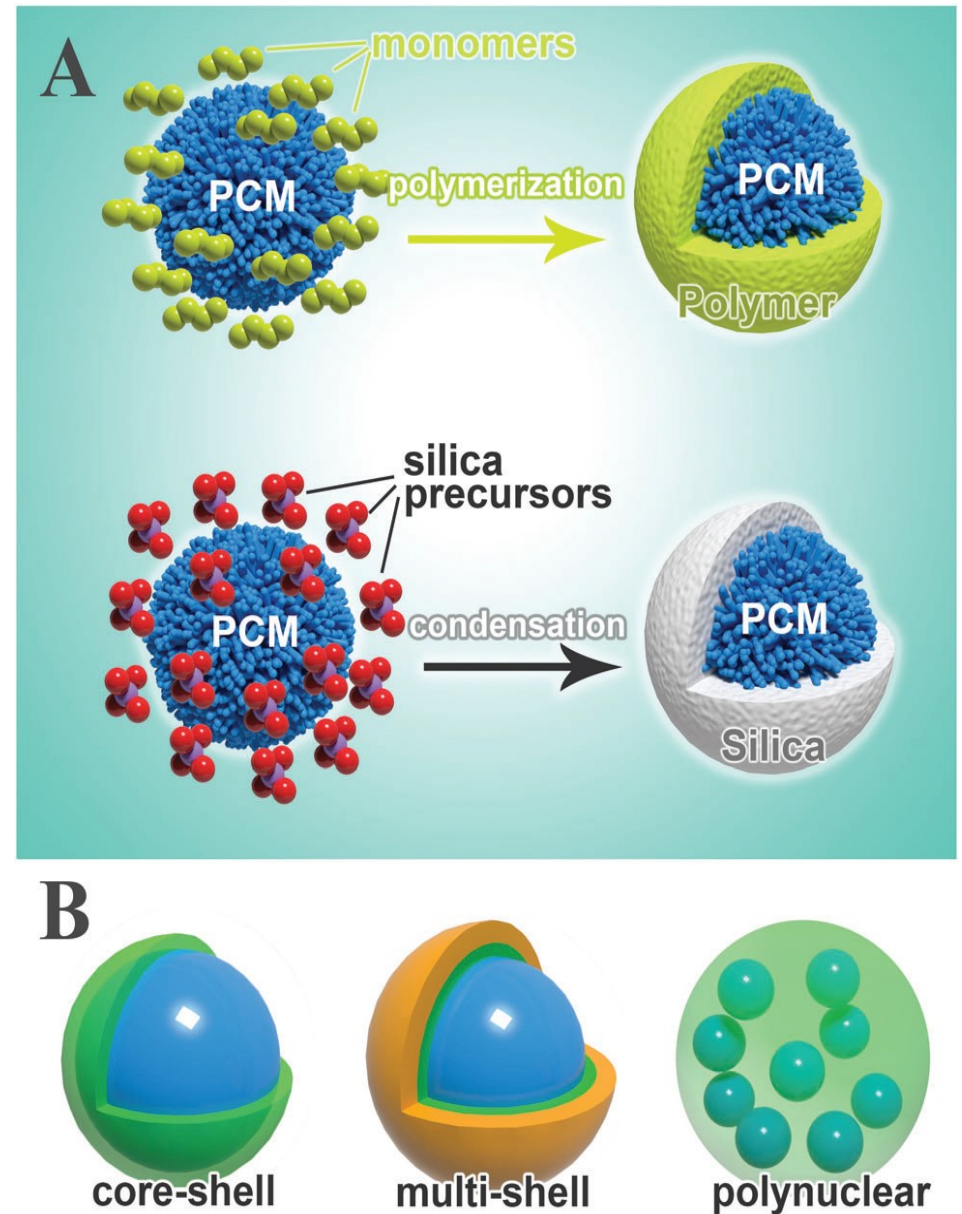

Figure 2: (A)-Synthetic illustration of phase change EPCMs (B) and various structures. Reused from Ref. [41] with permission from The Royal Society of Chemistry.

The OPCMs with temperature range of -10 to $80^{\circ} \mathrm{C}$ are mostly under development with various encapsulation techniques into micro and nano capsules [50]. The encapsulation techniques depend on 
the physical and chemical properties of shell and core materials as well the method of encapsulation 50, 51, 52. From the 50 years developments in nanotechnology, the macro and micro encapsulation technologies of PCMs have gained a lot of improvement increasing the thermal performance and stability of encapsulated PCMs. As the stability of the EPCMs capsules relies on the size of particles, microPCMs can increase the viscosity of the fluid [53,54,55] also they can fractured in the fluid flow resulting the fluid flow obstacle. To overcome this issue, nano-PCMs of small particle size, large surface area, low leakage, uniform fluid flow and suspension stability have taken the attention as new TES materials for energy storage applications [56]. Additionally, the nano-PCMs have volume and surface effect, easily dispersed in fluid and steadily flow in slurry make them favourable in thermal energy storage and thermal management applications [57, 58].

Up to now, a few studies have summarised the progress on preparation of micro-PCMs [59, 60] and nano-PCMs [40]. However, this review critically summarises the research in the area of novel energy storage materials for the applications of TES systems. Initially, ideal characteristics of EPCMs are elaborated which are potentially necessary to enhance the thermal storage and heat transfer performance. Further, the detailed discussion on preparation technologies to encapsulate PCM into macro--, micro-, and nanosized of capsule are discussed using physical-mechanical, physical-chemical, chemical-mechanical and chemical encapsulation methods. Thermophysical properties of these novel EPCMs are summarized representing their enhancement in thermal conductivity, latent heat of fusion and encapsulation efficiency. Additionally, the detail discussion on characterisation techniques are explained to evaluate the chemical, thermal, physical, morphological, thermal reliability and thermal cyclic properties of EPCMs. The stability which is a real challenge of the PCMs capsules is discussed with respect to chemical and thermal properties point of view to explore the functionality and thermodynamic nature as an energy storage materials. The potential applications such as solar-to-thermal, electrical-to-thermal, thermal management, building, textile, foam, and medical industry of micro and nano PCMs are reviewed critically. Finally, this review paper highlights the emerging future research directions of EPCMs for the scientist and researchers to explore the unhidden characteristics in area of TES.

\section{Ideal characteristics of EPCM}

An ideal characteristics of EPCM significant influence the thermal systems while performing as a TES material especially at varying operating conditions. Thus, for an ideal EPCM it is necessary to meet the specific criteria and environment conditions for a longer duration. Figure 3 presents the ideal characteristics of EPCM which are necessary for utilization of thermal applications. Since, these ideal characteristics of EPCMs depend on their fundamental chemical, physical, thermal and economics properties which are as follows 61 :

- Sufficient phase-transition temperature: The suitable phase change temperature of EPCM is very essential and must match the operating conditions of specific application at melting and solidification temperature points.

- High latent heat of fusion: The latent heat of fusion, also called enthalpy of fusion, of the EPCM 
is the most desirable thermal property to absorb large amount of heat with less amount of volume especially to reduce the size of the TES system which makes it light weight. EPCMs based on the organic PCMs as core materials and polymeric materials as a shell, have the tendency to absorb higher latent heat.

- High thermal conductivity: The higher thermal conductivity provides the additional capability to store thermal energy while sensible heating phase resulting lower the charging and discharging phases. The inorganic materials coated EPCM have the more potential to increase the thermal conductivity resulting in transmit the heat at higher rate. However, the increase in thermal conductivity of EPCMs causes the less absorption of latent heat fusion.

- Durability: The EPCM must has to withstand from damage, friction, wear and tear. The strength of coated shell of EPCM has to sustain its mechanical properties while flowing through system.

- High density and small volume change at phase transition: The high density of the EPCM helps to reduce size of encapsulated container at smaller level. The small volume change while phase transformation help to minimize the complexity of the EPCM storage container.

- Congruent melting: The congruent melting of the EPCMs helps to prevent the irreversible segregation resulting reduces the loss of storage capacity while recycling.

- Favourable phase equilibrium: The favourable or suitable phase equilibrium temperature ensure the heat storage and extraction at constant temperature in TES system.

- Long-term chemical stability: The continuous charging and discharging of EPCMs, water loss, decomposition or chemical interaction with storage container can undergo the degradation in EPCMs. So, it is highly preferred that EPCMs should maintained its long-term chemical stability and corrosion resistance interacting with other materials.

- Non-hazardous: For safety measures, the EPCMs should be non-toxic, non-flammable and nonexplosive.

- High nucleation rate: An ideal EPCM should have high nucleation rate and good crystallization rate.

- Low super-cooling or sub-cooling: The low sub-cooling, also called super-cooling, ensures the melting and cooling at the same temperature which is due to metastable condition of the EPCM while solidification which means that during cooling the EPCM is not in thermodynamics equilibrium state. The super-cooling particularity occurs in salt-hydrates which prevents the extraction of thermal energy.

- Low vapour pressure and adequate crystallization rate: The low pressure and rapid crystallization of EPCM help to reduce the design complexity of EPCM storage system. 
- Low cost and availability: The cost and availability of EPCM have the major significance on the overall cost of the thermal system. As the development of EPCMs require high precision and clean environment so it may increase the cost of ECMs.

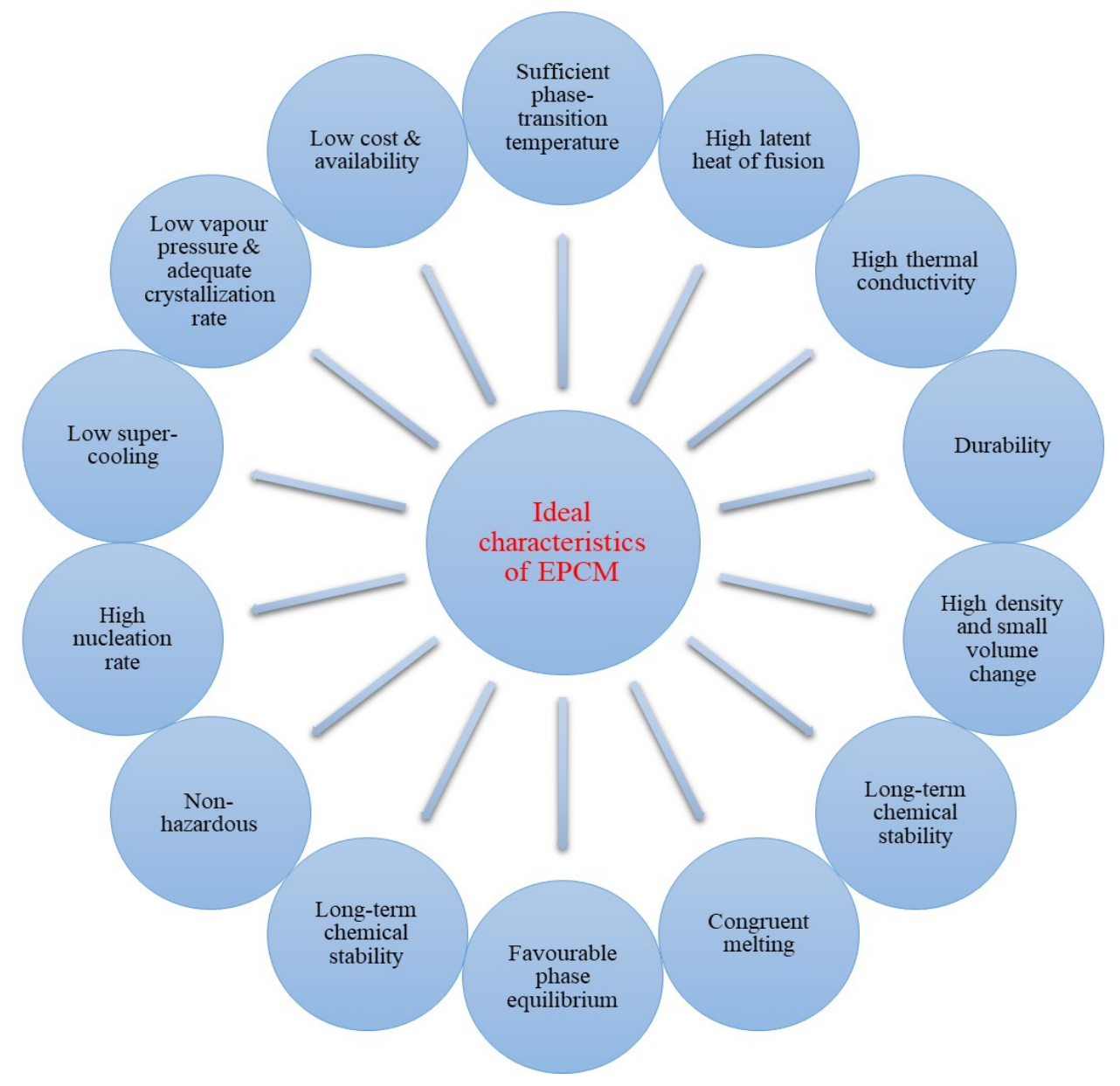

Figure 3: Ideal characteristics of EPCM.

\section{The preparation technologies for EPCMs}

The encapsulation techniques of PCMs are usually categories into four different methods; (i) physicalmechanical, (ii) physical-chemical, (iii) chemical-mechanical and (iv) chemical, which are based on synthesis of the EPCMs. Table1 1 highlights a brief summary of above mentioned methods, their sub-relevant techniques and resulting formed size of capsules for the relevant type of PCMs.

\subsection{Physical-mechanical methods}

Generally, the physical-mechanical methods do not involve any chemical reaction resulting in formed the micro-capsules of not so much smaller size. The Table 2 summaries the properties of each technique of physical-mechanical method. The advantages and disadvantages of physical-mechanical methods are summarized in Table 3. The physical-mechanical methods include the following techniques forming micro-capsules. 
Table 1: Summary of encapsulation methods, techniques, formed capsules, and type of PCMs.

\begin{tabular}{|c|c|c|c|}
\hline \multirow{4}{*}{ Methods } & Techniques & Formed capsules & PCMs \\
\hline \multirow{4}{*}{ Physical-mechanical } & Pan coating & micro & organic \\
\cline { 2 - 4 } & Air-suspension coating & micro & organic \\
\cline { 2 - 4 } & Centrifugal extrusion & micro & organic \\
\cline { 2 - 4 } & Vibration nozzle & micro & organic \\
\cline { 2 - 4 } & Spray drying & micro & organic \\
\cline { 2 - 4 } & Solvent evaporation/extraction & micro & organic \\
\hline \multirow{4}{*}{ Physical-chemical } & Vacuum impregnation & micro & organic \\
\cline { 2 - 4 } & Ionic gelation & micro & organic \\
\cline { 2 - 4 } & Coacervation & micro & organic \\
\hline \multirow{3}{*}{ Chemical-mechanical } & Sol-gel method & micro/nano & organic/inorganic \\
\cline { 2 - 4 } & Micro-fluidic Method & micro & organic \\
\cline { 2 - 4 } & Melt-coaxail electrospray method & micro & organic \\
\cline { 2 - 4 } & Interfacial polymerization & micro/nano & organic/inorganic \\
\cline { 2 - 4 } & Suspension polymerization & micro & organic \\
\cline { 2 - 4 } & Emulsion polymerization & micro/nano & organic/inorganic \\
\cline { 2 - 4 } & Miniemulsion polymerization & nano & organic/inorganic \\
\cline { 2 - 4 } & In-situ polymerization & nano & organic/inorganic \\
\hline
\end{tabular}

Table 2: Advantages and disadvantages of physical-mechanical methods.

\begin{tabular}{|c|c|c|}
\hline Techniques & Advantages & Disadvantages \\
\hline Pan caoting & Low cost production & $\begin{array}{l}\text { High skilled manpower required } \\
\text { Difficulty in control }\end{array}$ \\
\hline Air-suspension coating & $\begin{array}{l}\text { Low cost } \\
\text { large production volume }\end{array}$ & $\begin{array}{l}\text { High skilled level required } \\
\text { Agglomeration of particles }\end{array}$ \\
\hline Centrifugal extrusion & Suitable for encapsulation & High temperature range \\
\hline Vibrational nozzle & $\begin{array}{l}\text { Large volume of production } \\
\text { Easily scaled-up }\end{array}$ & High temperature range \\
\hline Spray drying & $\begin{array}{l}\text { Easily scaled- up } \\
\text { Easy availability of equipment } \\
\text { Controllable to produce }\end{array}$ & $\begin{array}{l}\text { High temperature range } \\
\text { Agglomeration of particles } \\
\text { Uncoated particle }\end{array}$ \\
\hline Solvent evaporation & $\begin{array}{l}\text { Economical } \\
\text { Easily scaled-up }\end{array}$ & Limited for lab production \\
\hline Vacuum impregnation & $\begin{array}{l}\text { Feasible to remove moisture } \\
\text { Low cost }\end{array}$ & Limited for large-scale production \\
\hline
\end{tabular}


- Pan coating

- Air-suspension coating

- Centrifugal extrusion

- Vibration nozzle

- Spray drying

- Solvent evaporation/extraction

- Vacuum impregnation

\subsubsection{Pan coating}

The pan coating process is the oldest and widely used in pharmaceutical industries to form small coated particles and pellets. The solid particles are mixed with a dry coating material then heated to a set temperature, thus melts the coating material, encloses the core of the capsule (e.g PCMs); and solidified by cooling medium. The alternative method is to gradually apply or spray the coating material onto the core material or particles into the tumbler machine/vessel resulting reduces the processing time as well energy and material consumption 62 . In this technique, the melting temperature of core material must be higher than the shell material melting temperature otherwise PCM encapsulation will not be eventuated effectively.

\subsubsection{Air-suspension coating}

Adopting air-suspension technique for micro-encapsulation gives more control and flexibility in comparison to pan coating by charging operation times of core material into the coating zone while processing 63. Solid particle are suspended in an upward air stream after coating and drying in the solutions with both water and volatile organic solvents. During a cyclic process in coating zone, the shell material usually polymer or inorganic material, is repeatedly sprayed on the core particles up to the required level of thickness for encapsulation. This encapsulation technique was employed for pharmaceutical [64], food 65], and cosmetic industries 66 and it is not suitable for PCM encapsulation. Figure 4 shows the typical operating principle of air-suspension particle operation with two growth mechanism of inter-particle agglomeration and surface layer.

\subsubsection{Centrifugal extrusion}

Southwest Research Institute (SwRI) 63 developed a mechanical process to produce the microcapsules on the principle of centrifugal force in which the core material, which is in liquid phase, flows through inside a tube. The coating or shell material which should be immiscible with core material, flow through the annular around the tube. The key parameters which influence the process are, rotational speed of cylinder, flow rate of core and shell materials, concentration, viscosity and surface tension of the core material. With the rotation or vibration of the tube the core and coating materials extrude from the orifice making spherical capsules due to surface tension forces. After then, the coated capsules are 


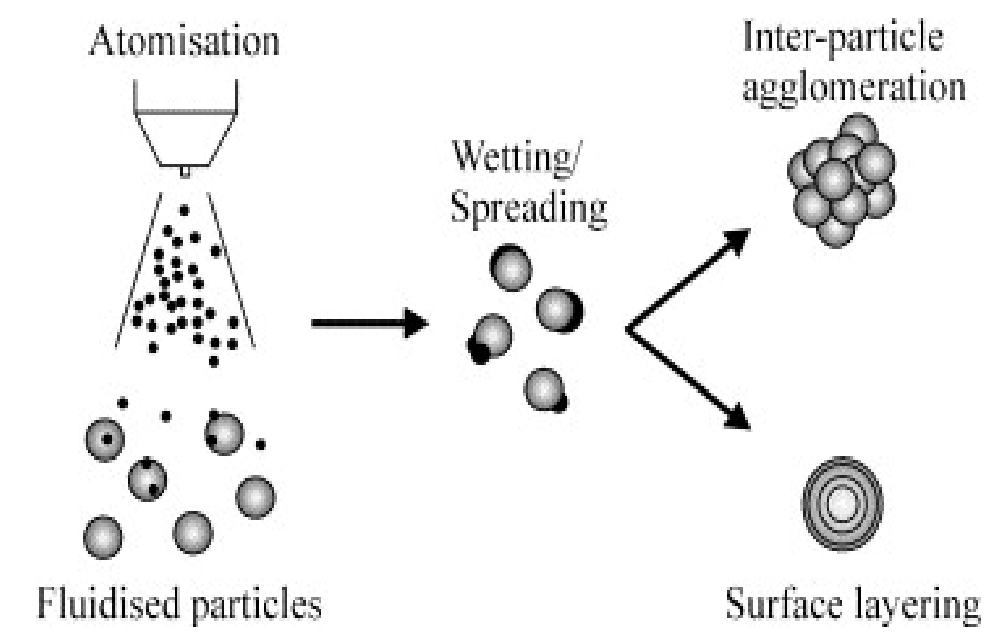

Figure 4: Two particle growth mechanisms (inter-particle agglomeration and surface layering) in an air-suspension particle operation 65], reused with permission from Elsevier license number 4385850236206.

solidified by heat or chemical reactions in a bath 45,67 . There is no study found of PCM encapsulation using this method.

\subsubsection{Vibration nozzle}

There are several studies available but without vibration, in which micro-granulation or matrixencapsulation is normally carried out through a vibrating nozzle under laminar flow regime. The uniform capsules are formed due to vibration 68, however this method has been carried out for PCM encapsulation. Some studies were reported the uniform stable PCM composites prepared by this method but without vibration $69,70,71,72,73,74,75$.

\subsubsection{Spray drying}

The spray drying encapsulation technique is an economical and easily scaled-up and controllable to produce homogeneous micro size capsules with efficient design of the atomizer 76, 77, 78. The spray draying process is the most commonly used technique in food and pharmaceutical industries $79,80,81$, 82 due to suitibility of encapsulation of heat-sensitive materials. This technique involves three major following steps 83 . Figure 5 presents the flow process of typical spray drying encapsulation technique 67 .

- Preparation of the dispersion/emulsion of wall material.

- Homogenization of the dispersion/emulsion.

- Atomization of the in-feed dispersions.

- Dehydration/evaporation of the atomized particles.

The produced micro-capsules are usually poly-nuclear or matrix type and with increasing the production rate or flow rate, agglomerated and uncoated particles are obtained 45]. 


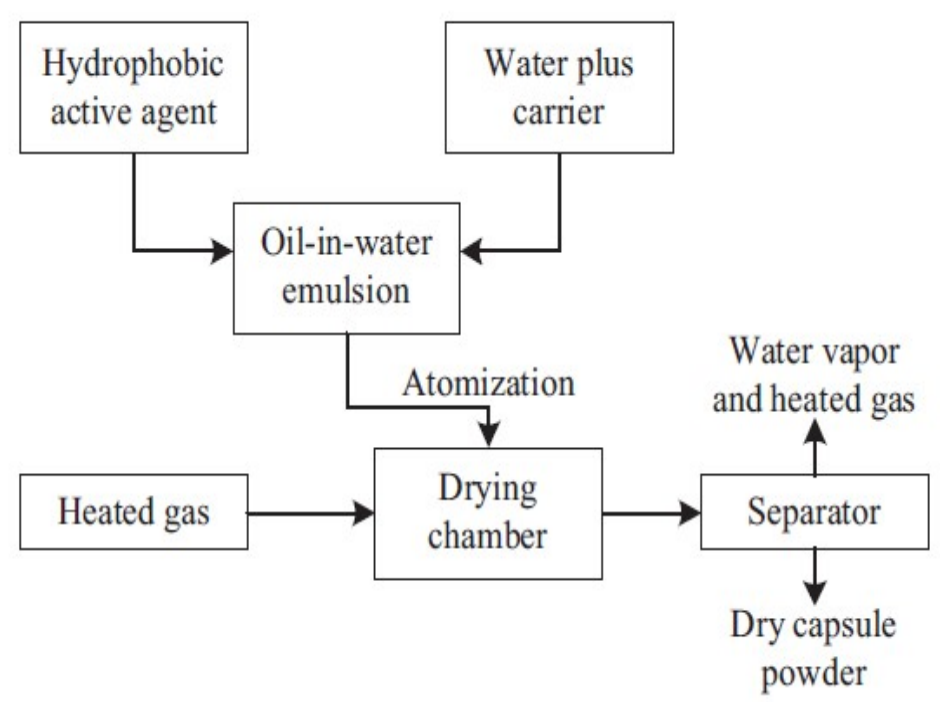

Figure 5: Flow diagram of spray drying encapsulation technique 67, reused with permission from John Wiley and Sons license number 4385841192579 .

\subsubsection{Solvent evaporation/extraction}

Solvent evaporation or extraction is extensively used in pharmaceutical industries and it is liquidliquid emulsification system. This technique is carried out in liquid manufacturing vehicle (LMV) and emulsification of polymer in a volatile solvent in water followed by a solvent removal. The basic steps of micro-encapsulation by solvent evaporation is shown in Figure 6] 84 . There are different methods of microencapsulation of drugs by solvent evaporation which depends on the hydrophilicity or the hydrophobicity of the core material. The detail procedure of solvent evaporation technique can be found in 84] .

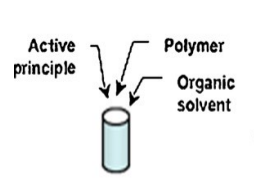

(1)

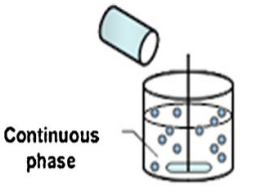

(2)

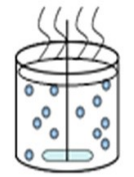

(3)

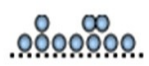

(4)

Figure 6: Basic step of micro-encapsulation by solvent evaporation 84, reused with permission from Elsevier license number 4385850567033 .

\subsubsection{Vacuum impregnation}

Vacuum impregnation technique is frequently used to remove air from the encapsulation materials and widely used in food industry. The process of macro-encapsulation carried out by Memon et al. 85] using paraffin as a core materials anf light weight aggregate (LWA) as a shell material for TES. The Figure 7 illustrates the preparing process of PCM (paraffin) and LWA using vacuum impregnation technique. 


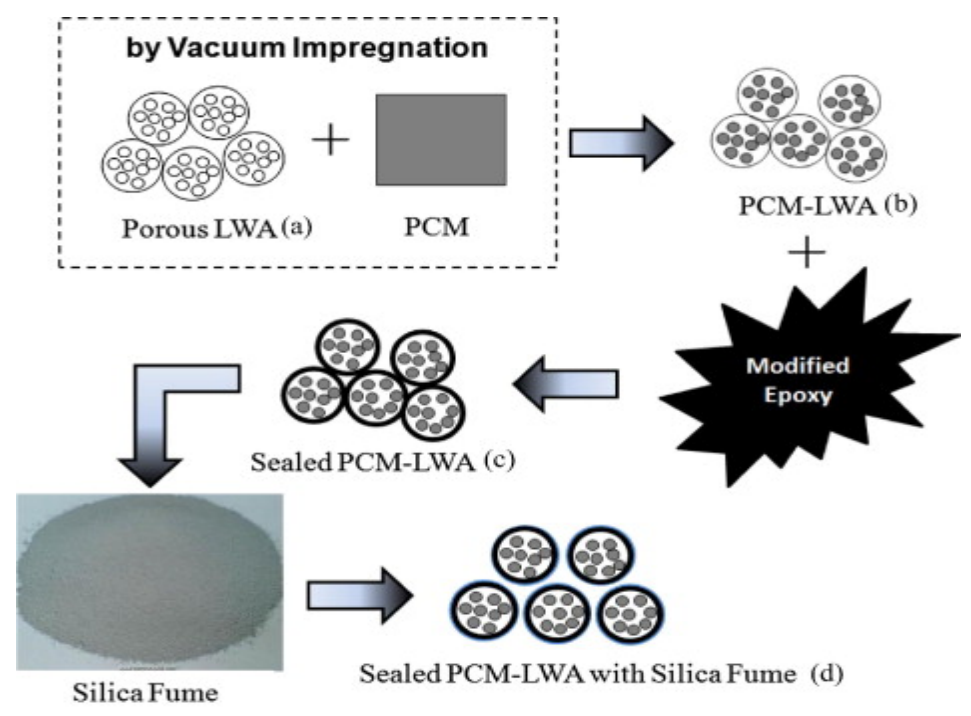

(a) Schematic image of the PCM-LWA preparing process

Figure 7: Flow process of a macro-encapsulated TES LWA (a)schematic image of PCM-LWA preparation process; (b) LWA; (c) paraffin-LWA; (d) paraffin-LWA coated with a mixture of epoxy graphite powder; and (e) paraffin-LWA graphite powder sample coated with silica fume [85], reused with permission from Elsevier license number 4385850945845. 
Table 3: Summary of prepared Micro-PCMs using physical-mechanical meth-

ods.

\begin{tabular}{|c|c|c|c|c|c|c|c|}
\hline Ref. & Method & Core & Shell & Particle size $(\mu m)$ & EE $(\%)$ & $T_{m}$ & $\begin{array}{c}\text { Latent heat } \\
\qquad(\mathrm{J} / \mathrm{g})\end{array}$ \\
\hline 78] & Spray drying & RT-27 & LDPE, EVA & 3.9 & 49.32 & 28.40 & 98.1 \\
\hline 86] & Spray drying & Paraffin wax & Gelatin and Gum arabic & $\sim 0.2$ & - & $\sim 60$ & 145 \\
\hline 87 & Spray drying & N-octadecane & $\mathrm{TiO}_{2}$ & $0.1-5$ & - & 28.7 & $92-97$ \\
\hline 88$]$ & Spray drying & Green coffee oil & Lecithin and chitosan & $1.35-3.70$ & 86 & - & - \\
\hline 89] & Spray drying & Flaxseed oil & Gum arabic & $\sim 20$ & $62.3-95.7$ & - & - \\
\hline 90] & Spray drying & $\begin{array}{l}\text { Lactobacillus plan- } \\
\text { tarum }\end{array}$ & WPI with SA, WPI with FOS & $53.99-105.07$ & $87.92-94.86$ & - & - \\
\hline 91] & Spray drying & Poppy-seed oil & Gelatin and Gum arabic & $\sim 5$ & 76.8 & 185 & - \\
\hline 85$]$ & $\begin{array}{l}\text { Vacuum impreg- } \\
\text { nation }\end{array}$ & Paraffin wax & LWA & $\sim 2 \times 10^{5}$ (macro) & 70 & 27 & 102.5 \\
\hline
\end{tabular}


Table 4: Advantages and disadvantages of physical-chemical methods.

\begin{tabular}{l|l|l}
\hline Techniques & Advantages & Disadvantages \\
\hline Ionic gelation & $\begin{array}{l}\text { Low cost production } \\
\text { Low temperature range }\end{array}$ & $\begin{array}{l}\text { High wall permeability } \\
\text { Difficulty in control }\end{array}$ \\
Coacervation & $\begin{array}{l}\text { Controllable to produce } \\
\text { Homogeoous particle size }\end{array}$ & $\begin{array}{l}\text { Limited to scaled-up } \\
\text { Agglomeration of particles } \\
\text { Aldehyde as hardener }\end{array}$ \\
Sol-gel method & $\begin{array}{l}\text { Suitable for encapsulation of inorganic shell } \\
\text { High thermal conductivity capsules }\end{array}$ & \begin{tabular}{l} 
Still need improvement \\
\hline
\end{tabular}
\end{tabular}

\subsection{Physical-chemical methods}

Generally, in physical-chemical methods include physical reactions such as, the phase separation, condensation, boiling and complexation etc. These include the following three main methods. The advantages and disadvantages of physical-chemical methods are summarized in Table 4 . Table 5 enumerates the thermophysical properties of prepared capsules under different types of physical-chemical methods.

- Ionic gelation

- Coacervation

- Sol-gel method

\subsubsection{Ionic gelation}

This method is generally used in pharmaceutical industries especially in drug supply systems and has not been carried out for the encapsulation of PCMs. In this method, the gel forming solution is dropped into droplet form in a gelation bath resulting hydrogel beads are formed. the gelation process may be occurred due the ionic bonding between the polymer chain such as the alginate solution is dropped in calcium bath which leads to the calcium alginate micro-capsules 92 or by cooling such as an agarose solution.

\subsubsection{Coacervation}

The coacervation word is derived form the Latin word "acerus" meaning "heap" 93]. Generally, the coacervation method is classified under two methods; (i) simple coacervation and (ii) complex coacervation. In simple coacervation method, the low-molecular substance is interacted dissolved polymer. The complex coacervation method, the interaction happens between two polymers who have the opposite charges. The complex coacervation method involves the mixture of two polymers and complexation processes such as cross linking, desolvation and thermal treatment which requires the extra cost and more unyielding operation as compare to simple coacervation. However, complex coacervation method produces more smaller size micro-capsules of spherical shape with greater stability. Figure 8 represents the typical flow diagram of complex coacervation. The complex coacervation consists of three stages; (i) the preparation of the oil-water emulsion by adding the core material (usually oil) dispersed in water forming 
a phase separation coacervation with aqueous polymer solution; (ii) the deposition of the shell material onto the core particles by adding second aqueous polymer solution of oppositely electric charge followed by adjusting the $\mathrm{pH}$ number, temperature or by dilution of the medium; (iii) finally, the mixture is cool down forming micro-encapsulation with stabilization by cross-linking and harvesting of the Micro-PCMs or thermal treatment 45,94 .

From complex coacervation, Konuklu et al. 95 produced micro-PCM using caprylic acid (octanic acid) using various wall materials (urea-formaldehyde resin, melamine formaldehyde resin and urea+melamine-formaldehyde resin) suitable for TES applications. The schematic of flow process and SEM image of produced particle size of mirco-capsules are shown in Figure 9 and Figure 10.

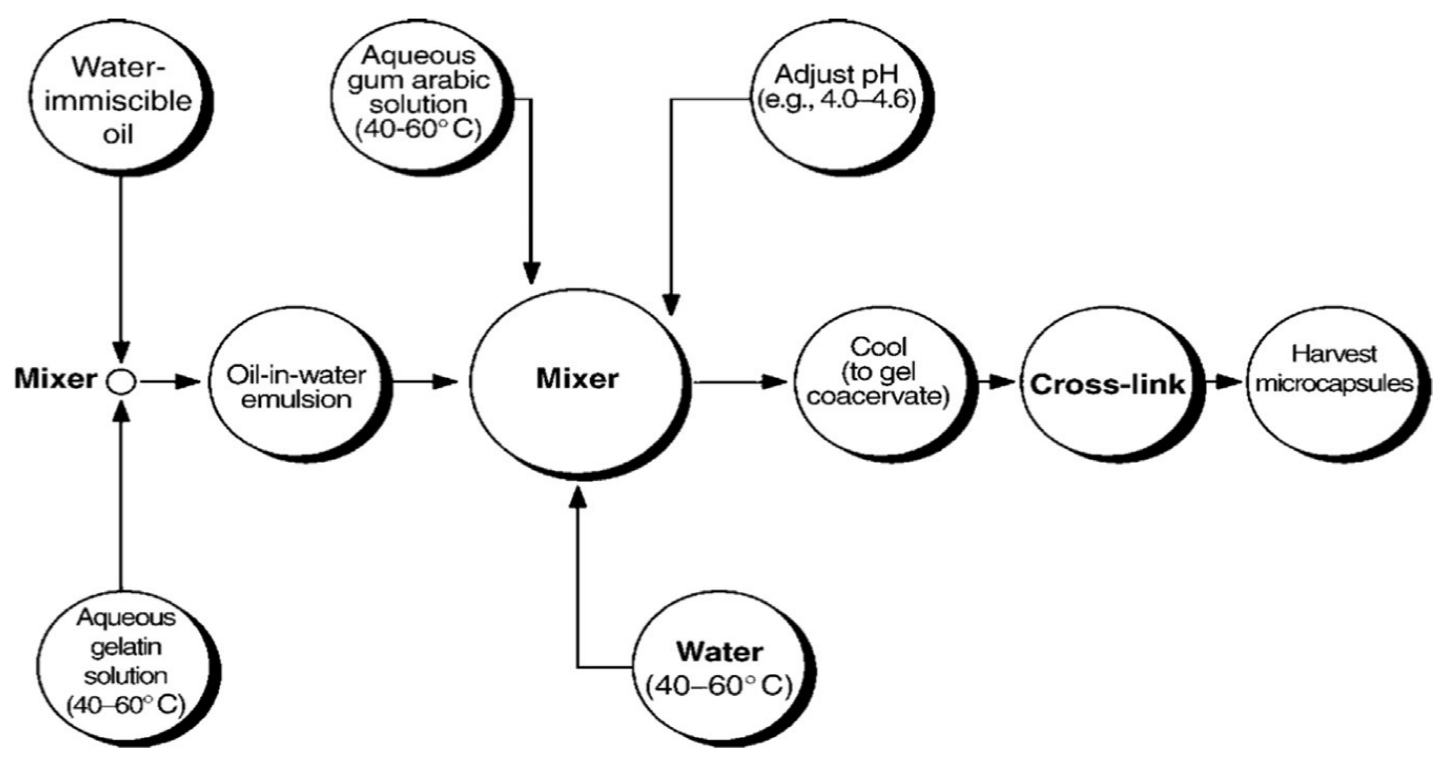

Figure 8: Flow diagram of a typical complex coacervation method for encapsulation 94, reused with permission from John Wiley and Sons license number 4385841192579.

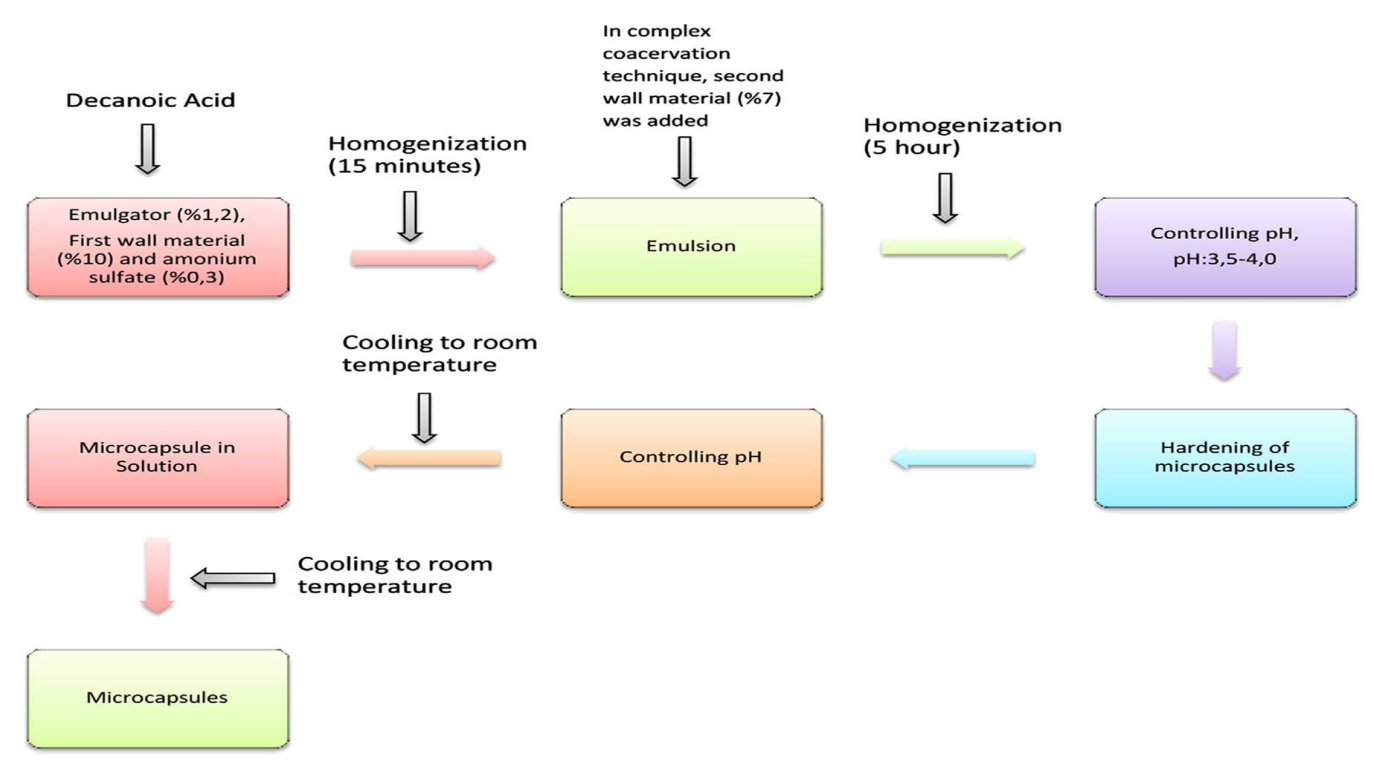

Figure 9: Schematic formation of microCA with coacervation method 95], reused with permission from Elsevier license number 4385860133315 . 


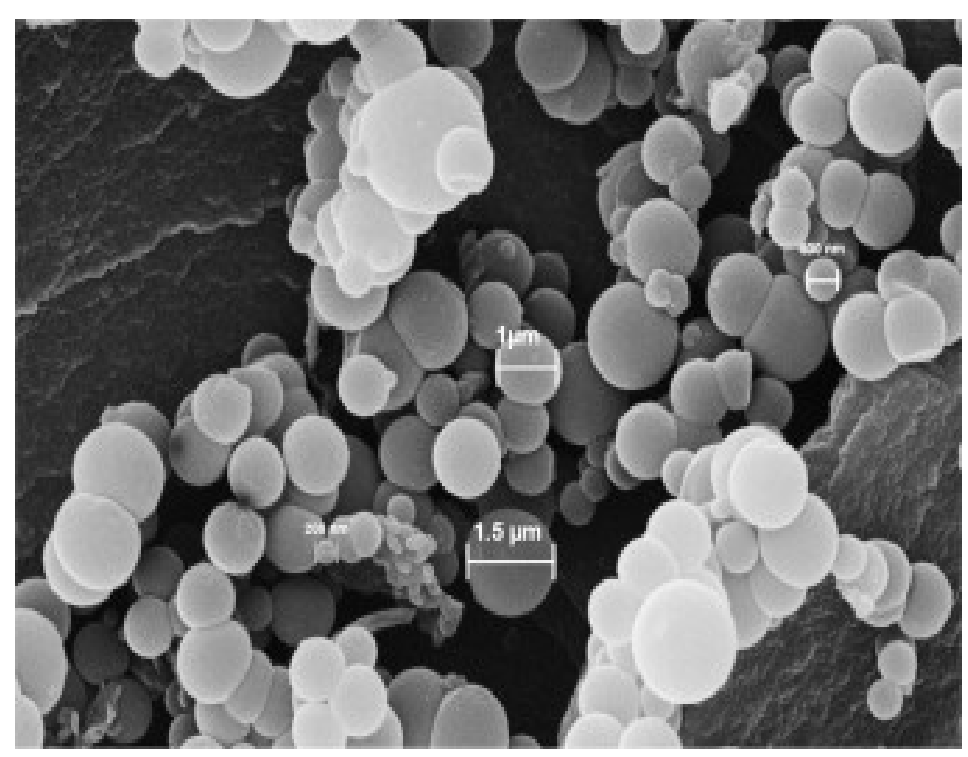

Figure 10: SEM image of particle size of micro-capsules 95], reused with permission from Elsevier license number 4385860133315 .

\subsubsection{Sol-gel method}

The "sol-gel" is the abbreviation of "solution-gelling" and used largely to synthesis the inorganic materials. The sol-gel process is a familiar physico-chemical technique to develop NCs with an inorganic shell. It has capture attention in recent years as its inexpensive and need mild processing conditions. The sol-gel process followed as the poly-condensation reactions of a molecular precursor in a liquid phase to form a colloidal solution (sol) which is subsequently converted to an oxide network (gel), Figure 11 shows the typical process of sol-gel method. In the sol-gel method, the processes are as follows; (i) the precursor (usually alkoxides and inorganics) is mixed uniformally with the solvent, catalyst and complex agent etc; (ii) then a stable and transparent colloidal solution is formed after hydrolysis and condensation chemical reactions; At this step, the condition of dispersion changes from solution to gel; that is why this method is known as the sol-gel method. (iii) the formed sol is further processed by aging to make three dimensional network structure; (iv) finally, micro and nano-PCM is formed after drying, sintering and curing processes $96,97,98$. Additionally the solgel method is mixed with the miniemulsion polymerization method to gain better thermophysical properties. For instance, Zhu et al. 99 prepared the nano-PCM using n-octadecane as PCM with organosilica shell via interfacial co-hydrolysis and copolycondensation of functional $\mathrm{SiO}_{2}$ precursors adopting mimiemulsion technique. The authors obtained the NCs of organosilica from $200-693 \mathrm{~nm}$ of precise core-shell structure. Using mesoporous particles, the interfacial contact of EPCM with solid support enhances the nucleation sites in comparison of core-shell particles resulting reduced the super-cooling. Thus, due to mesoporous confinement and heterogeneous nucleation sites, a thick shell is more promising to lessen supercooling than a thin shell.

Considering, the inflexibility of shell materials, some authors follow a track for enhancing the energy storage performance of hybrid systems. Zhang et al. 101 confined stearic acid with a $\mathrm{SiO}_{2}$ nanoshell with controlled shell density and improved the energy storage capacity of encapsulated PCM $36.9 \%$ likewise that of unconfined stearic acid, as shown in Figure 12. This improvement in latent heat is contributed 


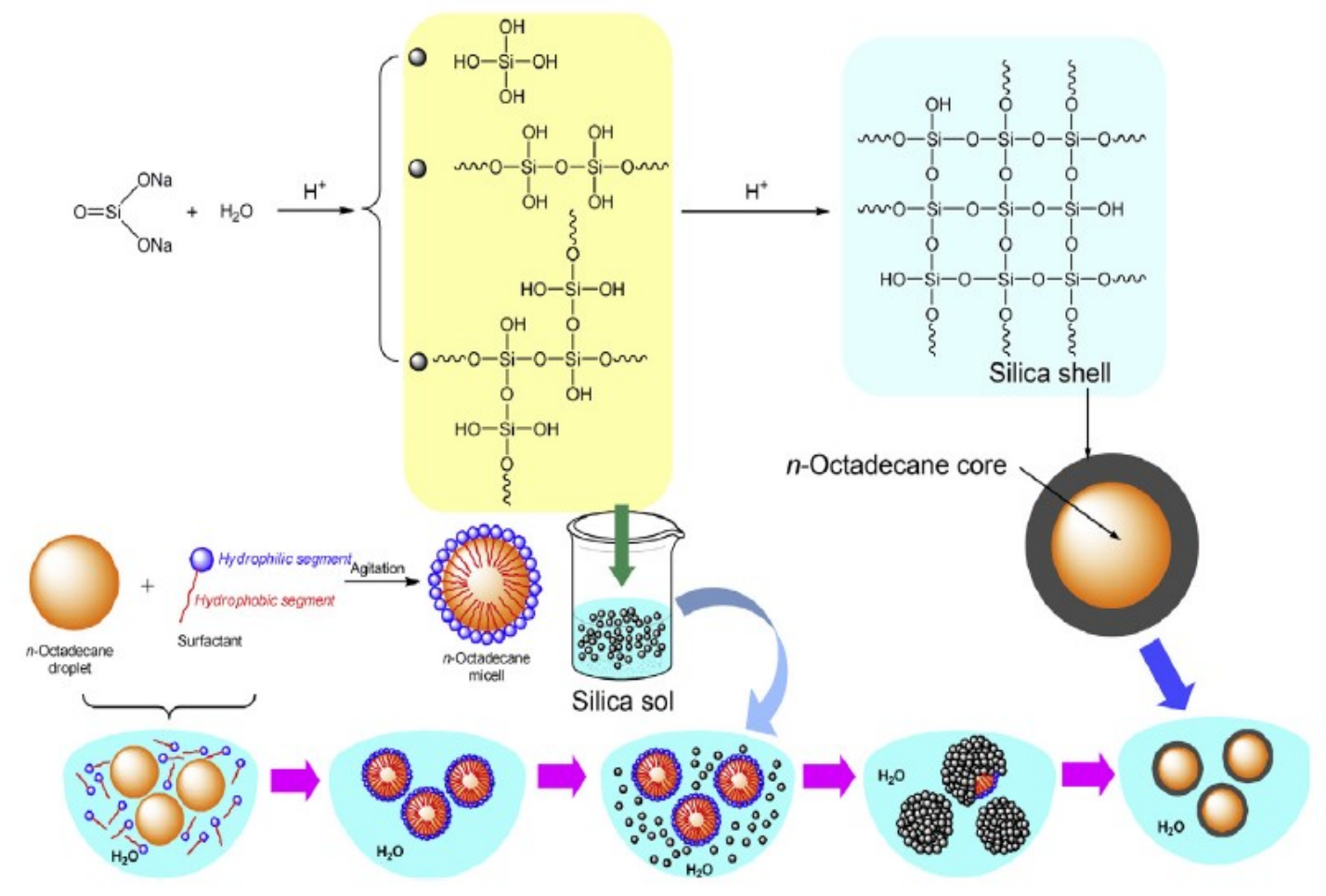

Figure 11: Process scheme of sol-gel method 100], reused with permission from Elsevier license number 4385860352467.

to the formation of a various stable hydrogen bonds network in high-superimposed stress on the encapsulated SA core from the $\mathrm{SiO}_{2}$ shell, which considerably decreases the intermolecular spacing of the SA core in contrast to its unconfined state. This improvement in latent heat is contributed to the formation of a various stable hydrogen bonds network in high-superimposed stress on the encapsulated SA core from the $\mathrm{SiO}_{2}$ shell, which considerably decreases the intermolecular spacing of the SA core in contrast to its unconfined state. Hence, collapsing and reshaping of these tightly packed stable hydrogen bonds contribute to the latent heat of SA while experience phase transition. Further, this strong hydrogen bonding causes the rise of phase transition temperature of confined SA. Despite of the merits of the rigid shell, there are also some demerits. Rao et al. 102 investigated the melting mechanism of NEPCM of confined n-octadecane with free and constrained $\mathrm{SiO}_{2}$ shell using molecular dynamic simulation method. The results sowed that the encapsulated n-octadecane was restrained with constrained $\mathrm{SiO}_{2}$ futher the soft shell can increase the fluidity and eventually improve the heat transfer speed of the TES systems. As comparison organic based PCMs, IPCMs have also been confined within the $\mathrm{SiO}_{2}$ shell. Zhang et al. 103] synthesized $\mathrm{Na}_{2} \mathrm{SO}_{4} 10 \mathrm{H}_{2} \mathrm{O}$ encapsulated $\mathrm{SiO}_{2}$ nanobowls via synchronous hydrolysis reactions of $\mathrm{SiO}_{2}$ precursors. The authors proposed as well as validated that the microstress inside the liquid particles or nano droplets was the responsible of the formation of solid nanostructures. Furthermore, the $\mathrm{SiO}_{2}$ wall, acting as a heterogeneous nucleator, reduces the degree of supercooling to minor extent, however, it is immense and unsuitable for actual life applications. Moreover organic and inorganic PCMs, metallic PCMs including indium, tin and alloys have also been confined by a $\mathrm{SiO}_{2}$ shell [104, 105]. Higher crystallinity and thermal conductivity reported in metallic PCMs. The silica shell can further reduce the corrosion and stop the leakage. Wu et al. 106 suspended bare indium and $\mathrm{SiO}_{2}$ encapsulated indium 
nanoparticles in a base liquid, poly- $\alpha$-olefin (PAO), for high-temperature heat transfer applications using colloid method. In contrary of prediction, they established the fact that the coalescence of indium particles within a single-phase fluid is not a big issue. Thus, indium nanoparticles can be employed without encapsulation. Metal based compound materials are also investigated by scientist to use as shell other than $\mathrm{SiO}_{2}$. In comparison to $\mathrm{SiO}_{2}$, the metal based materials have greater value of thermal conductivity, mechanical strength also provide a compact and rigid structure. The formation of a metal compound shell involves the condensation of a metal hydroxide precursor during in situ solgel and emulsion polymerization, similar to $\mathrm{SiO}_{2}$ shell formation. Till now, very few metal-based compounds have been utilised for encapsulation of PCMs [107, 108, 109]. Latibari et al. [110 utilized $\mathrm{TiO}_{2}$ to prepare NCs of SA and using $\mathrm{TiO}_{2}$ as a shell and found that the NCs present higher thermal conductivity and encapsulation efficiency up to $64.76 \%$ for NC of sizes $583.4 n m$ and $946.4 n m$. Pan et al. 111] used the boehmite $(\gamma-A L O O H)$ shell to encapsulate the SA and it had been discovered that the phase transition temperature of SA was lowered by $50^{\circ} \mathrm{C}$ due to the confinement effect, as shown in Figure 13 The heat storage density of the prepared NCs was about $\sim 140 \mathrm{~kJ} / \mathrm{kg}$, which is lower than that of the pristine PCM but still higher than that of the mostly room temperature PCMs. Therefore, boehmite coating technology can be utilized to alter the phase transition temperature of high-temperature PCMs having high-energy storage performance to room temperature. Sol-gel method is usually suitable for encapsulation of both micro and nano enhanced PCMs. The summary of different studies adopting sol-gel method is enumerated in Table 5 


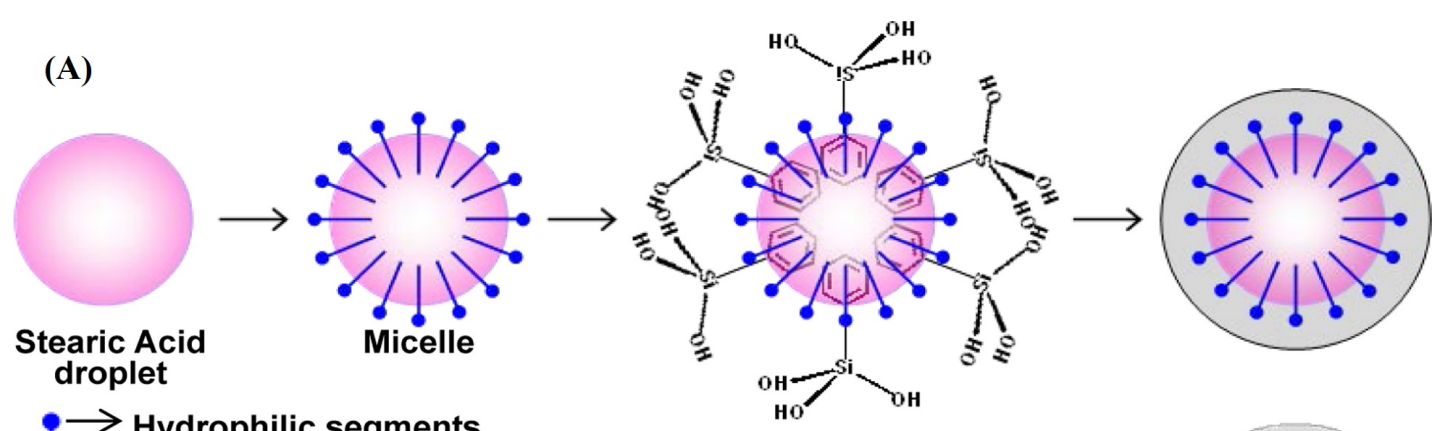

\section{$\rightarrow$ Hydrophilic segments \\ $\rightarrow$ Hydrophobic segments}

Emulsifier: SDS

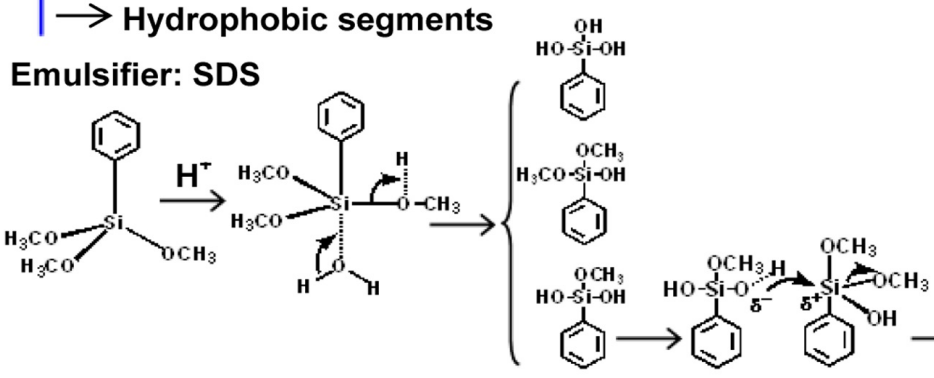

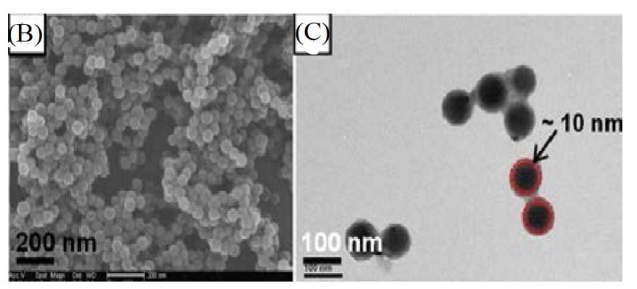

(D)
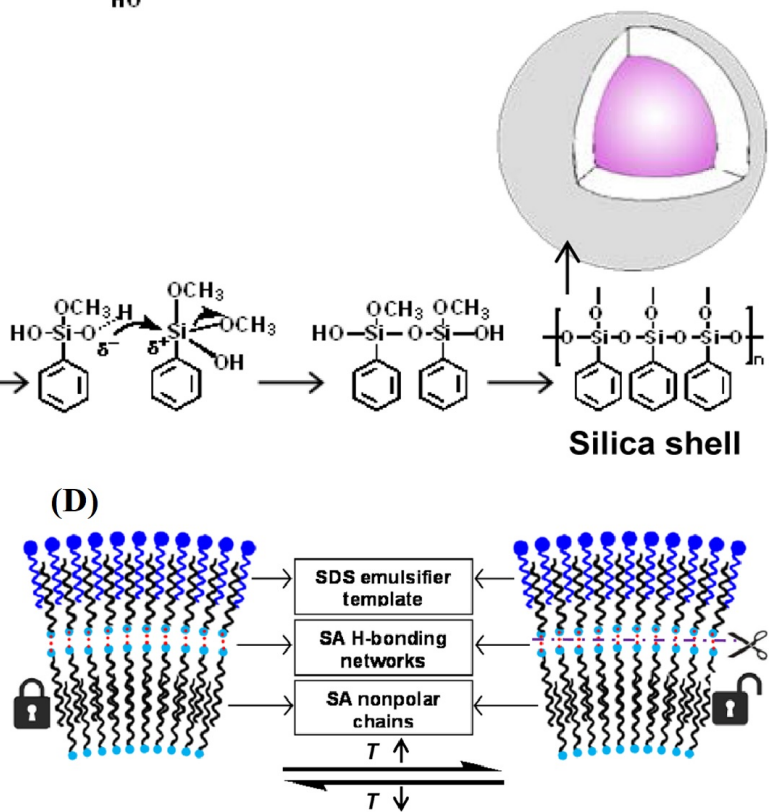

Figure 12: (A) Schematic formation of the silica encapsulated strearic acid (SA@SiO$\left.O_{2}\right) N C s ;(B)$ and (C) SEM and TEM images, respectively; $(D)$ illustration fo the formation and breaking of multiple stable hydrogen bonds under superimposed stress 101, Reproduced with permission of the American Chemical Society. 

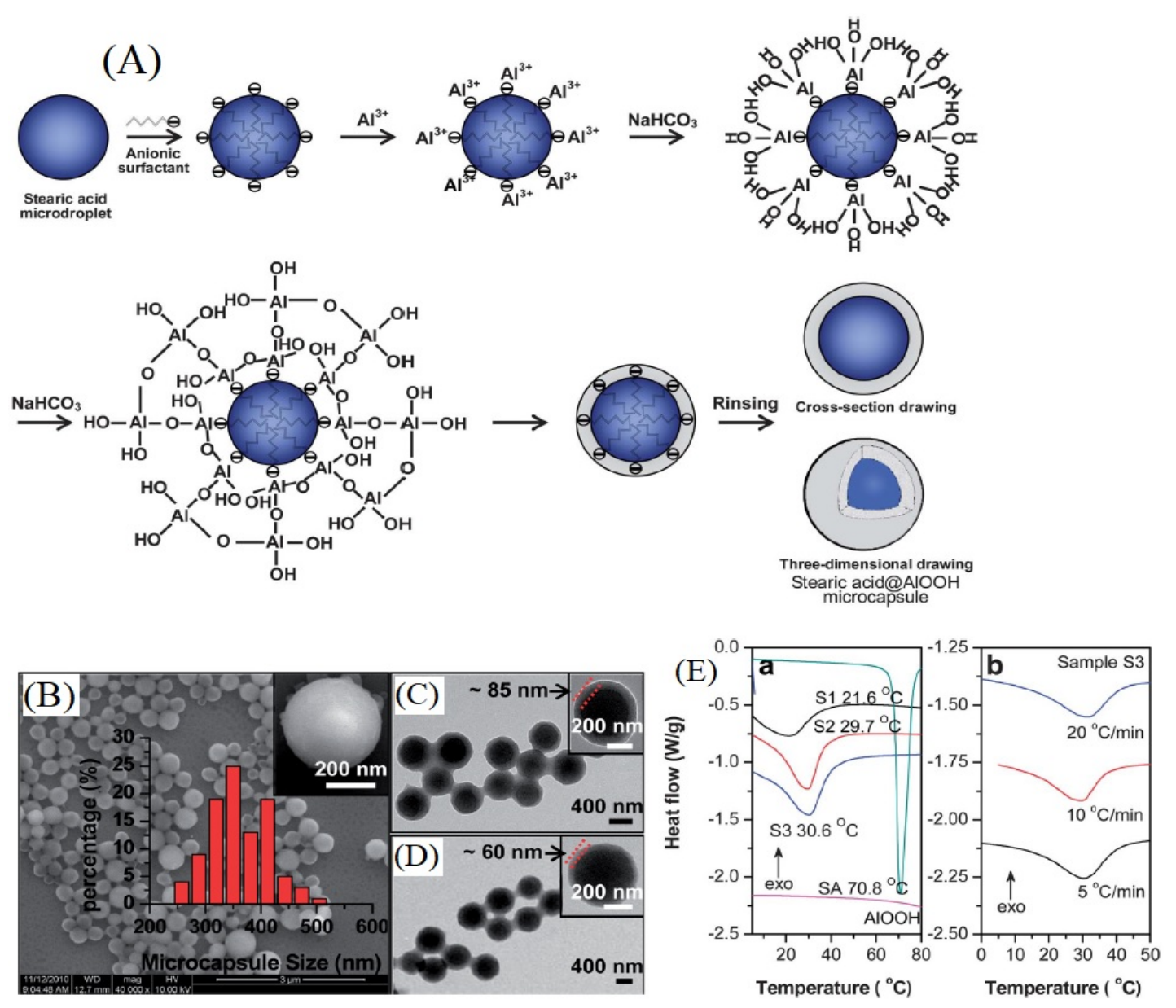

Figure 13: (A) Schematic formation of $S A @ \gamma-A L O O H$ NCs; (B) SEM image and size distribution of $S A @ \gamma-A L O O H$ with $21.6 \%$ of $S A$; $(C)$ and (D) TEM images of $S A @ \gamma-A L O O H$ with $21.6 \%$ and $28.5 \%$ of $S A$, respectively; (E) DSA thermogram of pure $S A, \gamma-A L O O H$ and $S A @ \gamma-A L O O H$ NCs with the same (left) and different (right) heating rate, respectively. Reproduced from Ref. [11] with permission from The Royal Society of Chemistry. 
Table 5: Summary of prepared Micro/Nano-PCMs using physical-chemical methods.

\begin{tabular}{|c|c|c|c|c|c|c|c|}
\hline Ref & Method & Core & Shell & Particle size $(\mu m)$ & EE $(\%)$ & $T_{m}$ & $\begin{array}{l}\text { Latent heat } \\
\qquad(\mathrm{J} / g)\end{array}$ \\
\hline 112 & Simple Coacervation & n-Hexadecane & Soy glycinin & $\sim 101.7$ & 65 & - & - \\
\hline 113] & Simple Coacervation & $\begin{array}{l}\text { Holy basil essen- } \\
\text { tial oil (HBEO) }\end{array}$ & Gelatin & 392.30 & $44.65-100.09$ & - & - \\
\hline 95] & Complex Coacervation & Octanic acid & $\mathrm{UF}, \mathrm{MF}, \mathrm{UMF}$ & $0.2-1.5$ & 59.29 & 13.90 & 93.9 \\
\hline 114] & Complex Coacervation & Paraffin wax & Gelatin and Gum arabic & $50-100$ & $9.43-94.26$ & - & $20-90$ \\
\hline 115 & Complex Coacervation & Paraffin wax & Gelatin and Gum arabic & $50-100$ & $79.43-94.26$ & - & $20-90$ \\
\hline 116] & Complex Coacervation & Paraffin wax & Gelatin and Gum arabic & $\sim 0.5$ & - & $\sim 60$ & 213 \\
\hline 117] & Complex Coacervation & Xylitol & Gelatin and Gum arabic & $78.45-109.31$ & $31-71$ & - & - \\
\hline 118 & Complex Coacervation & Sunflower oil & Fish gelatin and arabic gum & $40-240$ & - & - & - \\
\hline 119] & Complex Coacervation & n-tetradecane & Gelatin & $90-125$ & - & 5.30 & 192 \\
\hline 120 & Complex Coacervation & Coco-fatty acid & Gelatin and Gum arabic & $1 \mathrm{~mm}$ & - & $29-31$ & - \\
\hline 121] & Complex Coacervation & $\begin{array}{l}\text { n-Hexadecane, } \\
\text { n-Octadecane, } \\
\text { n-Nonadecane }\end{array}$ & Gelatin-Gum arabic mixture & - & - & $11-38$ & $19.70-165.80$ \\
\hline 122 & Complex Coacervation & RT-27 & $\begin{array}{l}\text { Sterilized Galatine/Arabic Gum, } \\
\text { Agar-Agar/Arabic Gum }\end{array}$ & 9,12 & 48,49 & $\begin{array}{l}298.3-301.3 \\
299.5-302.5\end{array}$ & 79,78 \\
\hline 123$]$ & Complex Coacervation & TMiglyol $812 \mathrm{~N}$ & Chitosan and Gum arabic & $5-10$ & - & - & - \\
\hline 124$]$ & Complex Coacervation & n-Eicosane & MF & 1.89 & 53 & 36.9 & 134.3 \\
\hline 125 & Sol-gel method & n-Eicosane & $\mathrm{Fe}_{3} \mathrm{O}_{4} / \mathrm{SiO}_{2}$ & $\sim 4-6$ & 71.78 & 39.15 & 170.20 \\
\hline 126 & Sol-gel method & Tris & $\mathrm{SiO}_{2}$ & $\sim 100-200$ & 67.90 & $110-155$ & 146 \\
\hline 127] & Sol-gel method & Paraffin wax & $\mathrm{TiO}_{2}$ & $\sim 50$ & 85.5 & 58.8 & 161.1 \\
\hline 128 & Sol-gel method & Palmitic acid (PA) & $\mathrm{TiO}_{2}$ & $200-400(n m)$ & 30.4 & 61.7 & 63.3 \\
\hline 129] & Sol-gel method & Stearic acid (SA) & $\mathrm{SiO}_{2}$ & $20-30$ & 90.7 & $52.6-53.5$ & $162.0-171.0$ \\
\hline 130] & Sol-gel method & Paraffin wax & $\mathrm{SiO}_{2}$ & $40-60$ & 82.2 & 57.96 & 156.86 \\
\hline
\end{tabular}




\begin{tabular}{|c|c|c|c|c|c|c|c|}
\hline 100] & Sol-gel method & n-Octadecane & $\mathrm{SiO}_{2}$ & $2-4$ & 41.45 & 27.96 & 87.46 \\
\hline 131 & Sol-gel method & n-Pentadecane & $\mathrm{SiO}_{2}$ & $4-8$ & $29.8-35.9$ & $\sim 5-10$ & $46.4-55.8$ \\
\hline 132 & Sol-gel method & Paraffin wax & $\mathrm{SiO}_{2}$ & $8-15$ & $69.1-87.5$ & $57.84-58.37$ & $130.82-165.68$ \\
\hline 133] & Sol-gel method & n-Octadecane & $\mathrm{SiO}_{2}$ & $7-16$ & 86.4 & 27.1 & 184.9 \\
\hline 55 & Sol-gel method & Palmitic acid (PA) & $\mathrm{SiO}_{2}$ & $\begin{array}{l}183.7 \mathrm{~nm}, \quad 466.4 \mathrm{~nm}, \\
722.5 \mathrm{~nm}\end{array}$ & $\begin{array}{l}82.53, \quad 84.28, \\
88.32\end{array}$ & $\begin{array}{l}61.06,60.92, \\
61.6\end{array}$ & $\begin{array}{l}168.16,172.16, \\
180.91\end{array}$ \\
\hline 110 & Sol-gel method & Stearic acid (SA) & $\mathrm{TiO}_{2}$ & $317.6-946.4 \mathrm{~nm}$ & $30.36-64.76$ & $58.23-59.14$ & $58.12-123.96$ \\
\hline 134 & Sol-gel method & n-Eicosane & $\mathrm{TiO}_{2}$ & $1.5-2$ & $49.90-77.97$ & $42.73-43.88$ & $97.60-152.50$ \\
\hline 135 & Sol-gel method & Indium & $\mathrm{SiO}_{2}$ & $200 \mathrm{~nm}$ & - & 155.3 & 19.6 \\
\hline 136 & Sol-gel method & RT 28 & $\mathrm{SiO}_{2}, \mathrm{EG}$ & $5-20,1-5$ & - & $27.53,27.72$ & $112.84,104.41$ \\
\hline 137] & Sol-gel method & n-Octadecane & $\mathrm{PMMA} / \mathrm{SiO}_{2}$ & 10 & - & - & 178.9 \\
\hline
\end{tabular}




\subsection{Chemical-mechanical methods}

In chemical-mechanical methods, mechanical machine is used to accomplished the chemical reaction to encapsulate the PCMs. It generally includes the following two methods. The detail summary of these two techniques are provided in Table 6

- Micro-fluidic technique

- Melt-coaxail electrospray technique

\subsubsection{Micro-fluidic technique}

In micro-fluidic technique, widely used in the medical and pharmaceutical fields [138, the capillary micro-fluidic device is utilized to form the mono-disperse double emulsion droplets following the flow motion geometry. Figure 14 illustrate the complete process of formation of mono-disperse double emulsion droplets developed by Sun et al [139]. The authors [139] used the water-oil-water (W-O-W) double emulsion template and produced the outer phase of materials (water, glycerol and polyvinyl alcohol (PVP)) and middle phase of materials (oils included Suppocire AIM oil, paraffin, nonadecane and eicosane) in a co-flowing channels with different flow rates. The micro-PCM is obtained following washing and drying processes. Fu et al. [140 prepared the silicone/n-hexadecyl bromide micro-capsules by micro-fluidic technique selecting n-hexadecyl bromide as a inner fluid and poly(dimethylsiloxane) vinyl terminated and poly(methylhydrosiloxane) as outer fluids. The optical and SEM images of produced micro-PCMs are shown in Figure 15

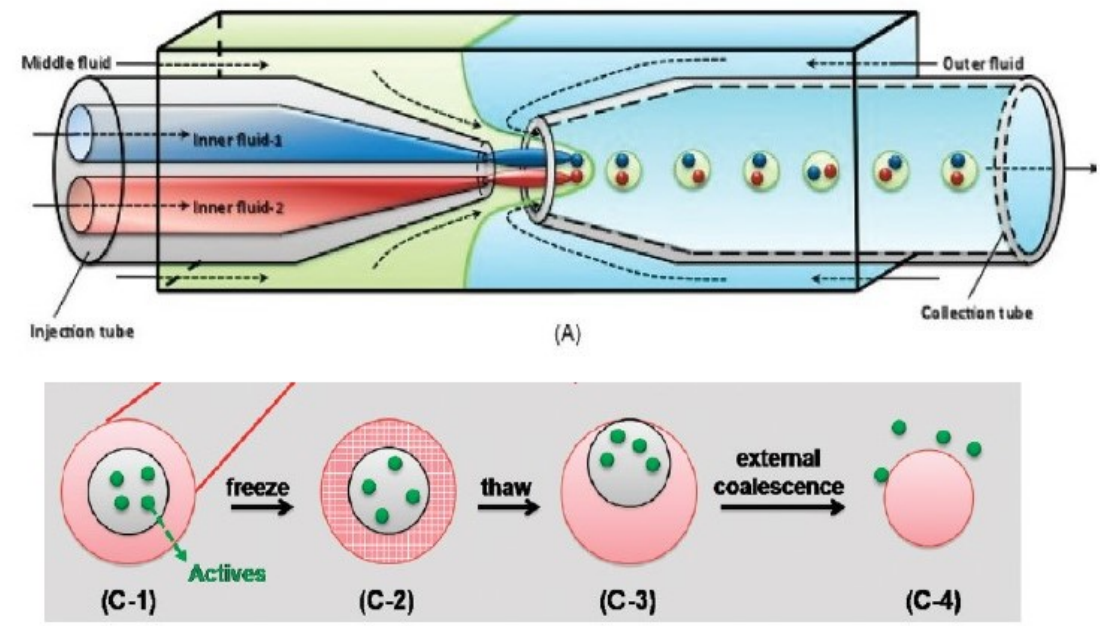

Figure 14: (A)-schematic of capillary micro-fluidic device generating two-bore double emulsions; (C)-schematic illustrating the encapsulation and release of activities using the double emulsion-templated capsules [139], Reprinted (adapted) with permission from $([139])$. Copyright (2010) American Chemical Society.

\subsubsection{Melt-coaxail electrospray technique}

This encapsulation technique is the further modification of spray drying technique introducing a chemical reaction during process. It was first introduced by Loscertales et al. [141] who proposed a 

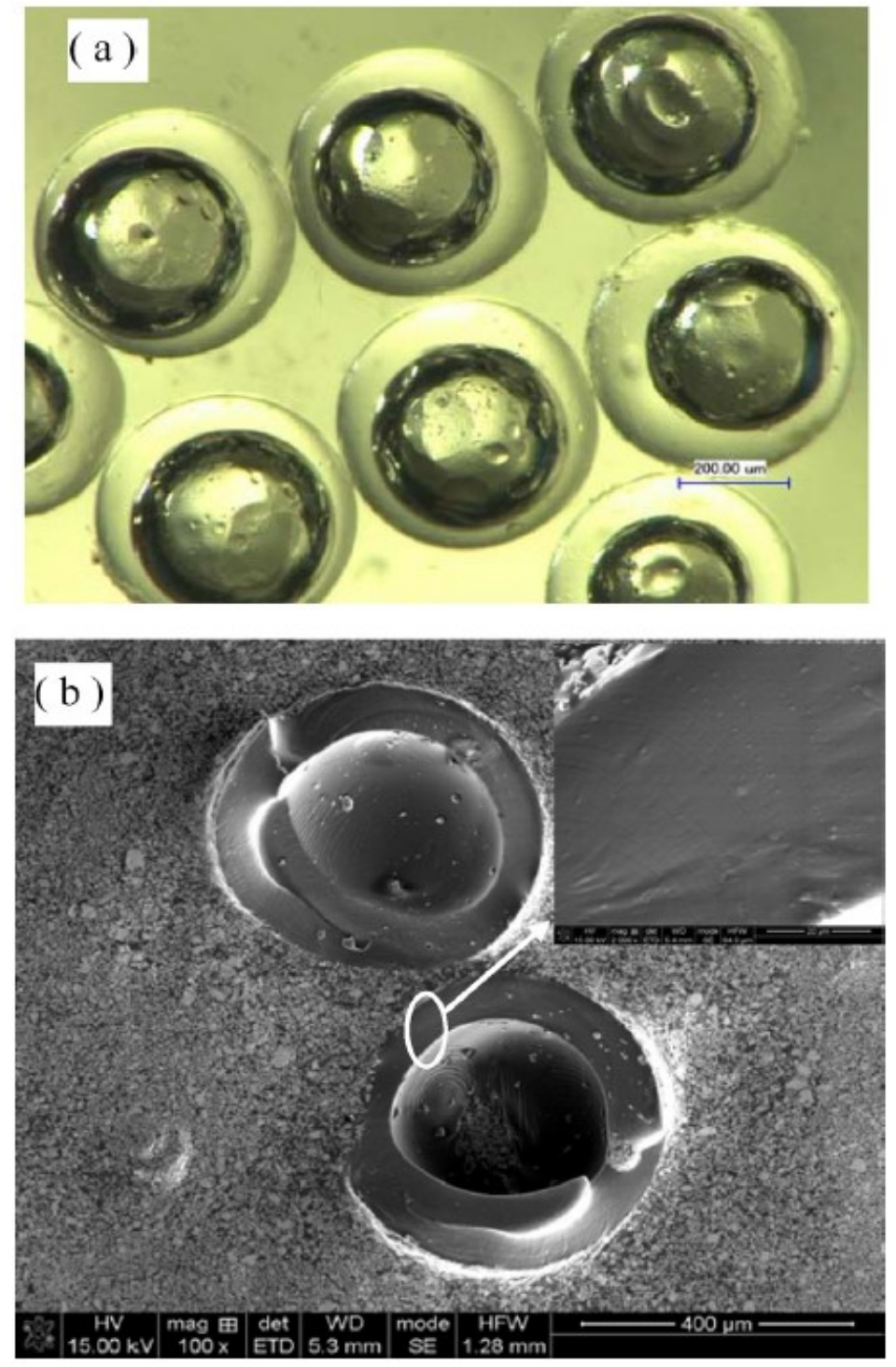

Figure 15: (a)-Optical microscope; (b)-cross-sectional SEM image of mico-PCMs [140], reused with permission from Elsevier license number 4385861063323 .

method to generate steady coaxial jets of immiscible liquids having micrometer/nanometer diameter in size. The schematic diagram of melt coaxail electrospray technique used by Moghaddam et al. $[142]$ is shown in Figure 16. The authors first time produced the micro-capsules using n-nonadecane and sodium alginate as core and shell materials, respectively. 


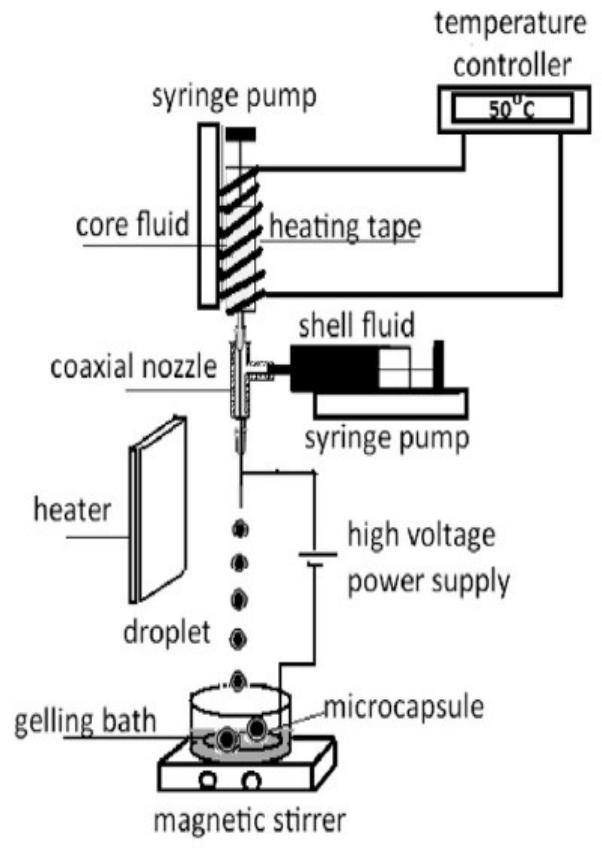

(a)

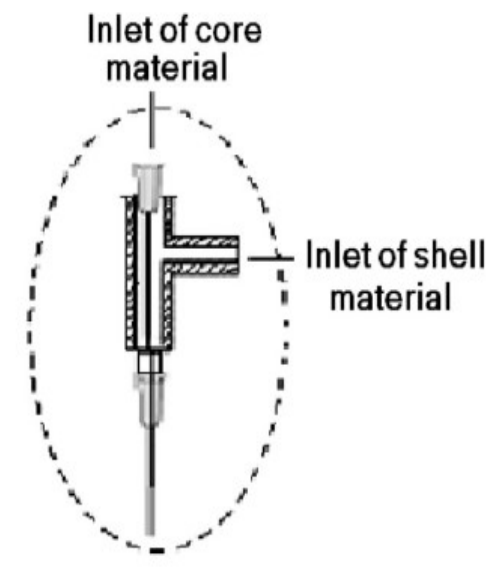

(b)

Figure 16: (a)-Schematic of the melt coaxial electrospray setup; (b)-coaxial needle setup [142], reused with permission from Elsevier license number 4385861260669. 
Table 6: Summary of prepared Micro/Nano-PCMs using chemical-mechanical

methods.

\begin{tabular}{|c|c|c|c|c|c|c|c|}
\hline Ref. & Method & Core & Shell & Particle size $(\mu m)$ & EE $(\%)$ & $T_{m}$ & $\begin{array}{l}\text { Latent heat } \\
\qquad(J / g)\end{array}$ \\
\hline 140$]$ & Micro-fluidic technique & n-hexadecyl bromide & PDMS, PMHS & 460 & 49 & 16.70 & 76.35 \\
\hline 143] & Micro-fluidic technique & Ascorbic acid & Solid lipid & $170.2-342.5$ & $73.4-96.6$ & - & - \\
\hline 144] & Micro-fluidic technique & Silicone & PDMS & $100-200$ & $\sim 100$ & - & - \\
\hline 145$]$ & Micro-fluidic technique & Ceramic & Silsesquioxane & - & - & - & - \\
\hline 142$]$ & $\begin{array}{l}\text { Melt-coaxail electrospray } \\
\text { technique }\end{array}$ & n-Nonadecane & Sodium alginate & $<100$ & 56 & 31.12 & 81.67 \\
\hline
\end{tabular}


Table 7: Advantages and disadvantages of chemical methods.

\begin{tabular}{|c|c|c|}
\hline Techniques & Advantages & Disadvantages \\
\hline Interfacial polymerization & $\begin{array}{l}\text { Controllable to produce } \\
\text { Homogeneous in size } \\
\text { Good mechanical resistance } \\
\text { Good thermal and chemical stability }\end{array}$ & $\begin{array}{l}\text { High wall permeability } \\
\text { Difficulty in control }\end{array}$ \\
\hline Suspension polymerization & $\begin{array}{l}\text { Controllable to produce } \\
\text { Efficient control of heat during reaction } \\
\text { Low cost production }\end{array}$ & $\begin{array}{l}\text { Fewer monomers are water soluble } \\
\text { High cost equipment }\end{array}$ \\
\hline Emulsion polymerization & $\begin{array}{l}\text { Low cost production } \\
\text { Rapid production } \\
\text { Uniform morphological capsules }\end{array}$ & $\begin{array}{l}\text { Limited for liquid PCMs } \\
\text { Polymer is purified from the surfactant } \\
\text { Used only in oiled system } \\
\text { Multi-phases of solution }\end{array}$ \\
\hline Miniemulsion polymerization & $\begin{array}{l}\text { Nano-scale production } \\
\text { Good thermal and chemical stability } \\
\text { Uniform morphological capsules }\end{array}$ & $\begin{array}{l}\text { High cost equipment } \\
\text { High skill is needed for preparation } \\
\text { Multi-phases of solution }\end{array}$ \\
\hline In situ polymerization & $\begin{array}{l}\text { Most effective for nano-scale production } \\
\text { Uniform coating } \\
\text { Uniform morphological capsules } \\
\text { Good thermal and chemical stability }\end{array}$ & $\begin{array}{l}\text { High cost equipment } \\
\text { High skill is needed for preparation }\end{array}$ \\
\hline
\end{tabular}

\subsection{Chemical methods}

The chemical methods ensures the production of smaller sizes such as nano-capsules using organic and inorganic materials as shell material or precursor to build the shell. Following are the most used techniques under chemical methods to produce PCMs encapsulations. Table 8 represents the different approches and properties of micro/nano-encapsulated PCMs prepared by various chemical methods. The advantages and disadvantages of chemical methods are summarized in Table 7

- Interfacial polymerization

- Suspension polymerization

- Emulsion polymerization

- Miniemulsion polymerization

- In-situ polymerization

\subsubsection{Interfacial polymerization/polycondensation}

In interfacial polymerization, the first process is the preparation of oil-water $(\mathrm{O} / \mathrm{W})$ or water-oil $(\mathrm{W} / \mathrm{O})$ emulsions by adopting appropriate emulsifier. The next step is the formation of polymer capsules in the surface of the core materials (i.e. OPCMs) by interfacial polymerization at an interface between two phases with each of them containing a suitable reaction monomers. The final step is the separation of the capsule from oil phase or water phase. Figure 17] [146, shows the synthesized micro-capsules via polycondensation. Park et al. 147] prepared the nano-PCMs using paraffin as a core and polyurea as 
a shell material via interfacial polycondensation. The SEM and TEM images of prepared Nano-PCM is shown in Figure 18 147]. Pan et al. [148] adopted the in-situ emulsion interfacial polycondensation method and prepared a novel micro-encapsulated PCM using palmitic acid (PA) and AlOOH as core and shell materials, respectively.
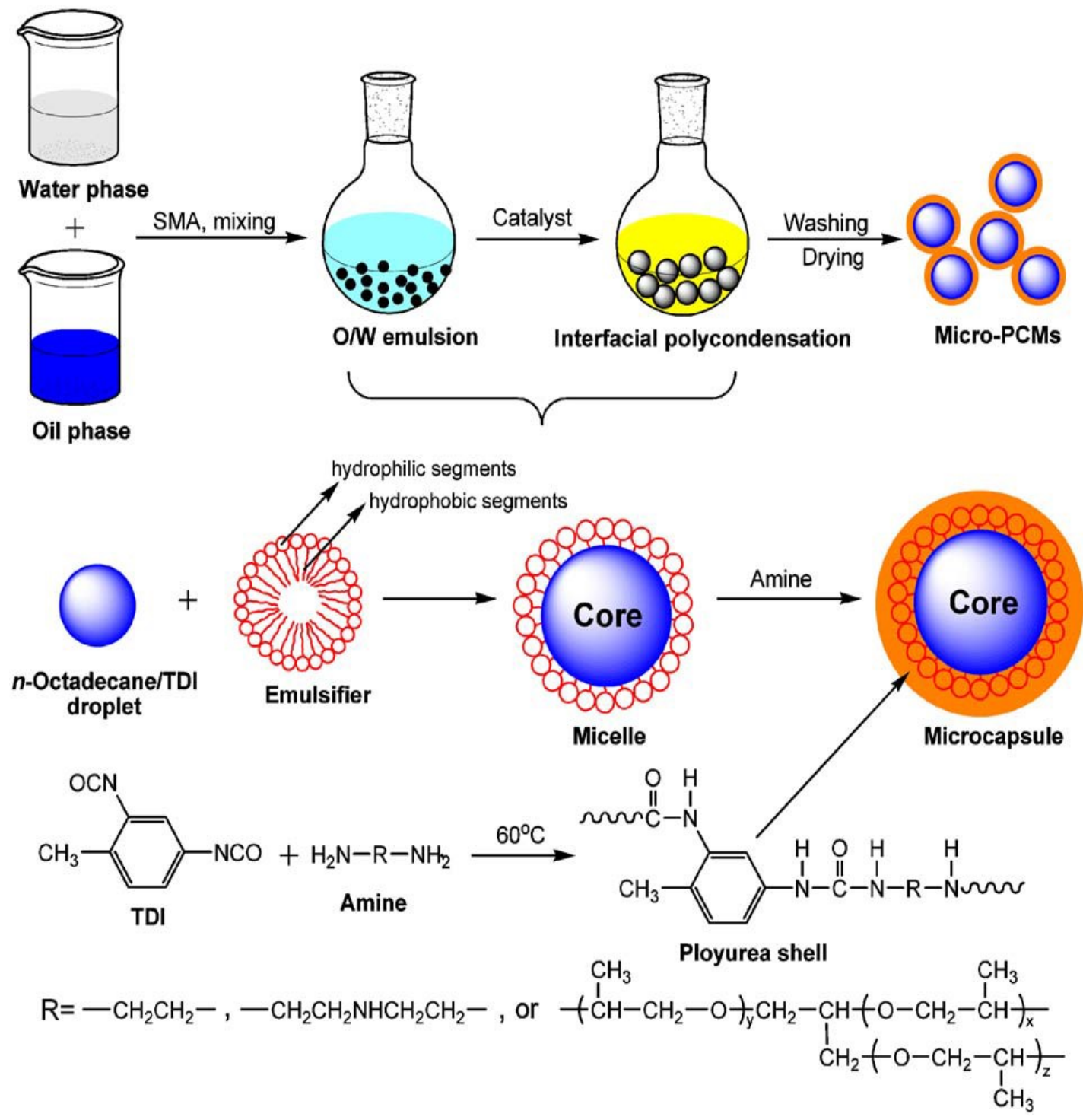

Figure 17: Schematic formation of the micro-encapsulated n-octadecane with the polyurea shells containing different soft segments via interfacial polycondensation [146], reused with permission from Elsevier license number 4385861412119.

\subsubsection{Suspension-like polymerization}

The suspension-like polymerization accomplishes on the system phases, (i) the discontinuous or dispersed phase, which contains the reagents of core material and monomers including initiator which prompt the chemical reaction; (ii) the continuous phase, which includes the reactants of shell materials and solvent [149]. The process of suspension-like polymerization consists of the following steps: (i) the dissolution of polymer monomers into core materials under stirring to obtain homogeneous oil solution; (ii) this homogeneous solution is then added to the continuous phase at constant temperature to produce the oil-water $(\mathrm{O} / \mathrm{W})$ emulsion; (iii) further an emulsifier is added to the $\mathrm{O} / \mathrm{W}$ solution to make it more 

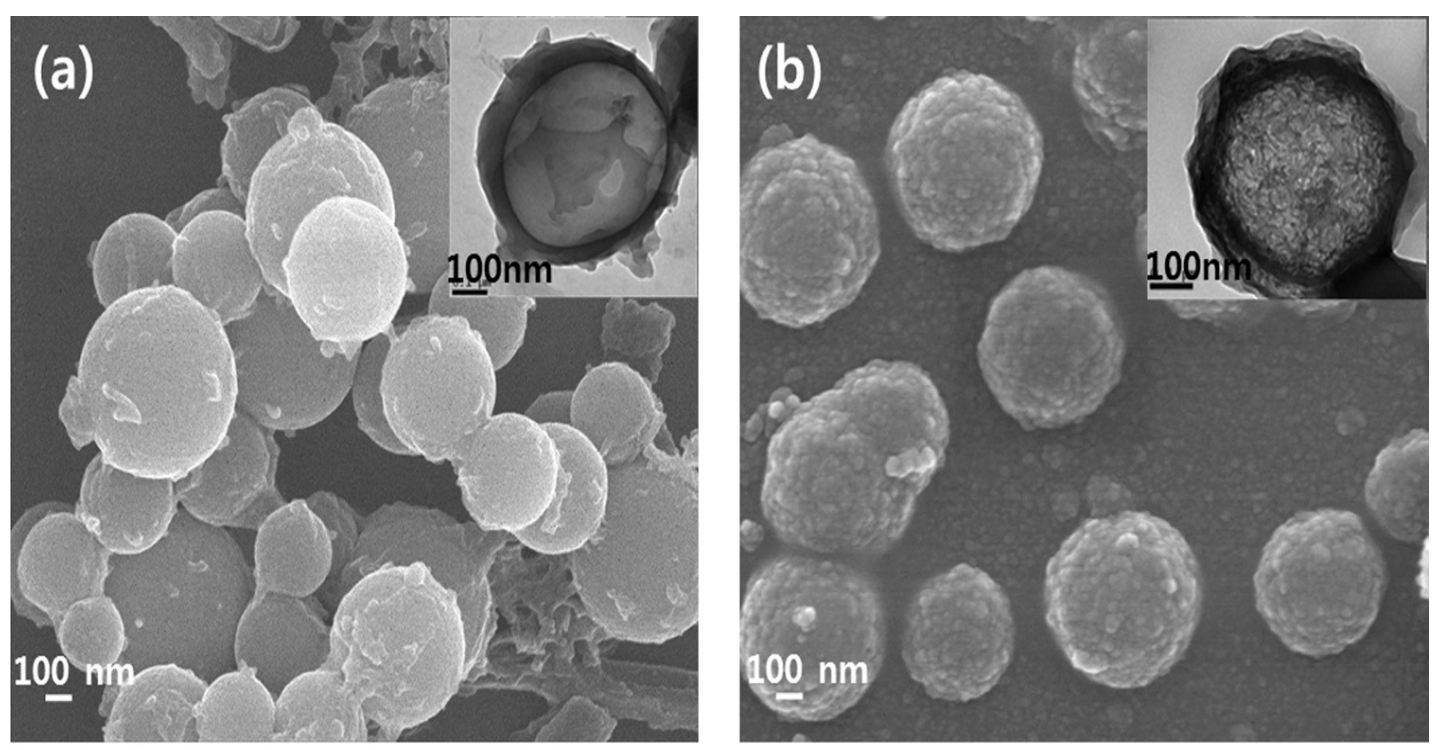

Figure 18: The SEM and TEM images of nano-PCMs (a)-with and (b)-without $\mathrm{Fe}_{3} \mathrm{O}_{4}$ nano-particles [147, reused with permission from Elsevier license number 4385870250913.

homogenized; (iv) then the prepared stable emulsion is stirred at constant high temperature for a period to give the proper polymerization reaction; (v) finally, the prepared encapsulated PCMs capsules are filtered, washed and dried. The schematic flow process of suspension-like polymerization is shown in Figure 19 150.

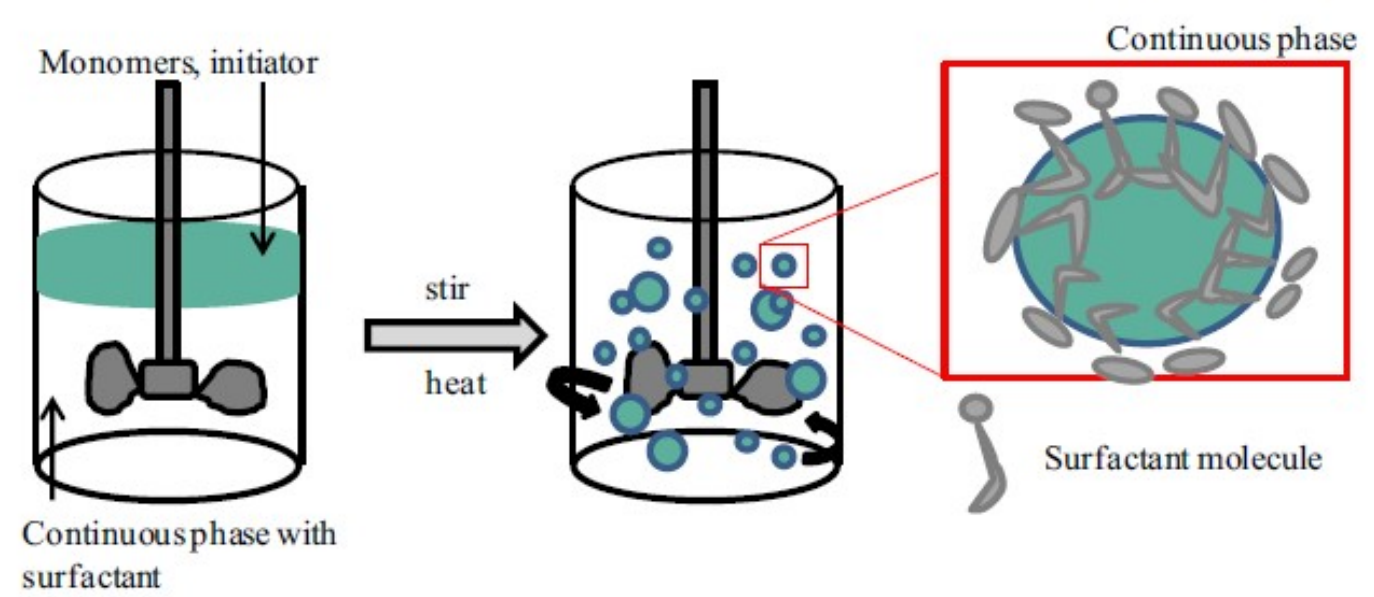

Figure 19: Scheme of the suspension-like polymerization process 150, reused with permission from Elsevier license number 4385870668358.

\subsubsection{Emulsion polymerization}

The emulsion polymerization method takes the mixing of the polymer in the presence of emulsifier in an oiled system. During the process, a number of thermal, chemical and physical processes occur to make the micro-PCM or nano-PCM. Unlike the suspension-like polymerization, in emulsion process the initiator is solved in the aqueous phase and the monomer is emulsified in the polymerization medium with the aid of a surfactant. Commonly, there are three steps on which the emulsion polymerization 
completes its process. Firstly (i) the insoluble monomer with emulsifier is dispersed in solvent reaction medium adding the surfactant and the mechanical stirring. Further (ii), the initiator is added which initiates the polymerization reactions resulting generates the polymer membrane on the surface of the core material. Finally (iii), the washing and removing of the oil to form the micro/nano-PCMs. Figure 20 shows the schematic of common emulsion polymerization method [150. In emulsion polymerization method, commonly used materials for shell are polystyrene (PS) or polymethylmethacrylate (PMMA) and alkhane is used as a core material. Additionally, polymer polymerization is often carried by emulsion polymerization which used the liquid PCM as a core material to prepare the mico/nano-PCM. The properties of various studies adopting emulsion polymerization are listed in Table 8

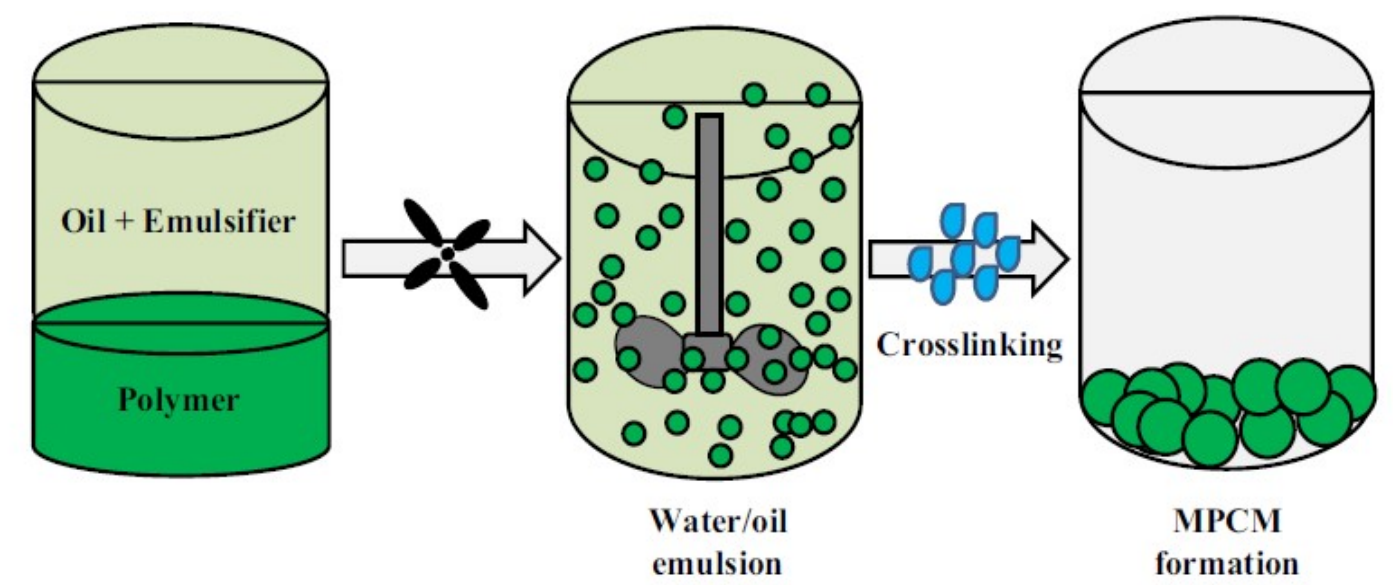

Figure 20: Scheme of the emulsion polymerization method 150], reused with permission from Elsevier license number 4385870668358 .

\subsubsection{Miniemulsion polymerization}

The miniemulsion polymerization method is most commonly used method to prepare the nano-PCM because the smaller encapsulated capsules can be formed as compared to the emulsion polymerization method. Comparing to emulsion polymerization, miniemulsion polymerization occurs within the small droplet which requires the less input energy. Thus, this technique is employed under ambient reaction conditions which are necessary for the production of stable NCs. In this method, the ultrasonication process is carried out to produce laboratory scale formation and high pressure homogenizer is used for large scale processes to obtain the homogenization. The scheme of miniemulsion polymerization is presented in Figure 21 151]. The first step is miniemulsion process under the sheering effect small nanometer tiny droplets are formed in a size range of $30-500 \mathrm{~nm}$ which are stable and contain the emulsifier, water, monomer, surfactant, initiator, the dispersed and continuous phase. The second step comprising on polymerization reaction in which these droplets are polymerized without changing their chemical composition, latex properties [152]. In miniemulsion polymerization, the monomers determines the morphological characteristics of prepared nano-capsules 153, 154. The miniemulsion polymerization technique is further categorized into three classes; direct emulsion (oil in water, $\mathrm{O} / \mathrm{W}$ ), indirect emulsion (water in oil, W/O) and Pickering inverse emulsion. Classical emulsifiers e.g. amphiphilic oligo (methacrylic acid 41-b-methyl 
methacrylate 8), sodium lauryl sulfate, Tween 80, Span 20 and Span 85 are usually utilized in direct and indirect emulsions. Contrarily, in Pickering inverse emulsion, solid particles are employed as an emulsifier [46, 47, 155].

Cortazar and Rodrguez [48 employed the miniemulsion polymerization technique to encapsulate paraffin wax with methyl methacrylate and investigated the kinetic, phase change properties and thermal stability. The maximum amount of encapsulated paraffin wax achieved was $60 w t . \%$ with latent heat capacity of $140.3 \mathrm{~J} / \mathrm{g}$ and obtained the capsule size of 439.4 . Furthermore, the authors reported that NCs having a higher weight percentage of paraffin wax undergo the phase separation phenomenon. Chen et al. 156 adopted the miniemulsion polymerization technique to encapsulate the n-dodecanol as a core and PMMA as a shell material using DNS-86 as a polymerizable emulsifier and hexadecane (HD) as a co-emulsifier. The NCs fabricated by this method are $100-200 \mathrm{~nm}$ in diameter and present a latent heat and encapsulation efficiency up to $98.8 \mathrm{~J} / \mathrm{g}$ and $82.2 \%$, respectively. The authors also explored the effect of mount of emulsifier and co-emulsifier on latent heat, diameter, size distribution and encapsulation efficiency. Zhang et al. 157] encapsulated n-octadecane PCM with PEMA and PMMA with an average shell thickness of $50 \mathrm{~nm}$, and a core/shell weight ratio of $80 / 20$ and obtained an average particle size of NCs $140 \mathrm{~nm}$ and $119 \mathrm{~nm}$, respectively. The authors found the encapsulation ratio and efficiency of $89.5 \%$ and $89.5 \%$, respectively. Further they reduced the degree of supercooling significantly and found that the PEMA shell has relatively better thermal performance. Wang et al. 158 designed a two-step Pickering emulsification technique to prepare the NCs of nonadecane as a PCM with a polystyrene as a shell material by using surface-modified amphiphilic zirconium phosphate platelets ( $\mathrm{ZrP})$ as an emulsifier for scale-up and mass production level. Further, this method is preferable to encapsulate the organic or alkane PCMs as a core materials and polystyrene (PS), polyurea (PU), styrene-buytl acrlate and polymethylmethacrylate (PMMA) as shell materials. In conclusion, miniemulsion is the most adopted polymerization technique in nano-capsules coating technology.

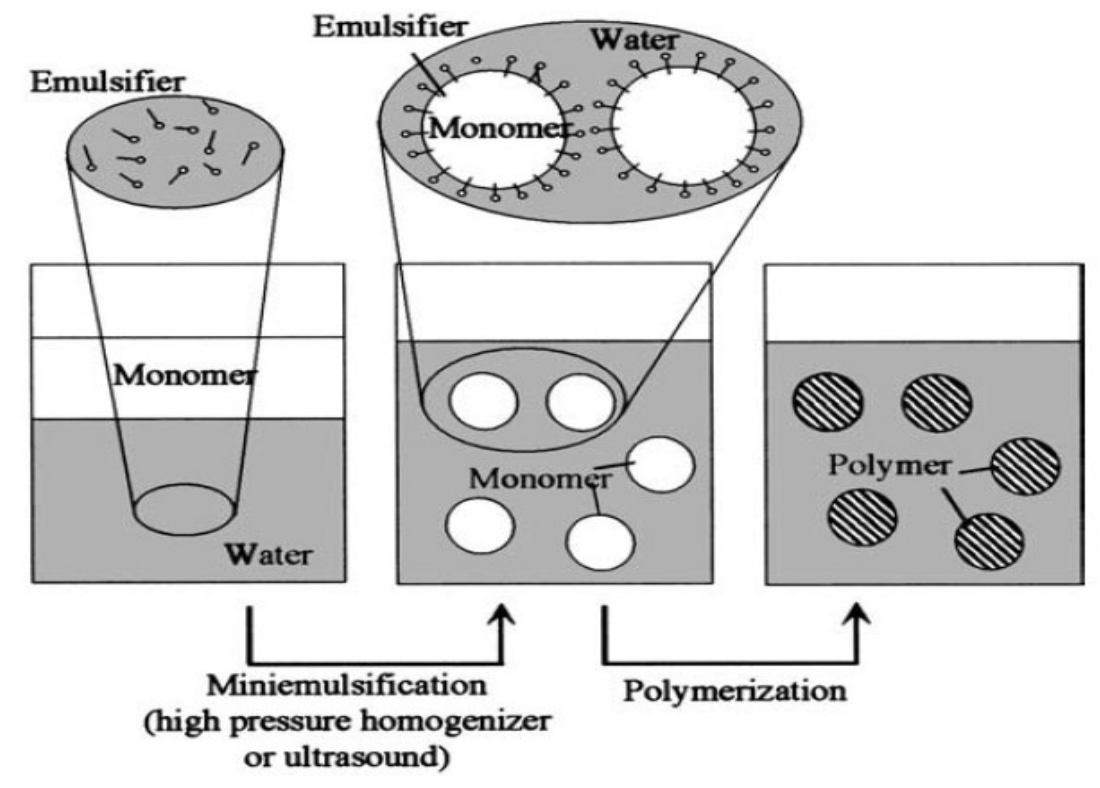

Figure 21: Scheme of the miniemulsion polymerization method 151, reused with permission from Springer Nature license number 4385871462764 . 


\subsubsection{In-situ polymerization}

The In-situ polymerization method involves chemical reaction in a continuous phase of two immiscible liquids (water soluble phase and oil soluble phase) rather two phase as in interfacial polymerization. In preparation of micro/nano-capsules through in-situ polymeirztion, the monomers are dissolved in the continuous phase, however, the polymers are not soluble in continuous phase whereby the polymerization reaction occurs on the surface of the core materials. Commonly, there are four steps which complete the in-situ polymerization: (i) formation of the oil-water $(\mathrm{O} / \mathrm{W})$ emulsion; (ii) preparation of the prepolymer mixture liquid; (iii) mixing the $\mathrm{O} / \mathrm{W}$ emulsion and prepolymer liquid to encapsulate the core materials; (iv) washing and drying of micro/nano-capsules. Figure 22 presents the example of in-situ polymerization method. Fang and his co-authors 159 employed the ultrasonic-assistant miniemulsion in-situ polymerization technique for coating of n-octadecane as a core with polystryrene as a shell material. The authors obtained the spherical shape nano-capsules of size ranging from $100-123 \mathrm{~nm}$ in diameter. In another study [53], these authors coated the n-tetradecane with PS for cold energy storage of average diameter of $132 \mathrm{~nm}$ and achieved the melting and freezing points and latent heats values of $4.04^{\circ} \mathrm{C}$ and $-3.43^{\circ} \mathrm{C}, 98.71 \mathrm{~J} / \mathrm{g}$ and $91.27 \mathrm{~J} / \mathrm{g}$, respectively. With same core material n-tetradecane, Fang et al. 160] used the urea and formaldehyde as shell materials adopting in-situ polymerization technique with adding $1-3 \% \mathrm{NaCl}$ to improve the thermal stability of the prepared nano-capsules. To investigate the effect of various shell materials on thermophysical properties Konuklu et al. [95] used the urea-formaldehyde (UF), melamine-formaldehyde (MF) and urea+melamine-formaldehyde (UMF) resins to prepare the nano-capsules of caprylic acid. The authors found the UF resin as a best resin for shell material among others in term of stability of nano-capsules. So far now, generally, the OPCMs as core materials and urea-formaldehyde (UF), melamine-formaldehyde (MF), carboxymethyl cellose (CMC), polymethylmethacrylate (PMMA), poly(melamine-formaldehyde) (PMF), and poly (allyl methacrylate) (PAMA) are used as a shell materials.

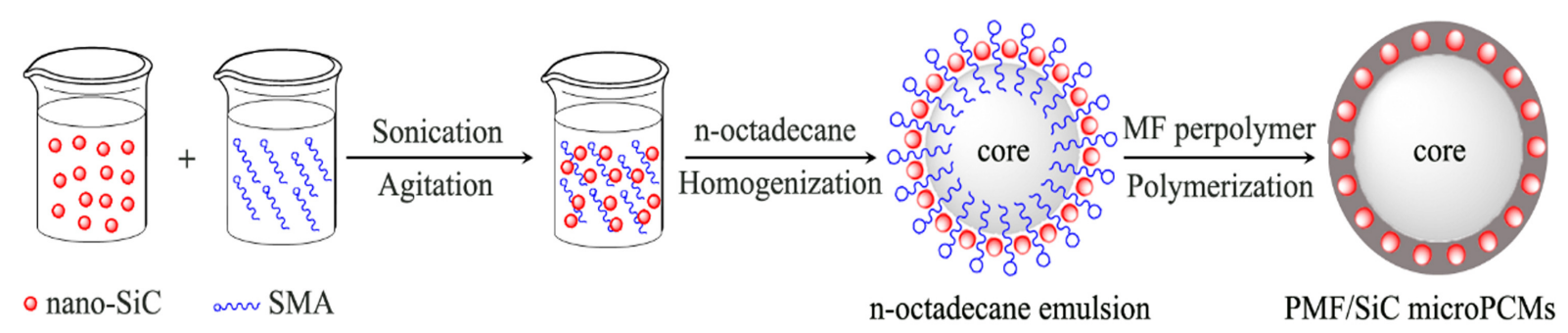

Figure 22: Schematic formation of the micro-PCMs based on n-octadecane core and poly(melamine-formaldehyde)/silicon carbide $(\mathrm{PMF} / \mathrm{SiC})$ shell through in-situ polymerization 161], reused with permission from Elsevier license number 4482000691089 . 
Table 8: Summary of prepared micro/nano-PCMs using chemical methods.

\begin{tabular}{|c|c|c|c|c|c|c|c|}
\hline Ref. & Method & Core & Shell & Particle size $(\mu m)$ & EE $(\%)$ & $T_{m}$ & $\begin{array}{l}\text { Latent heat } \\
\quad(J / g)\end{array}$ \\
\hline 146 & Interfacial polycondensation & n-Octadecane & PU & $11-20$ & 87.4 & 27.04 & 188.9 \\
\hline 162 & Interfacial polymerization & Insecticide & $\mathrm{PU}$ & $30-40$ & 90 & - & - \\
\hline 163 & Interfacial polymerization & Xylitol & PUR & $11.2-21.6$ & - & - & 196.3 \\
\hline 147 & Interfacial polycondensation & Insecticide & PU & $400-600 \mathrm{~nm}$ & - & 56.54 & 101.1 \\
\hline 164 & Interfacial polycondensation & Butyl stearate & TDI, EDA & $20-35$ & - & 29 & 80 \\
\hline 165 & Interfacial polycondensation & n-Hexadecane & TDI, EDA & - & - & - & - \\
\hline 166] & Interfacial polymerization & n-Octadecane & TDI, DETA & 1 & - & 30.8 & 112 \\
\hline 167] & Interfacial polymerization & n-Octadecane & TDI, DETA & 7.3 & 92 & - & - \\
\hline 168 & Interfacial polymerization & n-Octadecane & TDI, DETA & $5-10$ & 94.7 & - & 117.5 \\
\hline 169 & Interfacial polycondensation & $\begin{array}{l}\text { n-Pentadecane, } \quad \mathrm{n}- \\
\text { Eicosane, Paraffin wax }\end{array}$ & UF & $47,79,150$ & - & - & $109,148,127$ \\
\hline 170] & Interfacial polycondensation & n-Octadecane & $\mathrm{SiO}_{2}$ & $4-30$ & - & - & - \\
\hline 148 & $\begin{array}{l}\text { In-situ emulsion interfacial poly- } \\
\text { condensation }\end{array}$ & Palmitic acid & $\mathrm{AlOOH}$ & $100 \mathrm{~nm}$ & 69 & 16 & 27.8 \\
\hline 171] & $\begin{array}{l}\text { In-situ emulsion interfacial hy- } \\
\text { drolysis and polycondensation }\end{array}$ & Paraffin wax & $\mathrm{SiO}_{2}$ & $200-500 \mathrm{~nm}$ & 31.7 & 56.5 & 45.5 \\
\hline 172] & $\begin{array}{l}\text { In-situ emulsion interfacial hy- } \\
\text { drolysis and polycondensation }\end{array}$ & n-Octadecane & $\mathrm{SiO}_{2}$ & $169-563 \mathrm{~nm}$ & 49.3 & 27.35 & 109.5 \\
\hline 173] & Interfacial polymerization & Butachlor & PU & $1-20$ & - & - & - \\
\hline 174] & Interfacial polycondensation & Cyclohexane & $\mathrm{PU}$ & 1.6 & - & - & - \\
\hline 175 & Interfacial polymerization & Migrin oil & PU & $7.6-12.4$ & - & - & - \\
\hline 176] & Interfacial polymerization & Ovalbumin & PU & $50 \mathrm{~nm}-8 \mu \mathrm{m}$ & - & - & - \\
\hline 177] & Interfacial polycondensation & Octadecane & PU & $1-2$ & - & 31.9 & 54.8 \\
\hline 178 & Interfacial polymerization & n-Octadecane & PU & $5-10$ & $93.4-94.9$ & $29.8-31.0$ & $115.0-117.5$ \\
\hline
\end{tabular}




\begin{tabular}{|c|c|c|c|c|c|c|c|}
\hline 179] & Interfacial polymerization & n-Hexadecane & $\mathrm{PU}$ & $2-4$ & 50.1 & 15.52 & 66.09 \\
\hline 180$]$ & Interfacial polymerization & n-Eicosane & $\mathrm{PU}$ & - & $74.6-77.6$ & $35.7-36.5$ & $29.34-63.55$ \\
\hline 181] & Interfacial polymerization & Paraffin wax & Poly-amide & 6.4 & 99 & $29-44$ & 121.7 \\
\hline 182$]$ & Suspension-like polymerization & $\mathrm{Na}_{2} \mathrm{HPO}_{4} .7 \mathrm{H}_{2} \mathrm{O}$ & PMMA & $\sim 6.8$ & - & 51 & 150 \\
\hline 183 & Suspension-like polymerization & n-Octadecane & BMA & $1-46$ & - & $20.9-21.6$ & $116.4-144.3$ \\
\hline 184] & Suspension-like polymerization & n-Octadecane & ODMA-MAA & $0.5-4$ & - & 21.1 & 93 \\
\hline 185$]$ & Suspension-like polymerization & Paraffin wax & PS, MMA & 380 & - & $40.66-41.81$ & $83.70-96.47$ \\
\hline 186] & Suspension-like polymerization & $\begin{array}{l}\text { Paraffin wax, Tetrade- } \\
\text { cane, PEG 800, PEG } \\
\text { 1000, RT27, RT20, Non- } \\
\text { adecane }\end{array}$ & PS & $\begin{array}{lll}38.01, & 11.24, & 0.07 \\
0.07, & 27.85, & 64.87 \\
10.64 & & \end{array}$ & - & - & $\begin{array}{l}41.65,48.92,0, \\
0,58.83,12.01, \\
119.80\end{array}$ \\
\hline 187] & Suspension-like polymerization & Paraffin wax & PS & $\sim 200$ & 75.6 & $98-113$ & $21.2-41.7$ \\
\hline 188] & Suspension-like polymerization & RT27 & PS & 500 & - & - & - \\
\hline 189] & Suspension-like polymerization & n-Octadecane & PS-DVB & 80 & - & 29 & 126 \\
\hline 190] & Suspension-like polymerization & n-Octadecane & PS-DVB & $71-207$ & - & 29 & 125 \\
\hline 192] & Microsuspension polymerization & n-Octadecane & PDVB & $\sim 1.5$ & - & 22.6 & 192 \\
\hline 193] & Suspension-like polymerization & n-Octadecane & $\begin{array}{l}\text { BDDA, DVB, TMPTA, } \\
\text { PETRA }\end{array}$ & $0.72-0.75$ & - & $29.3-35.2$ & $83.7-156.4$ \\
\hline 194] & Suspension-like polymerization & n-Octadecane & TPGDA & $300-600 \mathrm{~nm}$ & 100 & - & 104 \\
\hline 195] & Suspension-like polymerization & $\begin{array}{l}\text { Paraffin wax, Butyl } \\
\text { stearate }\end{array}$ & Acrylate-based polymer & $10-80$ & $46-68$ & $29.08-32.12$ & $63.98-93.97$ \\
\hline 196] & Suspension-like polymerization & Paraffin wax & PS & 4.80 & - & - & 102.42 \\
\hline 197] & Suspension-like polymerization & RT31 & PS & $4.0-53.2$ & $49.0-67.9$ & 31.56 & $75.7-135.3$ \\
\hline 198] & Suspension-like polymerization & Paraffin wax & PS & $3.83,3.97$ & $43.6,35.1$ & - & $58.6,79.0$ \\
\hline 4] & Suspension-like polymerization & n-Octadecane & PBMA, PBA & $2-75$ & $47.7-55.6$ & $29.1-31.6$ & $96-112$ \\
\hline 199] & Emulsion polymerization & Paraffin wax & PMMA & 0.25 & - & $24-33$ & 101 \\
\hline 200] & Emulsion polymerization & $\begin{array}{l}\text { Paraffin wax, Palmitic } \\
\text { acid }\end{array}$ & PScEA & $0.166,0.265$ & - & $36.71,59.12$ & $49.03,97.93$ \\
\hline
\end{tabular}




\begin{tabular}{|c|c|c|c|c|c|c|c|}
\hline 201] & Emulsion polymerization & n-Octacosane & PMMA & 0.25 & - & 50.6 & 86.4 \\
\hline 202$]$ & Emulsion polymerization & n-Heptadecane & PMMA & $0.14-0.40$ & - & 18.2 & 81.5 \\
\hline 203] & Emulsion polymerization & Docosane & PMMA & 0.16 & - & 41.0 & 54.6 \\
\hline 204] & Emulsion polymerization & n-Eicosane & PMMA & 0.70 & - & 35.2 & 84.2 \\
\hline 205$]$ & Emulsion polymerization & n-Hexadecane & PMMA & $0.22,1.05$ & - & $15.69,17.34$ & $68.89,145.61$ \\
\hline 206] & Emulsion polymerization & n-Hexadecane & PMMA & $140-466 \mathrm{~nm}$ & - & 17.23 & 148.05 \\
\hline 207] & Emulsion polymerization & n-Octadecane & PS & $80 \mathrm{~nm}$ & $14.6-56.8$ & - & $6.48-49.76$ \\
\hline 208] & Emulsion polymerization & n-Heptadecane & PS & $1-20$ & 63.3 & 21.48 & 136.89 \\
\hline 155] & Emulsion polymerization & n-Nonadecane & PMMA & $0.1-35$ & 60.3 & 31.23 & 139.20 \\
\hline 209 & Emulsion polymerization & $\begin{array}{lr}\text { n-Heptadecane, } & \text { n- } \\
\text { Octadecane, } & \text { n- } \\
\text { Nonadecane, } & \text { n- } \\
\text { Eicosane, n-Tetracosane }\end{array}$ & PMMA & $0.01-100$ & $50.2-65.4$ & $19.24-35.80$ & $171.14-265.60$ \\
\hline 210] & Emulsion polymerization & $\begin{array}{l}\text { n-Tetracosane } / \mathrm{n}- \\
\text { Octadecane }\end{array}$ & PS & $0.01-115$ & 64.4 & 25.96 & 156.39 \\
\hline 212 & Miniemulsion polymerization & Paraffin wax & PS & $<100 \mathrm{~nm}$ & - & - & - \\
\hline 156] & Miniemulsion polymerization & n-Dodecanol & PMMA & $150 \mathrm{~nm}$ & 82.2 & 18.2 & 98.8 \\
\hline 213] & Miniemulsion polymerization & n-Dodecanol & SBA & $100 \mathrm{~nm}$ & 98.4 & 27 & 109.2 \\
\hline 214] & Miniemulsion polymerization & n-Hexadecane & UF & $270 \mathrm{~nm}$ & - & $16.15-16.36$ & $114.6-143.7$ \\
\hline 215 & Miniemulsion polymerization & RT 80 & SBA & $52-112 \mathrm{~nm}$ & $78-80$ & $77.7-84.1$ & $4.9-23.9$ \\
\hline 216] & Miniemulsion polymerization & n-Tetradecane & PS & $132 n m$ & 89 & 4.04 & 98.71 \\
\hline 159$]$ & $\begin{array}{l}\text { Miniemulsion in-situ polymer- } \\
\text { ization }\end{array}$ & n-Octadecane & PS & $100-123 n m$ & - & $30-35$ & 124.4 \\
\hline 217 & $\begin{array}{l}\text { Miniemulsion in-situ polymer- } \\
\text { ization }\end{array}$ & n-Octadecane & PS & $108-126 \mathrm{~nm}$ & - & - & $88.35-124.4$ \\
\hline 218 & Miniemulsion polymerization & n-Dotriacontane & PS & $168.2 \mathrm{~nm}$ & 61.23 & 70.9 & 174.8 \\
\hline 219] & $\begin{array}{l}\text { Miniemulsion in-situ polymer- } \\
\text { ization }\end{array}$ & n-Octadecane & PS-MMA & $102 \mathrm{~nm}$ & - & 29.5 & 107.9 \\
\hline 220] & Miniemulsion polymerization & Paraffin wax & PS & $100 \mathrm{~nm}$ & $47.7-55.6$ & $29.1-31.6$ & $96-112$ \\
\hline
\end{tabular}




\begin{tabular}{|c|c|c|c|c|c|c|c|}
\hline 157] & $\begin{array}{l}\text { Direct miniemulsion polymeriza- } \\
\text { tion }\end{array}$ & n-Octadecane & PEMA, PMMA & $140 \mathrm{~nm}, 119 \mathrm{~nm}$ & 89.5 & $32.2,31.9$ & $198.5,208.7$ \\
\hline 221$]$ & In-situ polymerization & Paraffin wax & $\mathrm{CMC}-\mathrm{MF}$ & $50 \mathrm{~nm}$ & 63.1 & 24.4 & 83.46 \\
\hline 222$]$ & In-situ polymerization & n-Octadecane & $\mathrm{P}(\mathrm{MMA}-\mathrm{CO}-\mathrm{AMA})$ & $577-693 \mathrm{~nm}$ & $64.0-71.6$ & $24.7-27.4$ & $129-151$ \\
\hline 160$]$ & In-situ polymerization & n-Tetradecane & $\mathrm{UF}$ & $100 \mathrm{~nm}$ & 60 & $5.57-9.01$ & $66.01-134.16$ \\
\hline 223] & In-situ polymerization & n-Tetradecane & $\begin{array}{l}\text { PVA, PS, PMMA, } \\
\text { PEMA }\end{array}$ & $23.15,16.89,18.59$ & - & $\begin{array}{l}2.06, \quad 5.97 \\
5.68\end{array}$ & $\begin{array}{l}\sim 0, \quad 66.26, \\
80.62\end{array}$ \\
\hline 224] & In-situ polymerization & Paraffin wax & UF & 20 & - & $53.3-54.4$ & $\begin{array}{ll}-98.5 & \text { to } \\
-200.4 & \end{array}$ \\
\hline 225$]$ & In-situ polymerization & n-Octadecane & MF & $0.9-9.2$ & - & $30.4-30.5$ & $169-172$ \\
\hline 226$]$ & In-situ polymerization & n-Octadecane & MF & 2.2 & 59 & 40.6 & 144 \\
\hline 227 & In-situ polymerization & Migrin oil & MF & $<10$ & - & - & - \\
\hline 228] & In-situ polymerization & $\begin{array}{l}\text { n-Hexadecane, n- } \\
\text { Eicosane }\end{array}$ & MF & $\sim 10$ & 70 & - & $163-170$ \\
\hline 229] & In-situ polymerization & n-Octadecane & $\mathrm{MF}$ & $20 \mathrm{~nm}$ & 92 & 26.91 & 146.25 \\
\hline 230] & In-situ polymerization & n-Octadecane & UMF & $0.2-5.6$ & $65-78$ & $32.77-34.88$ & $91.10-241.68$ \\
\hline 231 & In-situ polymerization & n-Octadecane & $\mathrm{MF}$ & $0.2-1.8$ & - & $24.4-36.2$ & $44-166$ \\
\hline 232$]$ & In-situ polymerization & n-Octadecane & $\mathrm{MF}$ & $1-2$ & - & - & $102-166$ \\
\hline 233] & In-situ polymerization & Dodecanol & PEG modified MF & $\begin{array}{l}0.83 \pm 0.23-14.4 \pm \\
5.56\end{array}$ & - & 25.8 & 118.9 \\
\hline 234] & In-situ polymerization & Decanoic acid & PMUF & 0.28 & - & 33 & 88 \\
\hline 235] & In-situ polymerization & Paraffin wax & $\mathrm{MF}$ & $15 \pm 3$ & - & 129.4 & 157 \\
\hline 236$]$ & In-situ polymerization & Paraffin wax & $\mathrm{SiO}_{2}, \mathrm{GO}$ & $\sim 10$ & 49.6 & 49.7 & 87.1 \\
\hline 237 & In-situ polymerization & n-Octadecane & MF & $\sim 1$ & 20 & - & 160 \\
\hline 238] & In-situ polymerization & $\begin{array}{l}\text { n-Octadecane, n- } \\
\text { Nonadecane, n-Eicosane }\end{array}$ & MF & $0.3-6.4$ & 70 & $\begin{array}{l}36.5, \quad 219.3, \\
45.3\end{array}$ & $167,161,172$ \\
\hline 239] & In-situ polymerization & n-Eicosane & $\mathrm{MF}$ & $0.1-10$ & 53 & 36.9 & 134.4 \\
\hline 240] & In-situ polymerization & n-Eicosane & $\mathrm{MF}$ & 1.89 & - & 36.9 & 134.3 \\
\hline 241 & In-situ polymerization & P1-S, RT25, RT40 & Amino-aldehyde & $5.91,2.78$ & - & - & - \\
\hline
\end{tabular}




\begin{tabular}{|c|c|c|c|c|c|c|c|}
\hline 12$]$ & In-situ polymerization & $\begin{array}{l}\text { n-Octadecane, n- } \\
\text { Eicosane, n-Hexadecane }\end{array}$ & MF & $1-500$ & - & 17.7 & 44.6 \\
\hline 242 & In-situ polymerization & n-Docosane & MF & 10 & - & - & 150 \\
\hline 243 & In-situ polymerization & n-Docosane & MF & $5-20$ & $68-135.4$ & $55.69-56.72$ & $17.74-57.81$ \\
\hline 244$]$ & In-situ polymerization & PETMP & $\mathrm{PMF}$ & $1-10$ & - & - & - \\
\hline 245] & In-situ polymerization & n-Dodecanol & MF & 30.6 & 93.1 & 21.5 & 187.5 \\
\hline 246$]$ & In-situ polymerization & $\begin{array}{l}\text { n-Octadecane, } \\
\text { Hexadecane }\end{array}$ & MF & $5-20$ & - & - & $150-210$ \\
\hline 226] & In-situ polymerization & $\begin{array}{l}\text { n-Octadecane, } \\
\text { Hexadecane }\end{array}$ & MF & 2.2 & 59 & 40.6 & 144 \\
\hline 247] & In-situ polymerization & n-Docosane & MF & 3.6 & - & - & - \\
\hline 248] & In-situ polymerization & Paraffin wax & Aniline $\left(\mathrm{C}_{6} \mathrm{H}_{7} \mathrm{~N}\right)$ & $300-500 \mathrm{~nm}$ & 49.7 & 53.4 & 65.1 \\
\hline
\end{tabular}




\section{Characteristics evaluation techniques of EPCMs}

A characterisation of EPCMs depends on the desired thermal, physical and chemical properties. The manufacturing of micro and nano level encapsulated capsules are only valuable and successful when they fulfil the industrial and end-users requirements to meet the clean energy demands. The characteristics of EPCMs are performed using various quantitative and qualitative techniques per the evaluation of the property. Table 9 presents the list of various characterization techniques conducted by researchers.

\subsection{Chemical Analysis}

\subsubsection{X-Ray diffraction (XRD)}

The $\mathrm{X}$-ray diffraction (XRD) or X-ray power diffraction (XPRD) technique is adopted to measure the crystalloid phase, material structure, crystallite atomic arrangement and size, crystal orientation or texture and parameters such as crystallinity, stain and distinguishes the amorphous and crystalline material. The physics of the diffraction of the $\mathrm{X}$-ray is similar to the diffraction of the electrons or neutrons except the only difference of the scattering mechanism. This technique ensures the crystalline structure of micro/nano capsules preferably suitable for inorganic shell materials. For instance, Zhang et al. 286 presented the XRD results of $\mathrm{Ag} / \mathrm{SiO}_{2}$ double-layered micro-PCM with n-eicosane as a core material to investigate the crystalline structure at different reaction time. The good crystallinity was retrained of silica layer on microcapsules surface and only an amorphous silica shell was fabricated onto the n-eicosane core. Zhao et al. 250 presented the XRD patterns of Ag-paraffin@Halloysite microspheres and obtained the consistent crystalline structure of Ag nanoparticles onto surface of paraffin@Halloysite. Additionally, the crystalline structure of paraffin was not affected in Ag-paraffin@Halloysite while encapsulation process.

\subsubsection{Fourier transformed infrared spectroscopy (FT-IR)}

The Fourier transformed infrared spectroscopy (FT-IR) technique evaluates the chemical composition or the functional groups of organic and inorganic compounds and micro/nano-capsules of EPCMs. The FT-IR is an effective analytical technique to identify the "chemical family" of the encapsulated core and shell materials. Further, FT-IR also confirms identifying the specific impurities in a pure compound in collection of the unique absorption bands. The FT-IR is preferred method of infrared spectroscopy passing the IR radiation through the sample. Some IR radiation is absorbed by the sample and some transmit through the sample. At the detector a spectrum arises due the singles which represents a molecular "fingerprint" of the sample. In IR spectroscopy the different spectral fingerprints arise due to the chemical structure (atoms and molecules) of different materials. In FT-IR method the infrared spectra is obtained firstly collecting an interferogram of a sample using an interferometer. Further, Fourier Transform (FT) is applied on the interferogram resulting spectrum is obtained. The FT-IR spectrometer collects and digitizes the interferogram performing the FT function and then displays the spectrum. For example, various researchers presented the FT-IR peaks to represent the chemical composition of micro/nanoPCMs. Presented FT-IT results by Zhang et al. 270 showed the excellent chemical composition of encapsulated $\mathrm{KNO}_{3} @ \mathrm{SiO}_{2}$ microcapsules. Kahraman et al. 299] synthesized microcapsules using PS 
Table 9: Characterization techniques used by the various researchers for characteristics evaluation of EPCMs.

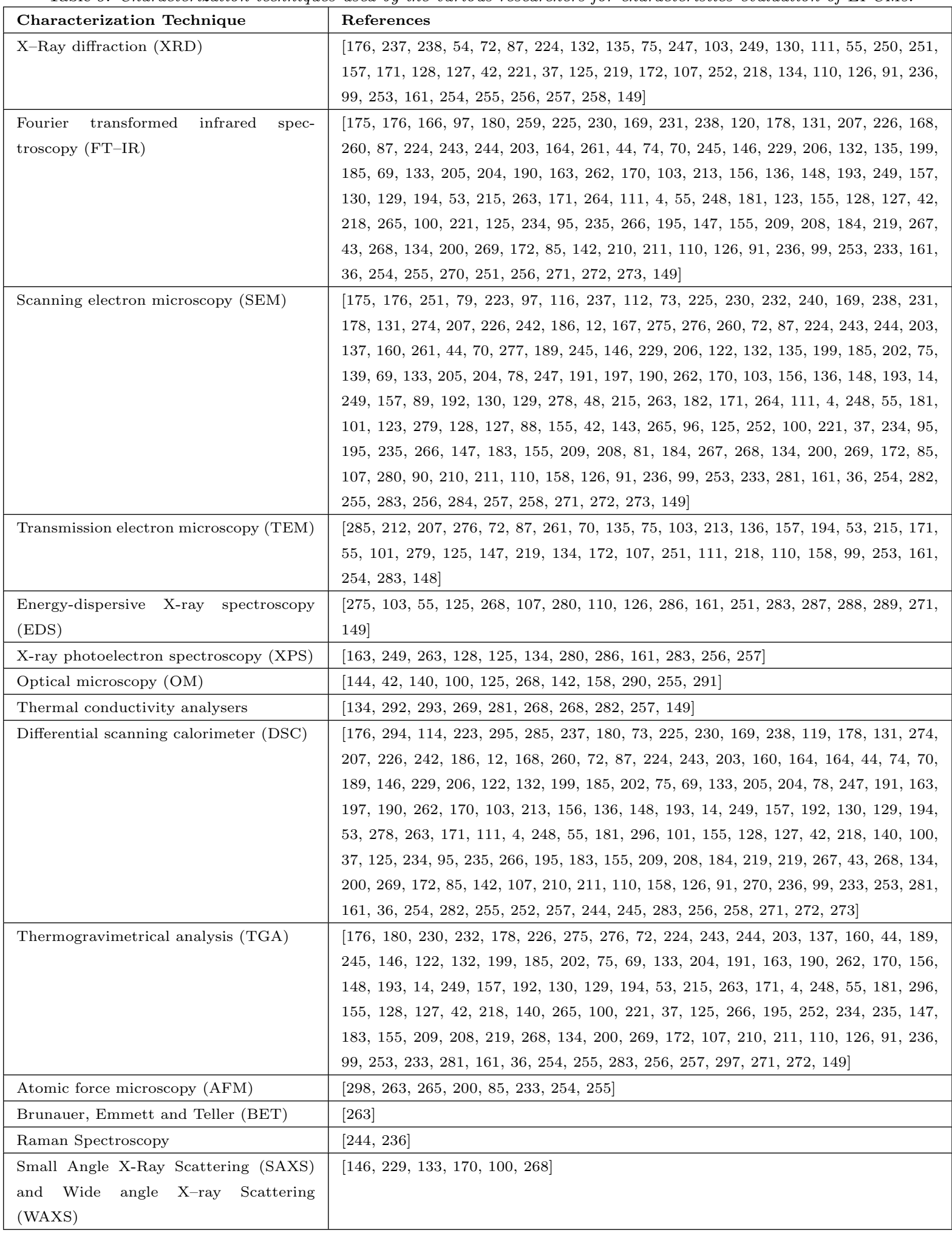


as a shell material and various n-alkanes eutectics (C17-C18. C20-C17, C20-C19, and C20-C24) and obtained the excellent functional group and chemical composition of EPCMs.

\subsubsection{Energy-dispersive X-ray spectroscopy (EDS)}

The energy-dispersive X-ray spectroscopy (EDS or EDX) is an analytical technique which is used to investigate the surface elemental analysis or chemical characterization or elemental composition of a sample. The EDS technique detects the X-rays emitted from the sample during the bombardment of a high-energy beam of charged particles such as electrons or a beam of X-rays focused into the sample. Normally, EDS technique is carried out in conjunction with scanning electron microscopy (SEM). Zhang et al. 286 performed the EDS analysis to investigate the surface elemental distribution of $\mathrm{Ag} / \mathrm{SiO}_{2}$ double-layered microcapsules with n-eicosane as a core material along with atomic percentage. Ma et al. 251 determined the chemical elements and purity of paraffin@ $@ \mathrm{TiO}_{2}$ microcapsules and confirmed the formation of $\mathrm{TiO}_{2}$ shell onto the surface of paraffin wax. Geng et al. 283 presented the EDS results with SEM of silver coated microcapsules found the equal proportion of silver which was in accordance with feed ratio.

\subsubsection{X-ray photoelectron spectroscopy (XPS)}

$\mathrm{X}$-ray photoelectron spectroscopy (XPS) which is also known as electron spectroscopy for chemical analysis (ESCA), is a surface analysis technique to study the surface chemistry or characterization of a sample material. XPS can measure the elemental composition, empirical formula, chemical and electronic states from the surface or within the sample. Additionally, XPS can investigate the uniformity of elemental composition of the surface as well as with other materials that contaminate a surface. The surface elemental composition analysis carried out by Zhang et al. 286 through XPS technique and observed the elemental characteristic peaks of $\mathrm{Ag} / \mathrm{SiO}_{2}$ double-layered microcapsules. Geng et al. 283] presented the XPS peak spectrum of silver coated microcapsules and observed the existence of face-centred cubic metallic silver. Advincula et al. 256 confirmed the functional groups and binding energy of RGO-SA microcapsules with XPS technique.

\subsection{Thermal Analysis}

\subsubsection{Thermal conductivity analysers}

Thermal conductivity is the major and fundamental property for the evaluation of EPCMs for efficient TES in various thermal systems. So far various instruments have been utilized for the measurement of thermal conductivity of micro/nano capsules such as laser flash apparatus (LINSEIS LFA1000) 134, TC 3020 thermal conductivity meter 292], TC3000 thermal conductivity meter [293, Sweden Hot Disk thermal conductivity meter 269, 281], EKO HC-110 thermal conductivity meter 268]. The encapsulated capsules are pressed in a tablet form to measure the thermal conductivity of micro/nano-capsules. The thermal conductivity of single a capsule can be predicted theoretically based on composite sphere approach as follows $300,301,262,302$ :

$$
\frac{1}{k_{p} d_{p}}=\frac{1}{k_{c} d_{c}}+\frac{d_{p}-d_{c}}{k_{s} d_{p} d_{c}}
$$


Here, $k_{p}, k_{c}$, and $k_{s}$ are the thermal conductivities of micro/nano-capsule, core material, and shell material, respectively. Additionally, $d_{p}$ and $d_{c}$ are the diameter of micro/nano-capsule and core material, respectively. As the most the PCMs especially OPCMs exhibit the low thermal conductivity which reduces heat transfer performance. The sole purpose to encapsulate the PCM is to enhance their thermophysical properties to utilize them for effective and efficient heat transfer applications. The enhancement in thermal conductivity of EPCMs solely depends on the shell material. Using organic polymeric shell materials exhibit the lower thermal conductivity which reduces the rate of heat transfer while thermal energy storage and release. However, coating of inorganic nanomaterials such as $\mathrm{Fe}_{3} \mathrm{O}_{2}$ 147, 125, $\mathrm{TiO}_{2}$ 127, 128, 134], $\mathrm{SiO}_{2}$ [171, 172, 125, 149], GNP [292], $\mathrm{Al}_{2} \mathrm{O}_{3}$ [269], $\mathrm{CaCO}_{3}[268], \mathrm{Cu}_{2} \mathrm{O}[161]$, and $M W C N T 254$. Although the higher thermal conductivity has been achieved however the decrease in latent heat of phase change enthalpy observed. Therefore, there should be compromised on the optimum values of thermal conductivity and latent heat of phase change enthalpy.

\subsubsection{Differential scanning calorimeter (DSC)}

The Differential scanning calorimeter (DSC) is one of the most widely adopted technique to measure the thermo-analytical properties such as melting onset and peak temperatures, cooling onset and peak temperatures, heat capacity, latent heat of melting and cooling, and degree of supercooling (defined as the difference of peak melting and cooling temperatures) [283]. During DSC analysis the amount of energy absorbed or released upon heating or cooling is measured providing qualitative and quantitative data while endothermic (heat absorption) and exothermic (heat rejection) phase transitions. In DSC analysis, the change of heat flux is recorded with respect to time, however, the heating rate and sample mass is the most important because the changing heat rate and sample mass will give temperature-heat flow responses 299,303 .

\subsubsection{Thermogravimetrical analysis (TGA)}

The thermogravimetry or thermogravimetrical analysis (TA) technique measures the amount and rate change of the material weight as a function of temperature or at isothermal condition as a function of time in a controlled atmospheric conditions upon melting and solidification [252]. The change in the mass of sample material of micro/nano capsules are examined under the various thermal modes such desorption, absorption, sublimation, vaporization, oxidation, reduction and decomposition [304.

\subsection{Physical Analysis}

\subsubsection{Performance parameters}

In literature, a few mathematical relations have been used to address the physical and thermal performance of EPCMs. These relations are mainly affected by the mass of core and shell materials, mass of emulsifier and cross-link agent, herein the synthesis encapsulation technique. The theoretical and actual loading or core content of PCM can be calculated as follows 161]:

$$
C_{t h}=\frac{m_{\text {core }}}{m_{\text {core }}+m_{\text {shell }}} \times 100 \%
$$




$$
C_{\text {act }}=\frac{m_{\text {core }}-m_{\text {shell }}}{m_{\text {core }}} 100 \%
$$

Major thermal performance of EPCMs are generally evaluated using encapsulation ratio (ER), encapsulation efficiency (EF), thermal energy storage capability (TESC), and thermal cycling performance (TCP) as follows 250, 251, 305:

$$
\begin{gathered}
E R=\frac{\Delta H_{m, E P C M}}{\Delta H_{m, P C M}} \times 100 \% \\
E F=\frac{\Delta H_{m, E P C M}+\Delta H_{s, E P C M}}{\Delta H_{m, P C M}+\Delta H_{s, P C M}} \times 100 \% \\
T E S C=\frac{\Delta H_{m, P C M}\left(\Delta H_{m, E P C M}+\Delta H_{s, E P C M}\right)}{\Delta H_{m, E P C M}\left(\Delta H_{m, P C M}+\Delta H_{s, P C M}\right)} \times 100 \% \\
T C P=\frac{\Delta H_{m, E P C M}^{\prime}}{\Delta H_{m, P C M}} \times 100 \%
\end{gathered}
$$

Here, $\triangle H_{m, E P C M}$ and $\triangle H_{s, E P C M}$ are the change in enthalpies of melting and solidifications, respectively of EPCM, $\triangle H_{m, P C M}$ and $\triangle H_{s, P C M}$ are the change in enthalpies of melting and solidifications, respectively of PCM. The change in enthalpy or latent heat of fusion is measured by the DSC. During the practical utilization of EPCMs in various applications, the shell of the encapsulated micro/nano-capsules possesses a crack or porous structure resulting in the leakage of the core PCM. So the core percentage or leakage rate in micro/nano-capsules at various times is usually used to define the leakage-performance 286, 255. The leakage rate $\left(L_{r}\right)$ between the initial mass $\left(m_{0}\right)$ of capsules and after heating periodically at certain melting temperature, indicated as $m_{t}$, is defined as follows:

$$
L_{r}=\frac{m_{0}-m_{t}}{m_{0}} \times 100 \%
$$

Herein, it can been noticed that increasing the thickness although deceases the percentage of leakage rate of the capsules. However, as a result of this, ER will decrease simultaneously.

\subsubsection{Optical microscopy (OM)}

To evaluate the particle size, morphology, transparency color and fixation a few researchers have been presented the images of EPCMs using optical microscopy (OM) technique [140, 100, 291]. Wang et al. 291 presented the images of SiC/PMF coated n-octadecane microcapsules and revealed that nano-SiC solid particles could be absorbed at oil-water interface. Additionally, showed the $10 \mu \mathrm{m}$ size of microcapsules using OM technique.

\subsubsection{Scanning electron microscopy (SEM)}

The SEM technique, based on the scattered electrons, is used to determine the particle size and shape using electron microscope of the micro/nano capsules. The SEM uses a higher-energy beam of electron on the surface of the sample which generates the various signals showing the image of sample surface. These variety of signals reveal the various characteristics information of the sample including 
topography (the surface features or texture) 273, 271, morphology (the shape and size) 284, 273, 272, composition (elements and compounds) 291, 272 and crystallography (atoms arrangement) 149, 271. Various researchers have been presented SEM images to represent chemical composition, morphology, and crystallography of EPCMs mentioned in Table 9

\subsubsection{Transmission electron microscopy (TEM)}

TEM, based on the transmitted electrons, is used to measure at high resolution than SEM such as nano level closer to the atomic structure. So the morphology and PSD of micro/nano-capsules can also be determined by TEM at more smaller level (e.g nano-meters) which is beyond the limit of SEM 251. In TEM the electron passes through the sample whereas in SEM the electron beam just scans over the surface of the sample material. Geng et al. 283 presented the TEM images of Ag-MMF coated micro-capsules of 1-tetradecacanol with diameter of $100 \mathrm{~nm}$.

\subsubsection{Atomic force microscopy (AFM)}

The atomic force microscopy (AFM) is a surface topography measuring technique which measures the surface images near nanometer resolution as well as the local properties such height, friction and magnetism with a scanning probe. Further, AFM can also evaluate the mechanical properties of the micro/nano-capsules. Zheng et al. 297] evaluated the highest elastic modulus of CNTs coated neicosane micro-capsules. Huang et al. 254 evaluated the surface profile of CNT coated n-octadecane micro-capsules and obtained the average roughness and root-mean-square roughness with CNT were $17.12 \mathrm{~nm}$ and $21.09 \mathrm{~nm}$, respectively, which were approximately three times of microcapsules without A-CNTs/PSS multilayers.

\subsubsection{Brunauer, Emmett and Teller (BET)}

The BET techniques is used to measure the specific surface area of the solid including pore size distribution by adsorption/desorption of nitrogen gas on the surface and then calculating the amount of the adsorbate gas into the surface corresponding to a monomolecular layer of the surface. The BET equation can be used to determine the surface area of the wide variety of gases or vapours [306]. The most commonly used BET equation is described below, see Equation 9

$$
\frac{x}{V(1-x)}=\frac{1}{V_{m} \cdot c_{B E T}}+\frac{x \cdot\left(c_{B E T}-1\right)}{V_{m} \cdot c_{B E T}}
$$

Where, $V$ and $V_{m}$ are the volumes of absorbed molecules and monolayer volume, respectively, $c_{B E T}$ is the BET constant, and $x$ is the relative pressure $\left(x=P / P_{o}\right)$.

\subsubsection{Small Angle X-Ray Scattering (SAXS) and Wide angle X-ray Scattering (WAXS)}

The Small Angle X-Ray Scattering (SAXS) is used to determine the crystalline structure of polymers coated micro/nano-capsules at a range of $0.02-10^{\circ}$ 307. The Wide angle X-ray Scattering (WAXS) or Wide-Angle X-ray Diffraction (WAXD) is used to measure the crystalline structure of inorganic and organic polymeric encapsulated materials at wider angles at $2 \theta>1^{\circ}$. The Bragg peaks (diffraction peaks) are analysed by function of scattering angles which arise by scattering from the subnanometer-size crystal structures 308. A few researchers have utilized SAXS and WAXS techniques for EPCMs $170,100,268$. 


\section{Stability of EPCMs}

The stability of ECPMs is the real challenge for the current industrial revolution. Stability of EPCMs mainly concerns with the thermal and chemical stability to ensure the long-term usage of micro/nano encapsulated PCMs. Generally a number of repeated thermal cyclic tests are performed to validate the thermal reliability by measuring the thermo-physical properties. The quality of the encapsulated PCMs is evaluated by assuring that there is no geometrical variation, leakage of micro/nano capsules, sedimentation, aggregation and crystallization of inter layer materials and so far. A thermodynamically and chemically encapsulated PCMs ensures the long-term performance as TES materials for industrial and research applications. Further, thermal and chemical stability of the EPCMs enhance the economic feasibility maintaining their latent heat of fusion and melting for employing under repeated melting/freezing cycles with time.

\subsection{Chemical stability}

The chemical stability of the encapsulated capsules is generally determined by adopting anti-osmosis test in which sealing performance of encapsulated capsules of PCMs is determined. Anti-osmosis test determines the weight loss of the extracted micro/nano capsules, and it can be used to evaluate the durability of the encapsulated capsules 133, 146, 168. Zhang et al. [133] conducted the anti-osmosis to evaluate the leaf performance of $\mathrm{SiO}_{2}$ (shell material) and $n$-octadecane (core material) under different conditions. The authors reported that micro-capsules of 50/50 weight ratio had the best anti-osmosis performance as compared to others weight ratios. Further, the they evidenced that the release rates of micro-capsules were depended on the thickness of the silica shell. The more the thickness of the shell, lesser the release rate of the encapsulated capsules. Similar method to determine the leaking performance or durability of micro-encapsulated $n$-octadecane by Zhang and Wang [146, 229]. The authors (In Ref. 229 ) used the styrene-maleic anhydride (SMA), sodium dodecyl sulfate (SDS) and polyvinyl alcohol (PVA) as an emulsifiers and results showed that by using SMA and SDS, shown in Figure 23 The Figure showed that the release rate of the micro-capsules increased with increasing with the weight percentage of the core materials. Further, the authors reported that release rate of micro-capsules prepared by using SDS is was much higher than that of micro-capsules using SMA at the same weight ratio. Su et al. 168 also adopted the same method and SMA was used as a surfactant with percentage of 1.0,2.0,3.0 and $4.0 \%$ under the presences of ethyl alcohol as an extraction solvent. They found that the $4.0 \%$ of SMA showed the lower release rate of polyurethane-shell, shown in Figure 24. Further they suggested that this releasing phenomena might be attributed to the emulsion effect and shell polymerization.

\subsection{Thermal stability}

The thermal stability of the encapsulated micro/nano capsules of PCMs has the greater potential and significance in TES systems. Several studies have been conducted to ensure the consistency in latent heat of fusion and melting temperature of EPCMs. Thermal cycles or thermal cycling tests can be conducted using TGA and DSC 294, 309]. Silakhori et al. 248 conducted the thermal cycles tests using TGA and DSC methods up to 1000 cycles for paraffin wax/polyaniline nano-capsules and found 


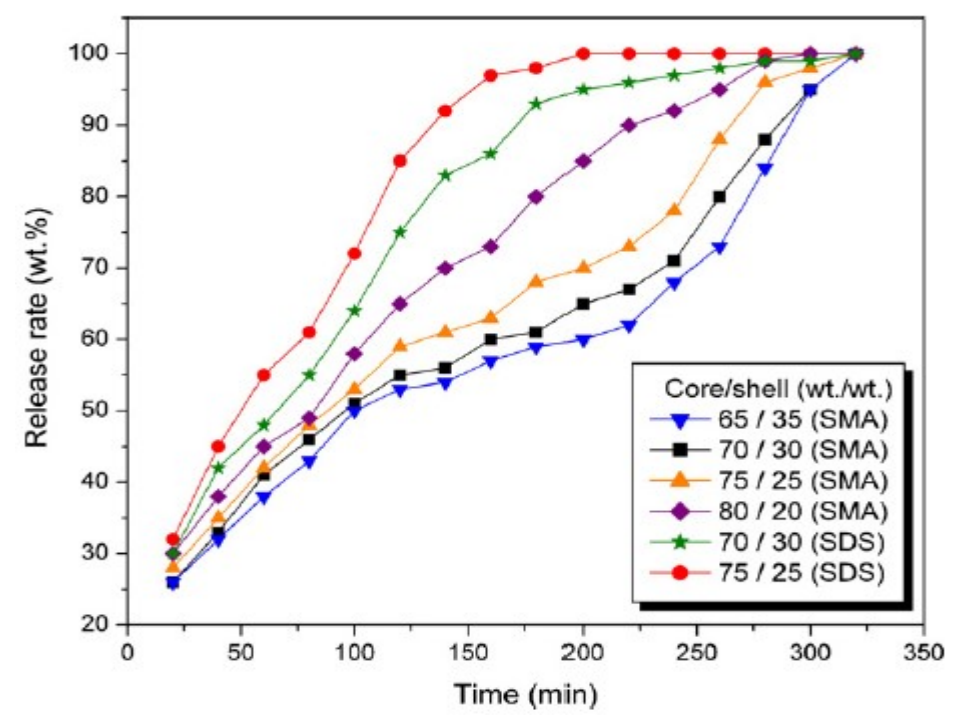

Figure 23: Release curves of micro-EPCMs capsules with different weight ratios of core/shell materials 229], reused with permission from Elsevier license number 4385880183182.

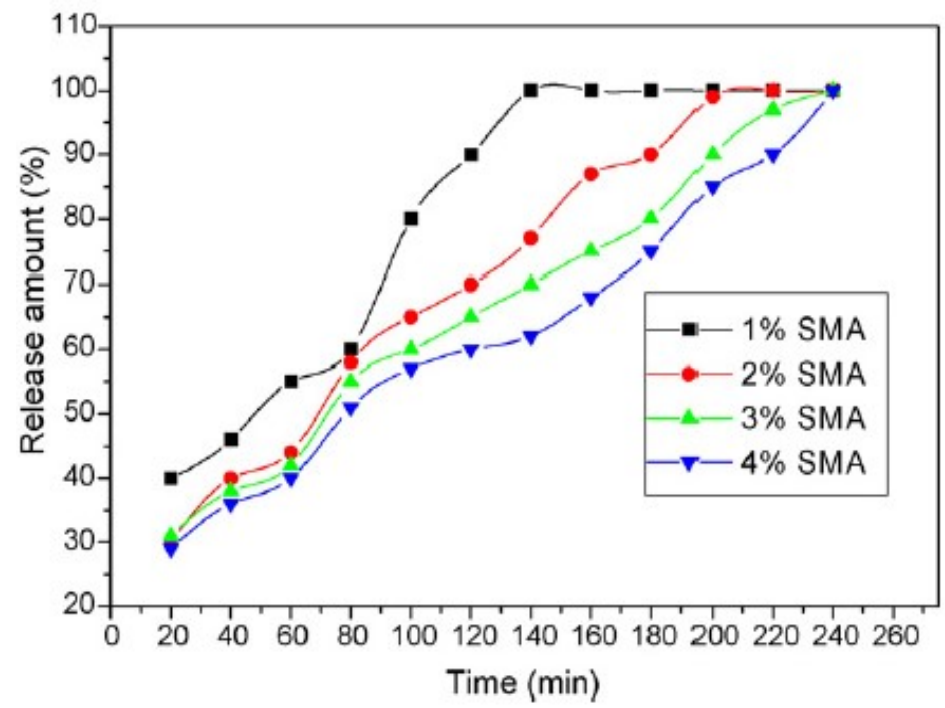

Figure 24: Release curves of micro-EPCMs samples prepared by 1.0, 2.0,3.0 and 4.0\% of SMA 168, reused with permission from Elsevier license number 4385881263849.

the chemical and thermal structure of the capsules remained unchanged. Similarly, Hawlader et al. 115 claimed that encapsulated capsules of paraffin wax maintained their original geometrical profile and energy storage capacity even after 1000 thermal cycles. Fortuniak et al. 278] used DSC for 50 cycles of fusion and crystallization and reported the proof of thermal stability of micro-capsules of n-eicosane coated with polysiloxane. Sar et al. 201 performed the FT-IR, TGA and DSC analysis of PMMA/noctadecane micro-capsules for 5000 thermal cycles, shown in Figure 25. They reported that melting temperature changed from $51.1^{\circ} \mathrm{C}$ to $52.3^{\circ} \mathrm{C}$ freezing temperature was changed from $53.7^{\circ} \mathrm{C}$ to $55.2^{\circ} \mathrm{C}$ and the latent heats of melting and freezing were measured as $79.9 \mathrm{~J} / \mathrm{g}$ and $81.7 \mathrm{~J} / \mathrm{g}$, respectively, after 5000 thermal cycling. The authors concluded that there was good thermal and chemical stability of 
PMMA/n-octadecane micro-capsules in terms of changing of its thermal properties. Alkan et al. 203] carried out the FT-IR, DSC and TGA tests for thermal and chemical stability of PMMA/docosane after 1000, 3000 and 5000 thermal cycles. The authors found the melting point of PMMA/docosane changed from $40.1-41.4^{\circ} \mathrm{C}$ and crystallizing point changed from $41.6-41.7^{\circ} \mathrm{C}$, moreover, the latent heat of melting and crystallization were found of $75.2 \mathrm{~J} / \mathrm{g}$ and $67.7 \mathrm{~J} / \mathrm{g}$, respectively, after 1000,3000 and 5000 thermal cycles. The authors evidenced that there was no significant changed in phase change thermal properties as well as in chemical structure of the micro-capsules after thermal cycling tests, shown in Figure 26. Sharma et al. 295] carried out the 1500 repeated melt/freeze cycles to study the thermal stability of commercial grade acetamide, stearic acid and paraffin wax. The DSC curves of three PCMs concluded that acetamide and paraffin wax showed the good thermal stability regarding phase change temperature and latent heat of fusion, however, the stearic acid showed the melting over a wide range of temperatures.

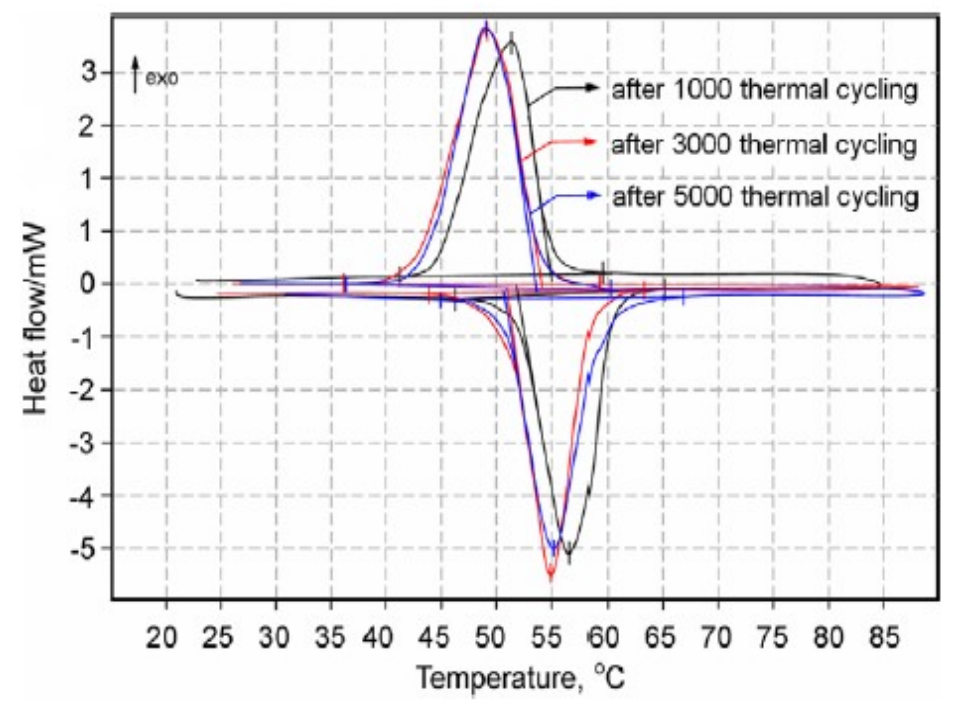

Figure 25: DSC thermogram for PMMA/n-octadecane micro-capsules after thermal cycling [201], reused with permission from Elsevier license number 4385881396518.

\section{Application of micro/nano-PCMs}

The utilization of developed micro and nano EPCMs have been categorized by exhibiting their new chemical and thermophysical properties. Moreover, the unique properties such as (i) suitable solid-toliquid phase transition, (ii) higher amount of energetic changes, (iii) chemical and thermal stabilization, (iv) variations in conduction and convection heats during phase transformation define the employability of EPCMs for a specific application. In this section, we reviewed the some potential applications which have been greatly accelerated incorporating micro and nano EPCMs.

\subsection{Solar-to-thermal energy storage}

An unlimited, economic, and sustainable energy source has always been potential requirement in the sight of researchers and industrialist. Nature has gifted us such a fundamental, unlimited and economic 


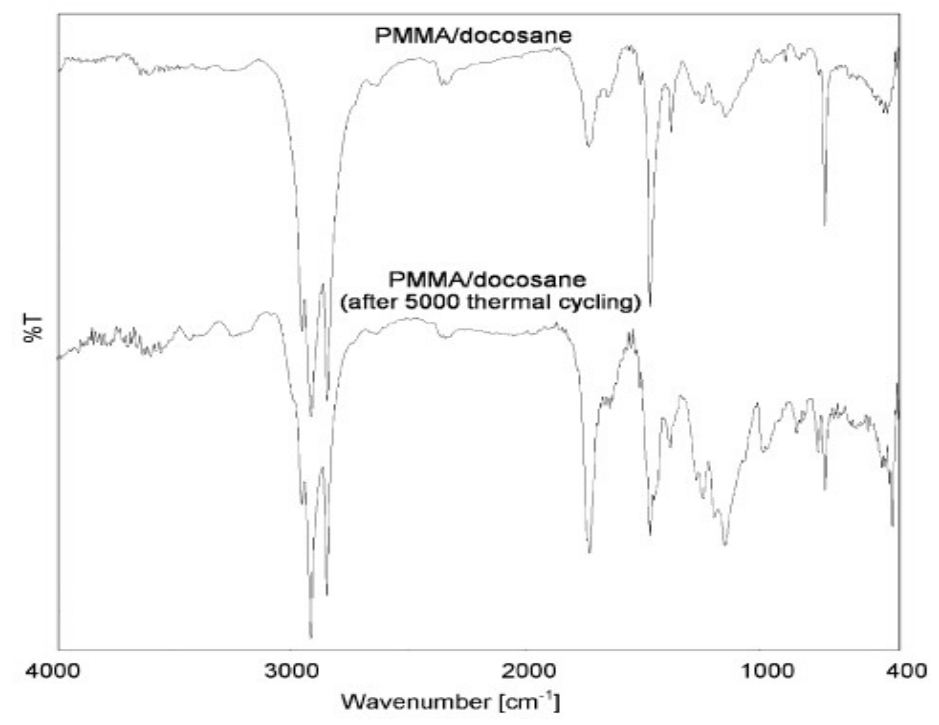

Figure 26: FT-IR spectra for PMMA/docosane micro-capsules before and after thermal cycling [203], reused with permission from Elsevier license number 4385890037722 .

energy source in the form of sun. From the creation of this universe, the sun has been providing us a huge amount of energy in the form of solar energy on the earth. Here, the question is that how to utilize this energy in an efficient and longer time period to meet the energy requirement for both in day and night times. As, more heat and electricity are required at night because of the absence of sun. To address this challenge, the novel smart energy storage materials are needed to be developed which can efficiently store this renewable solar energy source along with reducing the global warming and climate changes issues. Therefore, EPCMs have been gaining the promising attention in recent era to absorb solar thermal energy in form of latent heat and release it later on to meet the energy demands. The utilization of micro- and nano-PCMs have been under investigation for photo-thermal conversion, solar cells, direct absorb solar collector, photo catalyst, storage tank or container, heat exchanger, minichannel and so on to harvest and convert the solar energy directly and indirectly [303, 292]. Zeng et al. [310] synthesized the core-shell nanoparticles using $\mathrm{Sn} / \mathrm{SiO}_{2} / \mathrm{Ag}$; where $\mathrm{Sn}$ was used the as core material to store the thermal energy, $\mathrm{SiO}_{2}$ was used as a shell material to provide containment and $\mathrm{Ag}$ shell was used to enhance the light absorption intensity. They found the good optical absorption and TES capabilities of $\mathrm{Sn} / \mathrm{SiO}_{2} / \mathrm{Ag}$ composite nanoparticles which improved the volumetric absorption efficiency of DASC from medium-tohigh temperature range. Zheng et al. 297 investigated the geometry dependent heating efficiency and stability of hollow structure micro-PCMs (h-micro-PCMs) and solid PCM core particles (s-micro-PCMs) to enhance the thermal diffusivity and reliability of micro-PCMs for solar-thermal energy conversion and storage systems. The results revealed more stability and higher heat diffusivity within and above the phase transition range in case of $\mathrm{h}-$ micro-PCMs than s-micro-PCMs. Pethurajan et al. 311] synthesized the $\mathrm{SiO}_{2}$ /D-Mannitol micro-PCMs using sol-gel technique for solar energy harvesting and storage systems. Fundamental thermophysical properties were studied and found the enhancement in thermal conductivity of $1.77 \mathrm{~W} / \mathrm{m} . \mathrm{K}$. Additionally, they found the excellent thermal stability that after 100 cycles latent heat of melting was $250.75 \mathrm{~J} / \mathrm{g}$, and encapsulation ratio and efficiency were reported of $88.925 \%$ and 
85.024\%, respectively. $\mathrm{Xu}$ et al. synthesized the micro-PCMs consisting of paraffin@ $\mathrm{Cu}-\mathrm{Cu}_{2} \mathrm{O}$ by a hydrothermal method for solar energy storage and photo-thermal conversion and found the encapsulation efficiency of $62.79 \%$. Further, micro-PCMs capsules are suspended in DI water studied the photo-thermal conversion characteristics. They results summarized that paraffin@ $\mathrm{Cu}-\mathrm{Cu} \mathrm{O}_{2} \mathrm{O}$ slurry had the better light absorbing properties, thermal conductivity, and photo-thermal conversion performance which can be potentially used for DASC systems. Chen et al. 312 found the melting temperature and latent heat of $59.28^{\circ} \mathrm{C}$ and $91.94 \mathrm{~J} / \mathrm{g}$, respectively, of SA/MWCNTs prepared by vacuum absorption method. Further estimated the photo-thermal conversion efficiency by suspending the SA/MWCNTs into water making a stable suspension. They predicted the excellent photo-thermal conversion performance with temperature increased from $30^{\circ} \mathrm{C}$ to $80^{\circ} \mathrm{C}$ and found the $85 \%$ receiver efficiency which shows its potential to store solar energy for practical applications. Zhao et al. 250 developed innovative hybrid microPCMs consisting Ag-Paraffin@Halloysite to store the solar energy and studied the catalytic reactions by self-assembly method. Figure 27 shows the catalytic activity of Ag-Paraffin@Halloysite used as a catalysis and revealed the better conversion activity of $95.3 \%$ in $6 \mathrm{mins}$ compared with one without heat storage with conversion of $71.1 \%$ in $6 \mathrm{mins}$ for catalytic reduction of 4 -nitophenol. The efficiency $(\eta)$ of solar-to-thermal energy conversion and storage systems confined with EPCMs can be determined from Equation 10 .

$$
\eta=\frac{m \Delta H}{A I t}
$$

Here, in Eq. $10 m$ is the mass of confined EPCMs, $\Delta H$ is the latent heat enthalpy while phase transformation, $A$ is the effective surface area of solar system, $I$ is the intensity of solar irradiation, and $t$ is phase transition completion duration. Recently, Kahraman et al. 299 encapsulated the various n-alkanes eutectics such as n-heptadecane, n-octadecane, n-nonadecane, n-eicosane, and n-tetracosane and their mixtures with PS to harvest the solar energy. They found that micro-PCMs eutectics mixtures had reversible and isothermal phase transition temperature between $21^{\circ} \mathrm{C}$ and $35.9^{\circ} \mathrm{C}$ and latent heat of enthalpy between $61.2 \mathrm{~J} / \mathrm{g}$ and $146.1 \mathrm{~J} / \mathrm{g}$ which are highly suitable for a wide range of solar thermal applications.

\subsection{Electrical-to-thermal energy storage}

The energy harvesting and conversion from electrical to thermal is a very emerging area to store the heat for beneficial usage. The fundamental evaluation parameter is the enhanced or reduced temperature at a certain input power which encourages the researchers to develop the practical devices or systems of higher energy conversion efficiency. From the last three decades, the researchers have been putting keen interests on the solar-to-thermal energy harvesting and conversion using PCM which stores the heat through absorption only in the sunshine duration. Contrarily, there is a huge challenge for the countries located at the North-Pole of the globe which experience the lack of sunlight mostly in winter season. To overcome this challenge few studies are available who developed the electrical conductive micro/nano-PCMs to convert and store the energy from electrical-to-thermal. The conductive EPCMs converts the electrical energy into heat on applying the small input voltage and store that heat in form 

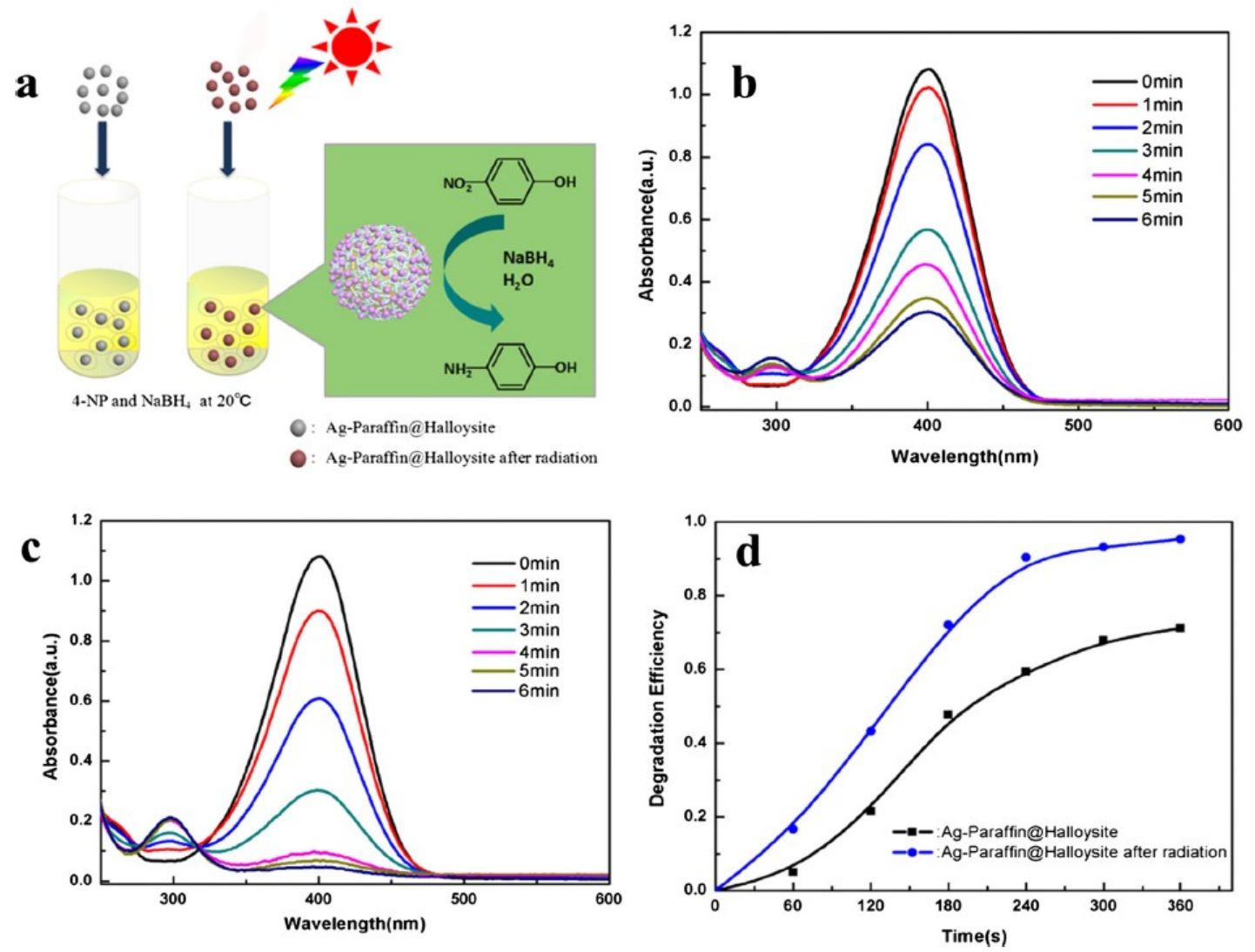

Figure 27: (a) Schematic catalysis mechanism of Ag-Paraffin@Halloysite under different treatment processes. Time evolution of UVvis absorbance spectra for successive reduction of 4-nitrophenol by $\mathrm{NaBH}_{4}$ with Ag-Paraffin@Halloysite catalyst (b) without radiation and (c) after solar radiation treatment, (d) Degradation efficiency of Ag-Paraffin@Halloysite with and without solar radiation treatment [250], reused with the permission from Elsevier license number 4444690967317.

of latent heat while melting of the PCMs within the micro- and nano-capsules. Zheng et al. 313 presented a joule heating system to reduce the convective heat transfer from electrothermal system to surrounding by inserting the highly conductive and stable micro-capsules of docosane and GO-CNT as core and shell material, respectively. The results shown in Figure 28(a-e) illustrate that with loading of $5 \%$ of micro-PCMs, the working temperature can be improved by $30 \%$ even at lower voltage and ambient temperature which ensures a potential usage in daily household heat storage applications.

Figure 28: further presents that heat storage and release time-temperature curves are similar to solar-to-thermal energy conversion and storage. The conversion and storage efficiency from electricalto-thermal energy can be calculated by using Equation 11 314:

$$
\eta=\frac{m \Delta H}{V I t}
$$

Here, $m$ and $\Delta H$ are the mass and phase transition enthalpy of EPCMs, respectively and $V, T$ and $t$ are the voltage, current and time duration while phase transformation, respectively. To achieve the higher efficiency, EPCMs should have high TES capacity and high electrical conductivity so that it can be driven by low voltage. Recently, Hussain et al. 305 synthesized the bifunctional nano-PCMs consisting oleic acid (OA)-PEG core and $\mathrm{SiO}_{2} / \mathrm{SnO}_{2}$ shell materials to store the thermal and electrical energies. 

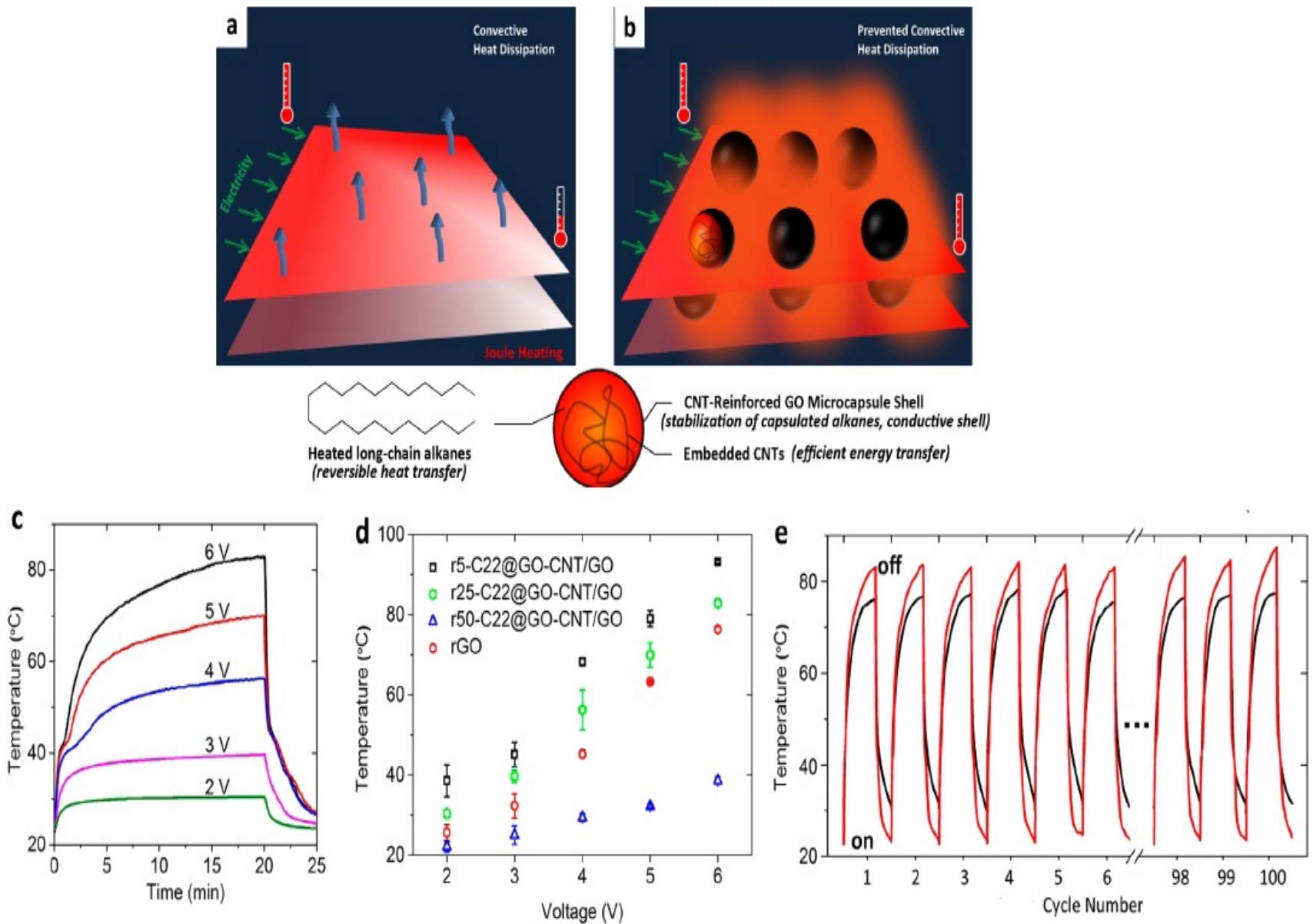

Figure 28: (a)-Illustration of convective heat dissipation in a Joule heating structure composed of nanocarbons, (b)illustration of prevented heat dissipation in a PCM capsule incorporated system, (c)-Temperature evaluation curves of an electrothermal structure containing 25vol.\% micro-PCM capsules, (d)-As a function of voltage, the balanced surface temperatures obtained at 20min heating are demonstrated, and (e)-A collection of temperature evolution curves of an electro-thermal structure containing 25vol.\% micro-PCM and a neat electro-thermal heater under $6 \mathrm{~V}$ repeated for 100 cycles 313, Reproduced with the permission of the American Chemical Society.

The authors reported the thermal and electrical conductivities of $0.7053 \mathrm{~W} / \mathrm{mK}$ and $1.08 \times 10^{-7} \mathrm{~S} / \mathrm{cm}$, respectively. Additionally, it was suggested that OA-PEG/SiO $2 / \mathrm{SnO}_{2}$ nano-PCMs can been used to as electrode material for electrochemical energy storage.

\subsection{Thermal management}

Thermal management is highly emerging and keen requirement for the efficient performance of thermal systems. The effective thermal management requires a highly conductive media to transfer the heat flux from hot source towards the sink. The PCMs with their dual favourable thermal properties of isothermal phase transition temperature and high latent of fusion have increased the demand for thermal cooling of electronics devices, Li-ion batteries, photovoltaic modules, high power lasers, thermoelectric and thermochemical systems, photo-thermal conversion systems, solar thermal energy storage systems, exothermic chemical reactions and energy harvesting industrial power plants 315, 316]. For cooling of each system, it requires confine amount of PCM and range of operating temperature. Overall, cooling 
techniques of are classified as active cooling and passive cooling. Here, we summarize the active cooling technique based on single-phase and multi-phase fluids based on EPCMs. For cooling of high heat generating microprocessing units, microchannel cooling technique has been introduced which uses the heat transfer fluid (HTF) to transfer the heat energy from hot source to cold source. The HTF is selected base on its viscosity and heat transfer capacity. The heat transfer capacity of single-phase fluid (e.g. water) is very low to ensure the efficient thermal performance maintaining the device temperature on comfortable level. In order to enhance the heat transfer capacity of HTF, the micro/nano-capsules are dispersed into the base fluid. The prepared fluid after adding the micro/nano-capsules is called slurry which has the capability to enhance the high heat transfer and high heat storage capacities by combing the latent heat of micro/nano-capsules and sensible heats both base fluid and micro/nano-capsules. This, EPCMs slurry (consisting on solid/liquid mixture), also called multi-phase fluid, has a multifunctional characteristics to serve as both heat HTFs and energy storage fluids (ESFs) 317. The emulsion of macroand micro-PCMs in base fluids under high pressure causes the fracture of capsules. Thus, increases the viscosity of slurry resulting reduces the heat transfer capacity and requires higher input power needed for pumping the slurry. Therefore, to address these issues, nano-PCMs have been dispersed into the base fluid. The effective specific heat $\left(C_{e f f}\right)$ of EPCMs slurry as a function of volume fraction $(\phi)$ of encapsulated capsules can be defined as:

$$
C_{e f f}=C_{o}+\phi H_{E P C M} / \Delta T
$$

Here, $C_{o}$ is the specific heat of base fluid, $H_{E P C M}$ is the latent heat of dispersed EPCM per unit volume, and $\Delta T$ is the temperature difference between the transfer surface and bulk fluid or the difference between the encapsulated capsules melting $\left(T_{m}\right)$ and freezing $\left(T_{f}\right)$ temperatures. Hong et al. 135 synthesized the $\mathrm{SiO}_{2}$-encapsulated $\mathrm{In}$ nanoparticles and polymer-encapsulated paraffin wax nanoparticles using colloid method and then slurry was prepared by dispersing into poly- $\alpha$-olefin (PAO) and water for potential high and low temperature applications, respectively. The heat transfer coefficients of PAO containing $30 \%$ In nanoparticles by mass and water containing $10 \%$ paraffin wax nano-capsules by mass are 1.6 and 1.75 times, respectively, higher than of base fluids. The comparison of adding nano-PCMs consisting of polymer/paraffin wax of $28 \mathrm{vol} . \%$ added with water was carried out by Wu et al. 220. The enhancement in heat transfer coefficient was found by $50 \%$ and $70 \%$ for jet impingement and spray cooling, respectively, compared to base fluid. Later, the authors prepared the without and with $\mathrm{SiO}_{2}$ encapsulated In nano-PCMs using colloid method and dispersed into PAO and conducted the experiments in a microchannel heat exchanger to study heat transfer characteristics 106. The authors found the heat transfer coefficient of $47,000 \mathrm{~W} / \mathrm{m}^{2} . \mathrm{K}$ without $\mathrm{SiO}_{2}$ coating of $30 \%$ In into PAO which was 2 times improvement over the single phase PAO. Further, they suggested after thermal cycling test involving 5000 cycles that In nanoparticles can be used without encapsulation.

In practical applications of micro- and nano-PCMs slurries at component level, the heat transfer and fluid flow characteristics in ducts, tubes, channels and thermal storage characteristics in a tank have been investigated. The design of advance microchannel is shown in Figure 29 which has the significant potential to overcome the internal heat generated inside the miniature and highly integrated electronics components 

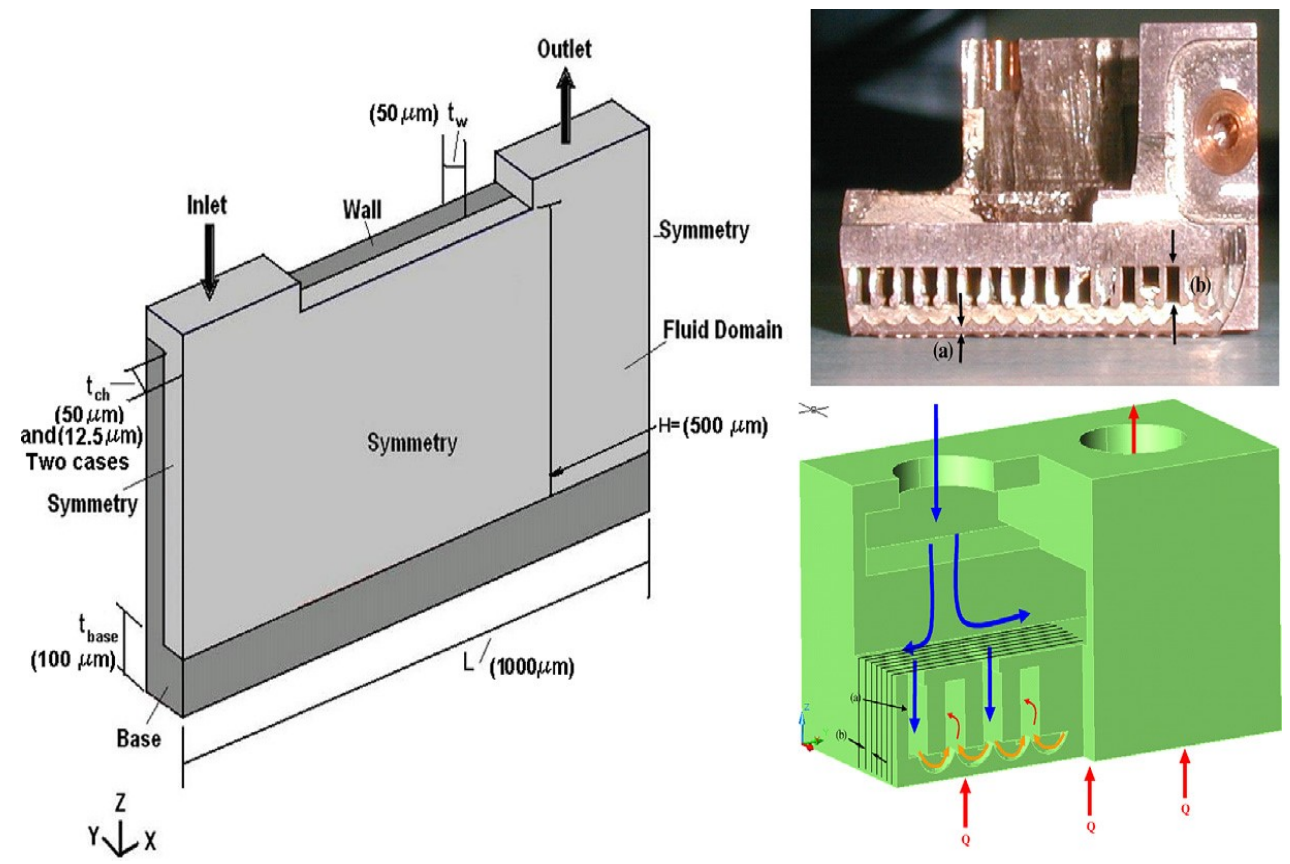

Figure 29: Design concept and cross-sectional view of microchannel heat exchanger [106], reused with the permission from Elsevier license number 4444700260609.

or systems. The hybrid water-based suspensions consisting of $\mathrm{Al}_{2} \mathrm{O}_{3}$ nanoparticles (nanofluid) and microPCMs particles (slurry) were prepared and then heat transfer characteristics were studied flowing through a circular tube [318] and minichannel heat sink [319]. The highest heat transfer enhancement of $57 \%$ was achieved at the highest flow rate in case of nanofluid, whereas the heat transfer enhancement was $51 \%$ at lowest flow rate in case of slurry. Seyf et al. 320 investigated effect of mass concentration and melting range of nano-PCMs dispersed in PAO as well as Re number on thermal and hydrodynamics characteristics of a microtube heat sink. They found that nano-PCM slurry as a coolant enhanced the thermal performance by decreasing the generated total entropy, thermal resistance, increasing the $N u$ number and maintaining the temperature uniformity. However, an increase in the pressure drop was observed with the increase of mass concentration which requires the more pumping power. Liu et al. 293 prepared the micro-PCM slurry composed of water/ethanol as a base fluid and paraffin/melamine resin micro-PCM as additive and studied the heat transfer performance in a horizontal circular tube. The results revealed that convective heat transfer coefficients of micro-PCM slurry were about 2 times and 3 times at $5 \%$ and $10 \%$ mass fractions, respectively, higher than to the base fluid. The drastic increase of pressure drop are due to the higher viscosity of slurry which increases by higher loading of capsules and Re number. Moreover, the higher heat transfer rate can also be achieved by reducing the thickness of thermal boundary layer 321 .

\subsection{Building}

The micro and nano EPCMs are currently employed in building in various forms such as concrete mixes, cement mortar, wall boards, gypsum plaster, sandwich panels and slabs to meet the energy consumption of buildings which requires for heating, cooling, air conditioning and ventilation, water heating 
and lighting 322 . The embedment of EPCMs have significant potential to increase the thermal inertia at constant mass in buildings especially mixing with concrete which influence the thermophysical and mechanical properties of concrete 323 . Additionally, the embedment of micro- and nano-PCMs in concrete increase the thermal and acoustic insulation of walls. Giro-Paloma et al. 324] reported the mechanical properties of micro-PCMs synthesizing of RT-21 with acrylic shell. The nano-indentation technique was used to determine the mechanical properties such as modulus of elasticity, load at maximum displacement, and displacement at maximum load. The results showed the significant mechanical resistance and stiffness of RT-21 micro-capsules and also better stability was achieved with less shortemission of volatile organic compounds. Aguayo et al. 325 proposed the infrastructural concrete mixing with two paraffin wax based micro-PCMs for mitigating early-age cracking and freeze-and-thaw induced damages. The evaluations of micro-PCMs on cement hydration and pore structure were carried out and it was ascertained that mechanical properties such as comprehensive strength of cement mortars was strongly depended on the mechanical properties of micro-PCMs. Cao et al. 326 fabricated the concretes of high TES by mixing the micro-PCMs of $R T-27$ coated with the LDPE-EVA copolymer shell into portland cement concrete (PCC) and geopolymer concrete (GPC). Figure 30 shows the SEM images PPC and GPC cements incorporating of micro-PCMs capsules. The results found higher heat storage capacity and lower thermal conductivity, simultaneously. The significant loss in compressive strength was observed by adding micro-PCMs capsules. However, the compressive strength fulfils the mechanical European regulation for concrete applications.
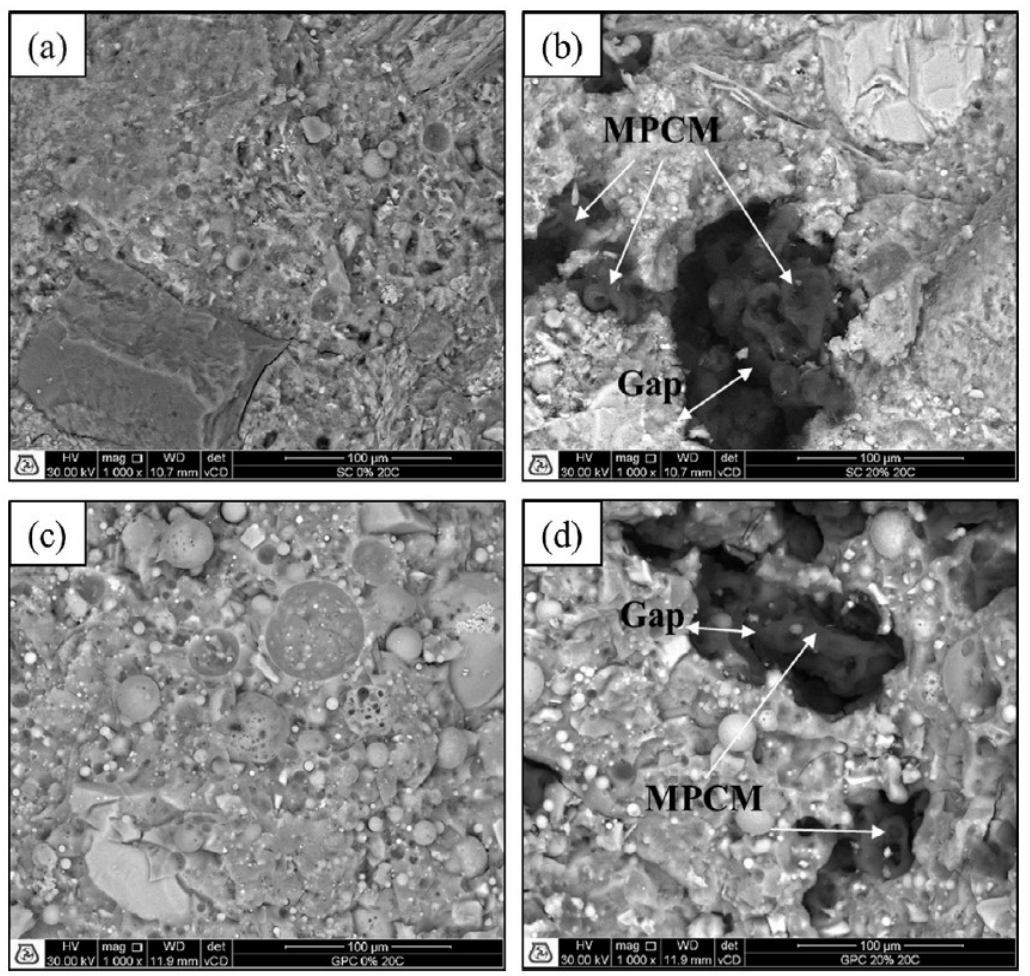

Figure 30: SEM images of (a)-PCC without micro-PCMs, (b)-PCC containing 3.2wt.\% micro-PCMs, (c)-GPC without micro-PCMs, (d)-GPC containing 2.7wt.\% micro-PCMs [326], reused with the permission from Elsevier license number 4444700728610 . 
Wei et al. 327 reported the durability of cementitious composite containing commercially available micro-PCMs. The results revealed that micro-PCMs reduced the rate and extent of water sorption, and did not affect the dry shrinkage of cementitious composites. However, in specific cases, microPCMs improved the durability of cementitious composites. Apart from the investigation on mechanical properties, the effect of thermal deformation was examined by Young et al. [328. The effective thermal deformation coefficient was predicted and found similar to the shell materials. Finally, a design rule was proposed to design the EPCM-mortar composites which found useful in the built environment and high performance composites. The other possibilities of using EPCMs are with building structures through wall-boards [329, gypsum plaster 330, 331], sandwish panels 332], and slabs 333 which could lead to reduce the energy demand both in residential and commercial building sectors.

\subsection{Textiles}

Various schemes have been investigated of EPCMs incorporating with textiles such to protect or give a durable finish on cotton or woolen, durable fragrances and skin softeners. Meanwhile, micro-PCMs have been utilized for waste yeast cells, coating on the surface of fabric or embedded within fibre Nelson [334. Sarier and his co-authors 12,121 firstly reported the thermal regulation or thermal comfort of four different micro-PCMs capsules of containing n-octadecane, n-octadecane/PE600, n-eicosane/n-hexadecane, and PEG/ $\mathrm{Na}_{2} \mathrm{CO}_{3} \cdot 10 \mathrm{H}_{2} \mathrm{O} / \mathrm{n}$-hexadecane as a core materials coated with PUF. The energy absorption capacities were enhanced from 2.5-4.5 times relative to the reference fabric at a particular temperature. Later on, authors found the higher thermal conductivities of micro-capsules which can be employed for thermal cooling of clothing fabrics, medical and automobile textiles and building materials. Additionally, the phase change enthalpies of $137 \mathrm{~J} / \mathrm{g}$ and $168 \mathrm{~J} / \mathrm{g}$ for n-hexadecane and n-octadecane, respectively, were achieved using silver nanoparticles. Alay et al. 205, 206, 335 synthesized the micro-PCMs of n-hexadecane/PBE and n-hexadecane/PMMA with the aim to increase the physical interaction between the micro-capsules and fibre surface for heat storage and thermoregulation in fabrics. The pad-cure method was adopted to add the micro-PCMs on woven fabrics The results showed that the cotton, cotton/polyester, and microfiber polyester fabrics were capable to absorb heat of $6.56 \mathrm{~J} / \mathrm{g}$ and $28.59 \mathrm{~J} / \mathrm{g}$ with n-hexadecane/PBE 335], 4.95J/g, 10.02 J/g, and 8.38J/g, respectively, with n-hexadecane/PMMA 205]. Moghaddam and his co-authors 142, 336 prepared the micro-capsules of n-nonadecane as a core and sodium alginate as a shell materials for application of thermal comfort of textile fabric. The authors found the high energy storing density more than $137.83 \mathrm{~J} / \mathrm{g}$ for phase transition temperature of $30-31^{\circ} \mathrm{C}$ which was the suitable for thermal regulation in textile. Aksoy and his co-authors 337, 290, 338] synthesized the micro-PCM of n-eicosane/PMMA-co-AA, n-eicosane/sodium alginate, and n-eicosane/PMMA-co-MAA to enhance the textile thermal comfort, thermal stability and flame retardant properties incorporated with cotton fabrics by pad-dry-cure method. The optical images proved the presence of micro-capsules incorporated fabric homogeneously onto the surface which are mainly located between the fibers and fiber spaces, as shown in Figure 31. The heat storage enthalpy of $97-114 \mathrm{~J} / \mathrm{g}$ was achieved which showed the significant potential for textile applications and thermal regulating properties of micro-PCM incorporated with fabrics. Further, the authors reported durability of micro-capsules onto the fabric surface 
after washing and rubbing tests and inconsistencies of micro-PCMs with fabrics are due the chemical compatibility of the fabric material and shell material of micro-capsules.
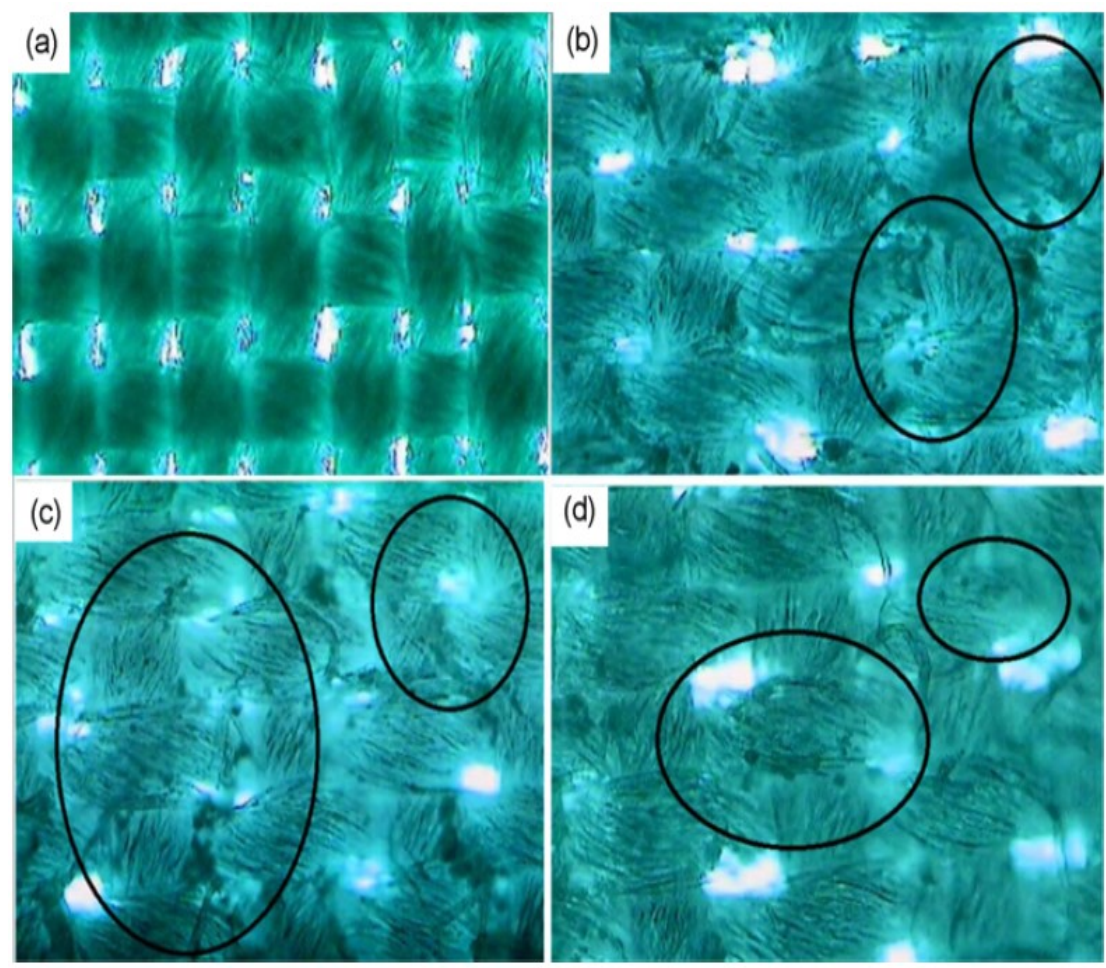

Figure 31: Optical microscopy images of the fabrics (a)-untreated, (b)-treated with microcapsule-1, (c)-treated with microcapsule-2, and (d)-treated with microcapsule-3 290, reused with the permission from Springer Nature license number 4444701208637.

Recently, Sun and Iqbal 339] synthesized the nano-PCMs containing n-octadecane and n-eicosane as core materials and applied on the cotton fabric through a pad-dry-cure process and compared to commercial available micro-PCM of n-octadecane. The results revealed that nano-PCM had $28 \%$ more capacity to absorb latent heat than commercial micro-PCM and nano-PCM treated cotton fabric showed the better durability due to its better adhesion with fibrous material of cotton while washing.

\subsection{Foam}

Foam is potentially used in structures to enhance the thermal performance, especially to reduce the rate of heat transfer or to increase the thermal resistance, acting as a insulating material. Mostly PS and PU are applied with micro- and nano-PCMs in building structures such as wall, windows roofs and flours, automotive and aerospace interiors and biomedical applications. You et al. [340] synthesized the n-octadecane/PU micro-PCMs and inserted it inside the foam. They reported that latent of fusion of micro-PCMs depends on the weight ratios of added micro-capsules i.e. increasing the content of micro-PCMs increases the enthalpy and vice versa. The maximum value of $12 \mathrm{~J} / \mathrm{g}$ at 12.59 wt.\% of micro-PCMs was achieved. Borreguero and his co-authors 341, 342 synthesized the rigid PU foams of varying weight concentrations of RT-27 based micro-PCMs for the purpose of building insulations and TES. The authors reported that increasing the micro-PCMs contents decreased the thickness of foam but increased the density and TES capacity. The PU foams with 18 wt. $\%$ of micro-capsules enhanced 
the TES capacity meanwhile along with sustaining the mechanical properties without addition of fillers. Whereas at higher content of 21 wt.\% of micro-capsules caused the reduction in mechanical properties. However, the 11 wt.\% containing foams maintained the advantages of improving TES capacity and exhibited higher compressive strength and elastic modulus. Later, the authors fabricated the rigid PU incorporating 18wt.\% microcapsules of two difference shell materials consisting PS and PMMA, named as mSP-(PS-TR27) and Micronal ${ }^{\circledR}$ DS 5001X 343. Figure 32 and 32 b exhibit the SEM of PU foams containing 18 wt.\% of mSP-(PS-TR27) and Micronal ${ }^{\circledR}$ DS 5001X, respectively. The results revealed that micro-PCMs of both shell materials improved the TES capacity of PU foams. Additionally, larger size of PS and agglomeration of PMMA micro-capsules caused the strut rupture and damaging the mechanical properties.

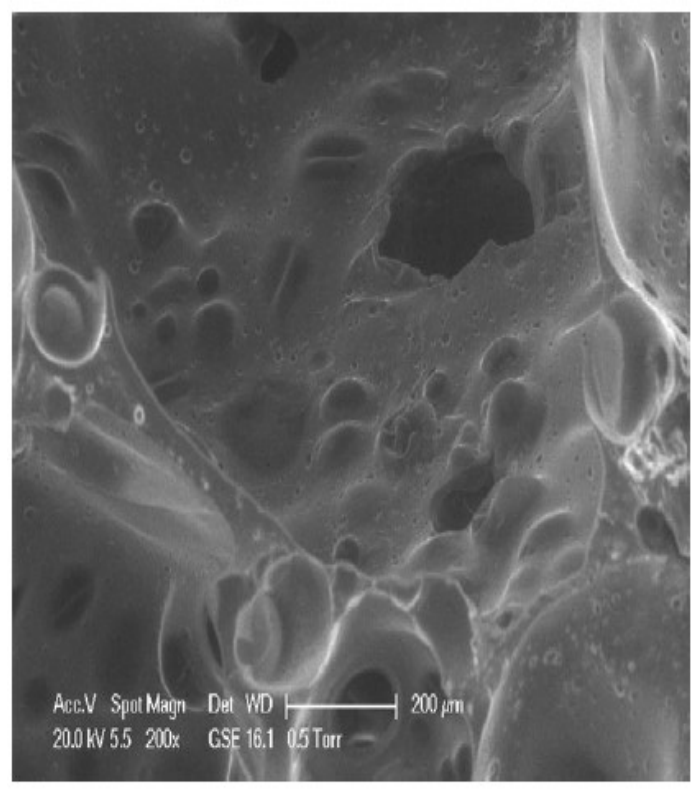

(a)

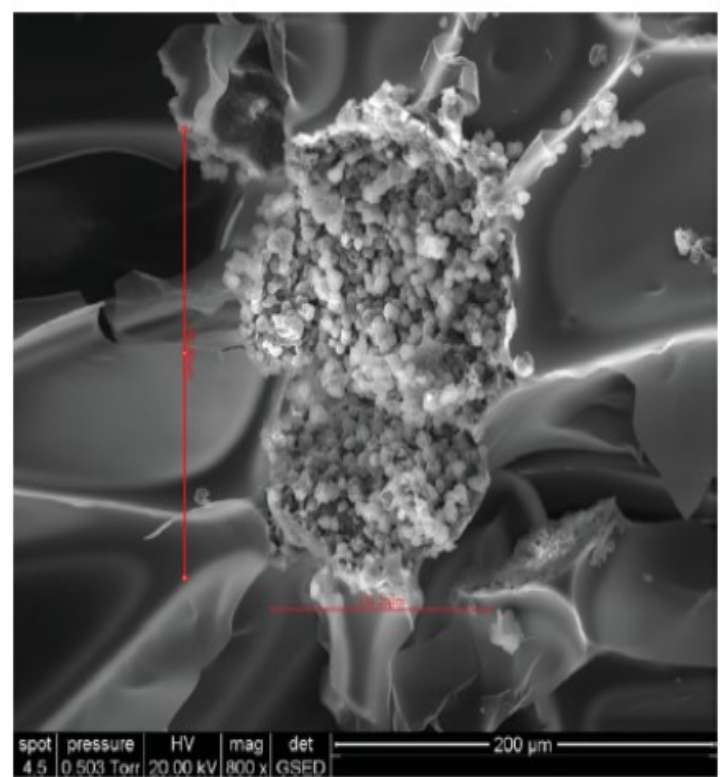

(b)

Figure 32: (a)-SEM images with 200× magnification of PU foam containing 18 wt.\% of mSP-(PS-TR27) and (b)-SEM images with $800 \times$ magnification of PU foam containing 18 wt.\% of Micronal ${ }^{\circledR}$ DS $5001 X$. 343, Reproduced with the permission from John Wiley and Sons license number 4444710857803.

Recently, Serrano et al. 344 developed the rigid PU of varying the weight percentage from $0 \%$ to $50 \%$ of micro-capsules of named mSD-(LDPE.EVA-RT27) and found the $40 w t . \%$ optimum weight percentage of micro-capsules to produce thermal regulating foams having latent heat of $34.4 \mathrm{~J} / \mathrm{g}$ which was higher than those rigid PU of similar materials reported in the literature. Further, the authors suggested that if this rigid $\mathrm{PU}$ will be employed in building the amount of $\mathrm{CO}_{2}$ leaving to the atmosphere can be reduced as well as saving the energy. Qiu et al. 345, 346, 347, 348 prepared the PS foam with micro-capsules containing paraffin wax and DEEP as core and P(MAA-co-EMA as a shell materials, and found that micro-PCM had good thermal regulation potential and TES capacity treated with foam. Later, they synthesized the micro-PCM of hybrid shell materials of PMMA and UF coated on n-tetradecane and found the higher enthalpy of $175.5 \mathrm{~J} / \mathrm{g}$. Additionally, the authors reported that the foam treated with micro-PCMs has the better thermal regulating properties than raw foam [348]. 


\subsection{Medical industry}

The antibacterial effectiveness of EPCMs has been paid an significant and emerging area for the development of hybrid functionality materials. Silver based nanomaterials are significantly used as a shell materials with EPCMs because of their inherent antimicrobial properties in medical application. Tobaldi et al. 349 devepoled the silvermodified titania nanoparticles through green aqueous sol-gel method to study the antibacterial and photocatalytic properties under both the UV and visible-light exposures. Under UV-light source, silver nanoparticles showed the significant antibacterial activity against Escherichia coli (Gram-negative bacteria) than methicillin-resistant Staphylococcus aureous (Gram-positive bacteria). Zhang et al. 286 synthesized the multifunctional micro-PCMs of n-eicosane as core and silver/silica of double-layered as shell material and found the high antibacterial especially against Escherichia coli, Staphylococcus aureus, and Bacillus subtilis. The antibacterial effectiveness, shown in Figure 33 , revealed that bacterial activities for Escherichia coli, Staphylococcus aureus, and Bacillus subtilis were inhibited up to $64.6 \%, 99.1 \%$, and $95.9 \%$, respectively, when contacting the micro-capsules for $2 \mathrm{hrs}$.

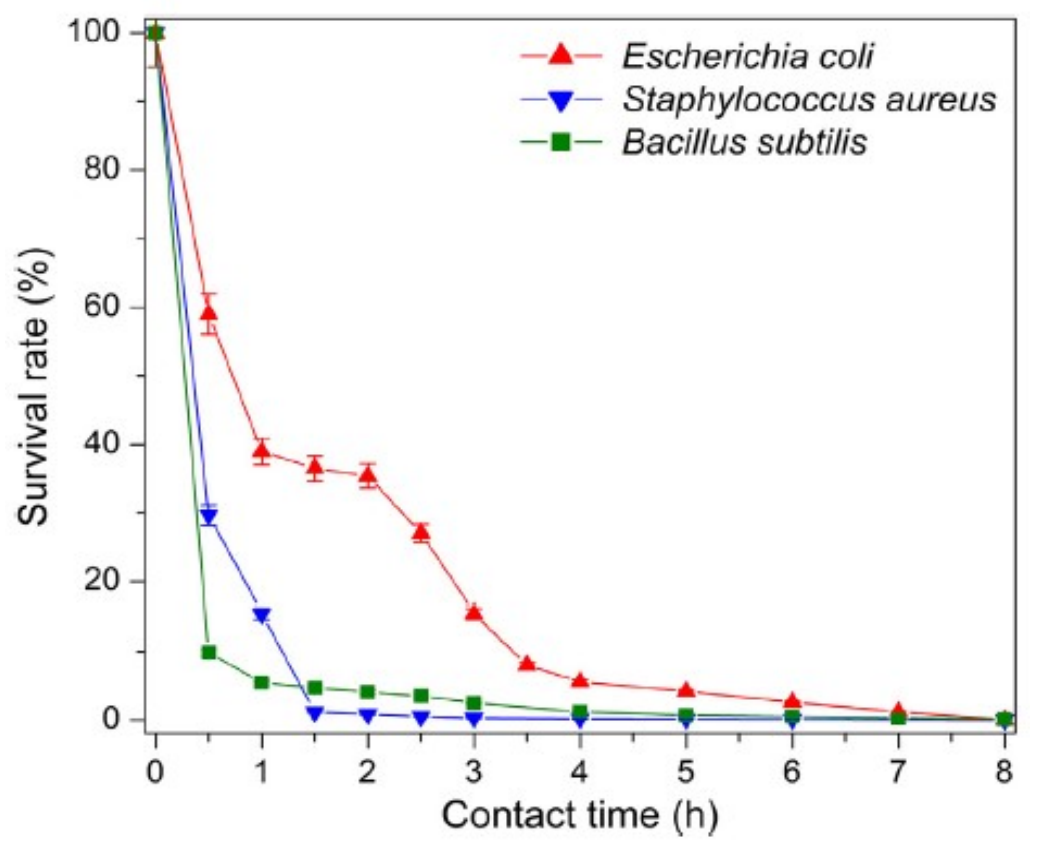

Figure 33: Plots of the survival rates of different bacteria as a function of contact time for the $n$-Eicosane/silver/silica microcapsules obtained at the reaction time of 20hrs 286], reused with the permission from Elsevier license number 4444720694482 .

\section{Future research on EPCMs}

The micro and nano EPCMs have the potential features in future applications. So far many OPCMs have been used as a core material for encapsulation, also most studies focused to develop micro-PCMs. A few studies have been reported to encapsulate the nano-PCMs. Although, many researcher are currently working on the preparation and characterization of nano-PCMs, however, there is the still need for further improvement in engineering applications. Followings are suggestions for future works: 
- Long-term stability: The stability of micro/nano-PCMs is the major need for the applications in every aspects of the life. Especially, when it is under usage of heat transfer and flow conditions.

- Efficiency enhancement: The encapsulation efficiency of the production of micro/nano-PCMs is still quite low, which is still facing the lack of to meet the requirements of industrial applications.

- Encapsulation of IPCMs: Since the inorganic PCMs (salt hydrates and molten salts) have the high latent of fusion during phase transformation, so they have more potential in TES applications e.g. active and passive heating and cooling through solar energy. However, they can degrade in moisture environment. Till yet, the research is focusing on the OPCMs to use as a core materials. Therefore, there is need mico/nano-encapsulation of molten salts and salt hydrates to use a core materials.

- Sub-cooling or super-cooling: The super-cooling of micro/nano-PCMs is the major obstacle in industrial applications. Further investigations of micro/nano-PCMs are needed to overcome this issue to enhance the thermal stability and efficiency of thermal systems.

- Leakage performance: More studies are needed to adopt a standard mechanical test to study the durability or leakage of EPCMs, especially the nano-PCMs to enhance its chemical stability.

- Application of EPCMs: Up to now, little investigations have been reported using EPCMs especially nano-PCMs in solar energy, battery and electronic thermal management, solar energy storage, solar panels thermal cooling control, smart building, waste heat recovery etc. Therefore, new technologies using nano-PCMs should be developed with potential feature to overcome the deficiency of conventional technologies.

- Enhancement of thermal properties: The encapsulation of PCMs, it has been reported the melting temperature latent heat of fusion are decreased as compared to pure PCMs. The purpose of PCMs is to use as energy storage materials in TES systems without losing of heat transfer and fluid flow performance. Hence, this is real challenge of EPCMs to increase or maintain the latent heat of fusion with different melting and freezing temperatures. Therefore, new studies are needed to focus in this direction of encapsulation of PCMs. Additionally, the lower thermal conductivity is also a real challenge of PCMs. Some novel encapsulation techniques are needed to enhance the thermal conductivity of PCMs at the cost of not affecting the latent heat of fusion of PCMs.

\section{Concluding remarks}

This review paper comprehensively covers research progress on the development of macro-, microand nano-EPCMs conducted from the last few decades. Initially, the ideal characteristics of EPCMs are elaborated for the selection of a specific criteria and application. Further, various encapsulation technologies based on different methods such as physical-mechanical, physical-chemical, chemical-mechanical and chemical methods have been thoroughly explained to synthesis the macro-, micro- and nano-meter encapsulated capsules. Additionally, thermophysical properties such as thermal conductivity, latent heat of enthalpy, encapsulation ratio and encapsulation efficiency are summarized respective to each method. In 
a similar way, detailed characteristics evaluation techniques of chemical, thermal and physical properties have been discussed. Stability of EPCMs based on chemical and thermal properties are also discussed. Finally, potential applications of EPCMs have been explained in detail. The following conclusions are summarized from this review:

- The encapsulation of OPCMs coating with a polymer shell material is simple and does not require any complication and can be achieved adopting simple polymerization techniques.

- The encapsulation of IPCMs is difficult and expensive because of the hydrophilic nature of salt hydrates which have the characteristics to alter their water content, thus limited to used only inverse emulsion and addition of polymerization reactions.

- Efficiency and stability of capsules during encapsulation can be restrained by monitoring the molecular weight of the polymers in shell formation process.

- Lower molecular weight shell materials although increase the encapsulation efficiency but contrarily reduce the mechanical strength while mobility of smaller molecules. Hence, there should be precise selection of encapsulation technique and reactants to obtain the required thermophysical properties.

- The selection of each core-shell confinement technology is based on morphological parameters of capsules such as size, distribution, degree of dispersion and environment of use and selection of shell material. As a specific shell material has its own merits and demerits regarding to thermophysical properties point of view.

- IPCMs as a shell materials are found favourable for encapsulation because they have high thermal conductivity, however, they possess low encapsulation efficiency, longer cross-linking and are less stable.

- Overall, it is concluded that after encapsulation of PCMs the leaking, sub-cooling and segregation issues had been overcome to some extent however the melting temperature and latent heat of fusion were decreased which limits the EPCMs for thermal management solutions.

- Considering all the encapsulation techniques, the in-situ polymerization technique is found better offering more encapsulation efficiency and thermophysical stability.

- This review reveals the good thermal and chemical stability of EPCMs which are strongly influenced by the morphology of encapsulated capsules.

- EPCMs are the most suitable for thermal management and TES applications in conjunction with various subsystems such as heat sinks, micro-mini-channels, heat pipes, heat exchangers, wallboards, panels and slabs and so on.

\section{Conflict of interest}

The authors declare no conflict of interest regarding this review article. 


\section{References}

[1] Pramod B. Salunkhe and Prashant S. Shembekar. "A review on effect of phase change material encapsulation on the thermal performance of a system". In: Renewable and Sustainable Energy Reviews 16.8 (2012), pp. 5603-5616. DOI: 10.1016/j.rser.2012.05.037.

[2] S. Jegadheeswaran and Sanjay D. Pohekar. "Performance enhancement in latent heat thermal storage system: A review". In: Renewable and Sustainable Energy Reviews 13.9 (2009), pp. 22252244. DOI: $10.1016 / \mathrm{j} . \mathrm{rser} .2009 .06 .024$.

[3] Xianglei Wang et al. "Heat transfer enhancement of neopentyl glycol using compressed expanded natural graphite for thermal energy storage". In: Renewable Energy 51 (2013), pp. 241-246. DOI: 10.1016/j.renene.2012.09.029.

[4] Xiaolin Qiu et al. "Preparation, thermal properties and thermal reliabilities of microencapsulated n-octadecane with acrylic-based polymer shells for thermal energy storage". In: Thermochimica Acta 551 (2013), pp. 136-144. DOI: 10.1016/j.tca.2012.10.027.

[5] Adeel Waqas and Zia Ud Din. "Phase change material (PCM) storage for free cooling of buildings-A review". In: Renewable and Sustainable Energy Reviews 18 (2013), pp. 607-625. DoI: $10.1016 / j . r s e r .2012 .10 .034$

[6] Gang Li et al. "Review of cold storage materials for subzero applications". In: Energy 51 (2013), pp. 1-17. DOI: $10.1016 / \mathrm{j}$.energy.2012.12.002

[7] L.A. Chidambaram et al. "Review of solar cooling methods and thermal storage options". In: Renewable and Sustainable Energy Reviews 15.6 (2011), pp. 3220-3228. DOI: 10.1016/j.rser. 2011.04 .018

[8] Jungwook Shon, Hyungik Kim, and Kihyung Lee. "Improved heat storage rate for an automobile coolant waste heat recovery system using phase-change material in a fin-tube heat exchanger". In: Applied Energy 113 (2014), pp. 680-689. DOI: 10.1016/j.apenergy.2013.07.049.

[9] V. Pandiyarajan et al. "Second law analysis of a diesel engine waste heat recovery with a combined sensible and latent heat storage system". In: Energy Policy 39.10 (2011), pp. 6011-6020. DOI: $10.1016 / j$.enpol.2011.06.065

[10] Weihuan Zhao et al. "Phase change material with graphite foam for applications in high-temperature latent heat storage systems of concentrated solar power plants". In: Renewable Energy 69 (2014), pp. 134-146. DOI: $10.1016 /$ j.renene.2014.03.031.

[11] Mohammed Mumtaz A. Khan et al. "Evaluation of solar collector designs with integrated latent heat thermal energy storage: A review". In: Solar Energy 166 (2018), pp. 334-350. DOI: 10.1016/ j.solener.2018.03.014.

[12] Nihal Sarier and Emel Onder. "The manufacture of microencapsulated phase change materials suitable for the design of thermally enhanced fabrics". In: Thermochimica Acta 452.2 (2007), pp. 149-160. DOI: $10.1016 /$ j.tca.2006.08.002 
[13] Alicja Nejman et al. "Methods of PCM microcapsules application and the thermal properties of modified knitted fabric". In: Thermochimica Acta 589 (2014), pp. 158-163. Dor: 10.1016/j.tca. 2014.05 .037

[14] Jun-Feng Su et al. "Fabrication and properties of microencapsulated-paraffin/gypsum-matrix building materials for thermal energy storage". In: Energy Conversion and Management 55 (2012), pp. 101-107. DOI: $10.1016 / \mathrm{j}$. enconman.2011.10.015.

[15] Mohammad Sayyar et al. "Experimental and numerical study of shape-stable phase-change nanocomposite toward energy-efficient building constructions". In: Energy and Buildings 75 (2014), pp. 249255. DOI: $10.1016 / \mathrm{j}$.enbuild.2014.02.018

[16] Michal Pomianowski, Per Heiselberg, and Yinping Zhang. "Review of thermal energy storage technologies based on PCM application in buildings". In: Energy and Buildings 67 (2013), pp. 5669. DOI: $10.1016 / \mathrm{j}$.enbuild.2013.08.006.

[17] Xiangfei Kong et al. "Experimental research on the use of phase change materials in perforated brick rooms for cooling storage". In: Energy and Buildings 62 (2013), pp. 597-604. DOI: 10.1016/ j.enbuild.2013.03.048.

[18] S.B. Riffat, S.A. Omer, and Xiaoli Ma. "A novel thermoelectric refrigeration system employing heat pipes and a phase change material: an experimental investigation". In: Renewable Energy 23.2 (2001), pp. 313-323. DOI: 10.1016/s0960-1481(00)00170-1.

[19] J. Sarwar and B. Mansoor. "Characterization of thermophysical properties of phase change materials for non-membrane based indirect solar desalination application". In: Energy Conversion and Management 120 (2016), pp. 247-256. DOI: 10.1016/j.enconman.2016.05.002.

[20] Adeel Arshad et al. "Experimental investigation of PCM based round pin-fin heat sinks for thermal management of electronics: Effect of pin-fin diameter". In: International Journal of Heat and Mass Transfer 117 (2018), pp. 861-872. DOI: 10.1016/j.ijheatmasstransfer.2017.10.008.

[21] Adeel Arshad et al. "An experimental study of enhanced heat sinks for thermal management using n-eicosane as phase change material". In: Applied Thermal Engineering 132 (2018), pp. 52-66. DOI: 10.1016/j.applthermaleng.2017.12.066

[22] Adeel Arshad et al. "Thermal performance of phase change material (PCM) based pin-finned heat sinks for electronics devices: Effect of pin thickness and PCM volume fraction". In: Applied Thermal Engineering 112 (2017), pp. 143-155. DOI: 10.1016/j.applthermaleng.2016.10.090.

[23] Hafiz Muhammad Ali and Adeel Arshad. "Experimental investigation of n-eicosane based circular pin-fin heat sinks for passive cooling of electronic devices". In: International Journal of Heat and Mass Transfer 112 (2017), pp. 649-661. DOI: 10.1016/j.ijheatmasstransfer.2017.05.004.

[24] Hafiz Muhammad Ali et al. "Thermal management of electronics devices with PCMs filled pinfin heat sinks: A comparison". In: International Journal of Heat and Mass Transfer 117 (2018), pp. 1199-1204. DOI: 10.1016/j.ijheatmasstransfer.2017.10.065 
[25] Muhammad Junaid Ashraf et al. "Experimental passive electronics cooling: Parametric investigation of pin-fin geometries and efficient phase change materials". In: International Journal of Heat and Mass Transfer 115 (2017), pp. 251-263. DOI:10.1016/j.ijheatmasstransfer.2017.07.114.

[26] Hazrat Usman et al. "An experimental study of PCM based finned and un-finned heat sinks for passive cooling of electronics". In: Heat and Mass Transfer (2018). DOI: 10.1007/s00231-018$2389-0$

[27] Abid Hussain et al. "Thermal management of lithium ion batteries using graphene coated nickel foam saturated with phase change materials". In: International Journal of Thermal Sciences 124 (2018), pp. 23-35. DOI: $10.1016 /$ j.ijthermalsci.2017.09.019.

[28] Abid Hussain, C.Y. Tso, and Christopher Y.H. Chao. "Experimental investigation of a passive thermal management system for high-powered lithium ion batteries using nickel foam-paraffin composite". In: Energy 115 (2016), pp. 209-218. DOI: 10.1016/j.energy .2016.09.008.

[29] Hafiz Muhammad Ali et al. "Thermal performance of LHSU for electronics under steady and transient operations modes". In: International Journal of Heat and Mass Transfer 127 (2018), pp. 1223-1232. DOI: $10.1016 /$ j.ijheatmasstransfer.2018.06.120

[30] J. C. Mulligan, D. P. Colvin, and Y. G. Bryant. "Microencapsulated phase-change material suspensions for heat transfer in spacecraft thermal systems". In: Journal of Spacecraft and Rockets 33.2 (1996), pp. 278-284. DOI: $10.2514 / 3.26753$

[31] Wan fan Wu et al. "Study on the effect of shape-stabilized phase change materials on spacecraft thermal control in extreme thermal environment". In: Energy Conversion and Management 69 (2013), pp. 174-180. DOI: 10.1016/j.enconman.2013.01.025.

[32] Atul Sharma et al. "Review on thermal energy storage with phase change materials and applications". In: Renewable and Sustainable Energy Reviews 13.2 (2009), pp. 318-345. DOI: 10.1016/j . rser.2007.10.005.

[33] D. Zhou, C.Y. Zhao, and Y. Tian. "Review on thermal energy storage with phase change materials (PCMs) in building applications". In: Applied Energy 92 (2012), pp. 593-605. DOI: 10.1016/j . apenergy.2011.08.025.

[34] Luisa F. Cabeza et al. "Thermal performance of sodium acetate trihydrate thickened with different materials as phase change energy storage material". In: Applied Thermal Engineering 23.13 (2003), pp. 1697-1704. DOI: 10.1016/s1359-4311(03)00107-8.

[35] Yanio E. Milián et al. "A review on encapsulation techniques for inorganic phase change materials and the influence on their thermophysical properties". In: Renewable and Sustainable Energy Reviews 73 (2017), pp. 983-999. DOI: 10.1016/j.rser.2017.01.159.

[36] Michael Graham et al. "Nanoencapsulated crystallohydrate mixtures for advanced thermal energy storage". In: Journal of Materials Chemistry A 5.26 (2017), pp. 13683-13691. DOI: 10.1039/ c7ta02494k 
[37] Xinyu Huang, Wei Xia, and Ruqiang Zou. "Nanoconfinement of phase change materials within carbon aerogels: phase transition behaviours and photo-to-thermal energy storage". In: J. Mater. Chem. A 2.47 (2014), pp. 19963-19968. DOI: 10.1039/c4ta04605f.

[38] Dong Choon Hyun et al. "Emerging applications of phase-change materials (PCMs): teaching an old dog new tricks". In: Angewandte Chemie International Edition 53.15 (2014), pp. 3780-3795.

[39] Takashi Uemura et al. "Unveiling thermal transitions of polymers in subnanometre pores". In: Nature Communications 1.7 (2010), pp. 1-8. DOI: $10.1038 /$ ncomms1091.

[40] Chenzhen Liu et al. "Review on nanoencapsulated phase change materials: Preparation, characterization and heat transfer enhancement". In: Nano Energy 13 (2015), pp. 814-826. DOI: 10.1016/j.nanoen.2015.02.016.

[41] Waseem Aftab et al. "Nanoconfined phase change materials for thermal energy applications". In: Energy \& Environmental Science 11.6 (2018), pp. 1392-1424.

[42] Keping Chen et al. "Preparation and characterization of form-stable paraffin/polyurethane composites as phase change materials for thermal energy storage". In: Energy Conversion and Management 77 (2014), pp. 13-21. DOI: 10.1016/j.enconman.2013.09.015.

[43] Su Xu et al. "Preparation and thermal reliability of methyl palmitate/methyl stearate mixture as a novel composite phase change material". In: Energy and Buildings 68 (2014), pp. 372-375. DOI: 10.1016/j.enbuild.2013.09.038.

[44] Ahmet Sarı et al. "Microencapsulated n-octacosane as phase change material for thermal energy storage". In: Solar Energy 83.10 (2009), pp. 1757-1763. DoI: 10.1016/j . solener.2009.05.008.

[45] Swapan Kumar Ghosh. "Functional Coatings and Microencapsulation: A General Perspective". In: Functional Coatings. Wiley-VCH Verlag GmbH \& Co. KGaA, 2006, pp. 1-28. DOI: 10.1002/ 3527608478.ch1.

[46] Yan Wang et al. "A Novel Method for the Preparation of Narrow-Disperse Nanoencapsulated Phase Change Materials by Phase Inversion Emulsification and Suspension Polymerization". In: Industrial \& Engineering Chemistry Research 54.38 (2015), pp. 9307-9313. DOI: 10.1021/acs. iecr.5b01026.

[47] Abbas Rezaee Shirin-Abadi, Ali Reza Mahdavian, and Sepideh Khoee. "New Approach for the Elucidation of PCM Nanocapsules through Miniemulsion Polymerization with an Acrylic Shell". In: Macromolecules 44.18 (2011), pp. 7405-7414. DOI: 10.1021/ma201509d.

[48] Maider García de Cortazar and Raquel Rodríguez. "Thermal storage nanocapsules by miniemulsion polymerization". In: Journal of Applied Polymer Science 127.6 (2012), pp. 5059-5064. DOI: $10.1002 /$ app. 38124

[49] A. Jamekhorshid, S.M. Sadrameli, and M. Farid. "A review of microencapsulation methods of phase change materials (PCMs) as a thermal energy storage (TES) medium". In: Renewable and Sustainable Energy Reviews 31 (2014), pp. 531-542. DOI: 10.1016/j.rser.2013.12.033. 
[50] V.V. Tyagi et al. "Development of phase change materials based microencapsulated technology for buildings: A review". In: Renewable and Sustainable Energy Reviews 15.2 (2011), pp. 1373-1391. DOI: $10.1016 /$ j.rser.2010.10.006.

[51] Bojana Boh and Boštjan Šumiga. "Microencapsulation technology and its applications in building construction materials Tehnologija mikrokapsuliranja in njena uporaba v gradbenih materialih". In: RMZ-Materials and Geoenvironment 55.3 (2008), pp. 329-344.

[52] C.Y. Zhao and G.H. Zhang. "Review on microencapsulated phase change materials (MEPCMs): Fabrication, characterization and applications". In: Renewable and Sustainable Energy Reviews 15.8 (2011), pp. 3813-3832. DOI: $10.1016 /$ j.rser.2011.07.019.

[53] Yutang Fang et al. "Preparation and thermal performance of polystyrene/n-tetradecane composite nanoencapsulated cold energy storage phase change materials". In: Energy Conversion and Management 76 (2013), pp. 430-436. DOI: 10.1016/j.enconman.2013.07.060

[54] Yutang Fang et al. "Preparation and characterization of novel nanoencapsulated phase change materials". In: Energy Conversion and Management 49.12 (2008), pp. 3704-3707. DOI: 10.1016/ j.enconman.2008.06.027.

[55] Sara Tahan Latibari et al. "Synthesis, characterization and thermal properties of nanoencapsulated phase change materials via sol-gel method". In: Energy 61 (2013), pp. 664-672.

[56] Yutang Fang et al. "Preparation and characterization of novel nanoencapsulated phase change materials". In: Energy Conversion and Management 49.12 (2008), pp. 3704-3707. DOI: 10.1016/ j.enconman.2008.06.027.

[57] Jochen Weiss, Paul Takhistov, and D. Julian McClements. "Functional Materials in Food Nanotechnology". In: Journal of Food Science 71.9 (2006), R107-R116. DOI: 10 . $1111 /$ j . 1750$3841.2006 .00195 . x$

[58] K. Cho and M. Choi. "Experimental study on the application of paraffin slurry to high density electronic package cooling". In: Heat and Mass Transfer 36.1 (2000), pp. 29-36. DOI: 10.1007/ s002310050360

[59] Tumirah Khadiran et al. "Encapsulation techniques for organic phase change materials as thermal energy storage medium: A review". In: Solar Energy Materials and Solar Cells 143 (2015), pp. 7898. DOI: $10.1016 /$ j.solmat.2015.06.039.

[60] Weiguang Su, Jo Darkwa, and Georgios Kokogiannakis. "Review of solid-liquid phase change materials and their encapsulation technologies". In: Renewable and Sustainable Energy Reviews 48 (2015), pp. 373-391. DOI: $10.1016 /$ j.rser.2015.04.044.

[61] Gaosheng Wei et al. "Selection principles and thermophysical properties of high temperature phase change materials for thermal energy storage: A review". In: Renewable and Sustainable Energy Reviews 81 (2018), pp. 1771-1786. DOI: 10.1016/j.rser.2017.05.271. 
[62] D. Poncelet. "Microencapsulation: fundamentals, methods and applications". In: Surface Chemistry in Biomedical and Environmental Science. Springer Netherlands, pp. 23-34. DOI: 10.1007/14020-4741-x_3

[63] P Venkatesan, R Manavalan, K Valliappan, et al. "Microencapsulation: a vital technique in novel drug delivery system". In: Journal of Pharmaceutical Sciences and Research 1.4 (2009), pp. 26-35.

[64] Dale E. Wurster. "Air-Suspension Technique of Coating Drug Particles**Schoolof Pharmacy, UniversityofWiscor In: Journal of the American Pharmaceutical Association (Scientific ed.) 48.8 (1959), pp. 451-454. DOI: $10.1002 / j p s .3030480808$.

[65] Stephen R.L. Werner et al. "Air-suspension particle coating in the food industry: Part I — state of the art". In: Powder Technology 171.1 (2007), pp. 25-33. DOI: 10.1016/j.powtec.2006.08.014.

[66] S.Y. Cheng et al. "Development of Cosmetic Textiles Using Microencapsulation Technology". In: Research Journal of Textile and Apparel 12.4 (2008), pp. 41-51. DOI: 10.1108/RJTA-1204-2008-B005, eprint: https : // doi . org/10 . 1108/RJTA-12-04-2008-B005. URL: https : //doi.org/10.1108/RJTA-12-04-2008-B005

[67] Curt Thies. "Microencapsulation". In: Kirk-Othmer Encyclopedia of Chemical Technology. John Wiley \& Sons, Inc., 2000. ISBN: 9780471238966. DOI: 10.1002/0471238961.1309031820080905. a01. URL: http://dx.doi.org/10.1002/0471238961.1309031820080905.a01.

[68] Christoph Heinzen et al. "Use of vibration technology for jet break-up for encapsulation of cells, microbes and liquids in monodisperse microcapsules". In: Landbauforschung Völkenrode, SH241 (2002), pp. 19-25.

[69] Lijiu Wang and Duo Meng. "Fatty acid eutectic/polymethyl methacrylate composite as form-stable phase change material for thermal energy storage". In: Applied Energy 87.8 (2010), pp. 2660-2665. DOI: $10.1016 / j$.apenergy . 2010.01.010

[70] Weilong Wang et al. "Preparation and performance of form-stable polyethylene glycol/silicon dioxide composites as solid-liquid phase change materials". In: Applied Energy 86.2 (2009), pp. 170174. DOI: $10.1016 / \mathrm{j}$. apenergy . 2007.12 .003

[71] Jianli Li et al. "Preparation and application effects of a novel form-stable phase change material as the thermal storage layer of an electric floor heating system". In: Energy and Buildings 41.8 (2009), pp. 871-880. DOI: 10.1016/j.enbuild.2009.03.009

[72] Yibing Cai et al. "Preparation, thermal and flammability properties of a novel form-stable phase change materials based on high density polyethylene/poly(ethylene-co-vinyl acetate)/organophilic montmorillonite nanocomposites/paraffin compounds". In: Energy Conversion and Management 49.8 (2008), pp. 2055-2062. DOI: 10.1016/j.enconman.2008.02.013.

[73] Ahmet Sarı. "Form-stable paraffin/high density polyethylene composites as solid-liquid phase change material for thermal energy storage: preparation and thermal properties". In: Energy Conversion and Management 45.13-14 (2004), pp. 2033-2042. DOI: 10.1016/j . enconman.2003.10. 022. 
[74] Ahmet Sarı and Ali Karaipekli. "Preparation, thermal properties and thermal reliability of palmitic acid/expanded graphite composite as form-stable PCM for thermal energy storage". In: Solar Energy Materials and Solar Cells 93.5 (2009), pp. 571-576. Dor: 10.1016/j.solmat.2008.11.057.

[75] Guolin Song et al. "Preparation and characterization of flame retardant form-stable phase change materials composed by EPDM, paraffin and nano magnesium hydroxide". In: Energy 35.5 (2010), pp. 2179-2183. DOI: $10.1016 /$ j.energy.2010.02.002.

[76] CM Land. Industrial drying equipment: selection and application. 1991.

[77] J.M. Obón et al. "Production of a red-purple food colorant from Opuntia stricta fruits by spray drying and its application in food model systems". In: Journal of Food Engineering 90.4 (2009), pp. 471-479. DOI: $10.1016 / \mathrm{j} \cdot \mathrm{jfoodeng} \cdot 2008.07 .013$.

[78] A.M. Borreguero et al. "Synthesis and characterization of microcapsules containing Rubitherm@RT27 obtained by spray drying". In: Chemical Engineering Journal 166.1 (2011), pp. 384-390. DOI: $10.1016 / j \cdot c e j \cdot 2010.10 .055$.

[79] A Billon et al. "Development of spray-dried acetaminophen microparticles using experimental designs". In: International Journal of Pharmaceutics 203.1-2 (2000), pp. 159-168. DOI: 10.1016/ s0378-5173(00)00448-8.

[80] Adem Gharsallaoui et al. "Applications of spray-drying in microencapsulation of food ingredients: An overview". In: Food Research International 40.9 (2007), pp. 1107-1121. DOI: 10 . $1016 / \mathrm{j}$. foodres.2007.07.004.

[81] Qian Shen and Siew Young Quek. "Microencapsulation of astaxanthin with blends of milk protein and fiber by spray drying". In: Journal of Food Engineering 123 (2014), pp. 165-171. DOI: 10 . $1016 / \mathrm{j} \cdot \mathrm{jf}$ foodeng.2013.09.002

[82] V.M. Silva, G.S. Vieira, and M.D. Hubinger. "Influence of different combinations of wall materials and homogenisation pressure on the microencapsulation of green coffee oil by spray drying". In: Food Research International 61 (2014), pp. 132-143. DOI: 10.1016/j.foodres.2014.01.052

[83] A Poshadri and Kuna Aparna. "Microencapsulation technology: a review". In: Journal of Research ANGRAU 38.1 (2010), pp. 86-102.

[84] Ming Li, Olivier Rouaud, and Denis Poncelet. "Microencapsulation by solvent evaporation: State of the art for process engineering approaches". In: International Journal of Pharmaceutics 363.1-2 (2008), pp. 26-39. DOI: 10.1016/j.ijpharm.2008.07.018.

[85] Shazim Ali Memon et al. "Development of structural-functional integrated concrete with macroencapsulated PCM for thermal energy storage". In: Applied Energy 150 (2015), pp. 245-257. DOI: $10.1016 / j$. apenergy.2015.03.137.

[86] M.N.A. Hawlader, M.S. Uddin, and Mya Mya Khin. "Microencapsulated PCM thermal-energy storage system". In: Applied Energy 74.1-2 (2003), pp. 195-202. DOI: 10.1016/s0306-2619(02) 00146-0 
[87] Bin Fei et al. "Multi-functional microcapsules produced by aerosol reaction". In: Journal of Aerosol Science 39.12 (2008), pp. 1089-1098. DOI: 10.1016/j.jaerosci.2008.07.007.

[88] A.G.S. Carvalho, V.M. Silva, and M.D. Hubinger. "Microencapsulation by spray drying of emulsified green coffee oil with two-layered membranes". In: Food Research International 61 (2014), pp. 236-245. DOI: $10.1016 /$ j.foodres.2013.08.012.

[89] Helena C.F. Carneiro et al. "Encapsulation efficiency and oxidative stability of flaxseed oil microencapsulated by spray drying using different combinations of wall materials". In: Journal of Food Engineering 115.4 (2013), pp. 443-451. DOI: 10.1016/j.jfoodeng.2012.03.033.

[90] R. Rajam and C. Anandharamakrishnan. "Spray freeze drying method for microencapsulation of Lactobacillus plantarum". In: Journal of Food Engineering 166 (2015), pp. 95-103. DOI: 10.1016/ j.jfoodeng.2015.05.029.

[91] Xun Yang et al. "Development and evaluation of novel microcapsules containing poppy-seed oil using complex coacervation". In: Journal of Food Engineering 161 (2015), pp. 87-93. DOI: 10 . $1016 / j \cdot j$ foodeng $\cdot 2015.03 .027$.

[92] Hua-Jiang Huang, Wei-Kang Yuan, and Xiao Dong Chen. "Microencapsulation based on emulsification for producing pharmaceutical products: A literature review". In: Asia-Pacific Journal of Chemical Engineering 14.3-4 (2006), pp. 515-544.

[93] N. Venkata Naga Jyothi et al. "Microencapsulation techniques, factors influencing encapsulation efficiency". In: Journal of Microencapsulation 27.3 (2010), pp. 187-197. DOI: 10 . $3109 /$ 02652040903131301 .

[94] Curt Thies. "Microencapsulation". In: Kirk-Othmer Encyclopedia of Chemical Technology. John Wiley \& Sons, Inc., 2000. ISBN: 9780471238966 . DOI: 10.1002/0471238961.1309031820080905. a01. URL: http://dx.doi.org/10.1002/0471238961.1309031820080905.a01.

[95] Yeliz Konuklu, Murat Unal, and Halime O. Paksoy. "Microencapsulation of caprylic acid with different wall materials as phase change material for thermal energy storage". In: Solar Energy Materials and Solar Cells 120 (2014), pp. 536-542. DOI: 10.1016/j.solmat.2013.09.035.

[96] Cristian Dima et al. "Microencapsulation of essential oil of pimento [Pimenta dioica (L) Merr.] by chitosan/k-carrageenan complex coacervation method". In: Innovative Food Science \& Emerging Technologies 22 (2014), pp. 203-211. DOI: 10.1016/j.ifset.2013.12.020.

[97] Ryosuke Kaneko et al. "Preparation and Properties of Hyperbranched Aromatic Polyamide-Silica Composites by Sol-Gel Method". In: High Performance Polymers 14.2 (2002), pp. 105-114. DOI: $10.1177 / 095400830201400101$.

[98] D. P. Macwan, Pragnesh N. Dave, and Shalini Chaturvedi. "A review on nano-TiO2 sol-gel type syntheses and its applications". In: Journal of Materials Science 46.11 (2011), pp. 3669-3686. DOI: $10.1007 / \mathrm{s} 10853-011-5378-\mathrm{y}$. 
[99] Yalin Zhu et al. "Preparation and properties of nanoencapsulated n-octadecane phase change material with organosilica shell for thermal energy storage". In: Energy Conversion and Management 105 (2015), pp. 908-917. DOI: 10.1016/j.enconman.2015.08.048.

[100] Fang He, Xiaodong Wang, and Dezhen Wu. "New approach for sol-gel synthesis of microencapsulated n-octadecane phase change material with silica wall using sodium silicate precursor". In: Energy 67 (2014), pp. 223-233. DOI: 10.1016/j.energy.2013.11.088.

[101] Shudong Zhang et al. "Increasing Phase Change Latent Heat of Stearic Acid via Nanocapsule Interface Confinement". In: The Journal of Physical Chemistry C 117.44 (2013), pp. 23412-23417. DOI: $10.1021 / \mathrm{jp} 408478 \mathrm{~h}$.

[102] Zhonghao Rao, Shuangfeng Wang, and Feifei Peng. "Self diffusion of the nano-encapsulated phase change materials: A molecular dynamics study". In: Applied Energy 100 (2012), pp. 303-308. DOI: $10.1016 / \mathrm{j}$. apenergy.2012.05.022.

[103] J. Zhang et al. "In Situ Synthesis and Phase Change Properties of Na2SO4·10H2O@SiO2 Solid Nanobowls toward Smart Heat Storage". In: The Journal of Physical Chemistry C 115.41 (2011), pp. 20061-20066. DOI: 10.1021/jp202373b

[104] Minghui Zhang et al. "Encapsulated nano-heat-sinks for thermal management of heterogeneous chemical reactions". In: Nanoscale 2.12 (2010), p. 2790. DOI: 10.1039/c0nr00585a.

[105] Chih-Chung Lai et al. "Tunable endothermic plateau for enhancing thermal energy storage obtained using binary metal alloy particles". In: Nano Energy 25 (2016), pp. 218-224. DoI: 10.1016/ j.nanoen.2016.02.058.

[106] W. Wu et al. "Heat transfer enhancement of PAO in microchannel heat exchanger using nanoencapsulated phase change indium particles". In: International Journal of Heat and Mass Transfer 58.1-2 (2013), pp. 348-355. DOI: 10.1016/j.ijheatmasstransfer.2012.11.032.

[107] Takahiro Nomura et al. "Microencapsulation of Metal-based Phase Change Material for Hightemperature Thermal Energy Storage". In: Scientific Reports 5.1 (2015). DOI: 10.1038/srep09117.

[108] Huan Liu, Xiaodong Wang, and Dezhen Wu. "Fabrication of Graphene/TiO2/Paraffin Composite Phase Change Materials for Enhancement of Solar Energy Efficiency in Photocatalysis and Latent Heat Storage". In: ACS Sustainable Chemistry \& Engineering 5.6 (2017), pp. 4906-4915. DOI: 10.1021/acssuschemeng. 7b00321.

[109] Shiyu Yu, Xiaodong Wang, and Dezhen Wu. "Self-Assembly Synthesis of Microencapsulated nEicosane Phase-Change Materials with Crystalline-Phase-Controllable Calcium Carbonate Shell". In: Energy \& Fuels 28.5 (2014), pp. 3519-3529. DOI: 10.1021/ef5005539

[110] Sara Tahan Latibari et al. "Facile synthesis and thermal performances of stearic acid/titania core/shell nanocapsules by sol-gel method". In: Energy 85 (2015), pp. 635-644.

[111] Lin Pan et al. "Diverting phase transition of high-melting-point stearic acid to room temperature by microencapsulation in boehmite". In: $R S C$ Advances 3.44 (2013), p. 22326. DOI: 10.1039/ c3ra43936d 
[112] J. Lazko, Y. Popineau, and J. Legrand. "Soy glycinin microcapsules by simple coacervation method". In: Colloids and Surfaces B: Biointerfaces 37.1-2 (2004), pp. 1-8. DOI: 10 . 1016/j . colsurfb.2004.06.004.

[113] Polin Sutaphanit and Pakamon Chitprasert. "Optimisation of microencapsulation of holy basil essential oil in gelatin by response surface methodology". In: Food Chemistry 150 (2014), pp. 313320. DOI: $10.1016 /$ j.foodchem.2013.10.159

[114] MNA Hawlader, MS Uddin, and H J_ Zhu. "Preparation and evaluation of a novel solar storage material: microencapsulated paraffin". In: International Journal of Solar Energy 20.4 (2000), pp. 227-238.

[115] MNA Hawlader, MS Uddin, and HJ Zhu. "Encapsulated phase change materials for thermal energy storage: experiments and simulation". In: International Journal of Energy Research 26.2 (2002), pp. 159-171.

[116] MNA Hawlader, MS Uddin, and Mya Mya Khin. "Microencapsulated PCM thermal-energy storage system". In: Applied energy 74.1-2 (2003), pp. 195-202.

[117] Milla G. Santos et al. "Microencapsulation of xylitol by double emulsion followed by complex coacervation". In: Food Chemistry 171 (2015), pp. 32-39. DoI: 10.1016/j . foodchem.2014.08. 093 .

[118] Emma Piacentini et al. "Microencapsulation of oil droplets using cold water fish gelatine/gum arabic complex coacervation by membrane emulsification". In: Food Research International 53.1 (2013), pp. 362-372. DOI: 10.1016/j.foodres.2013.04.012

[119] J Alvarado et al. "Characterization of supercooling suppression of microencapsulated phase change material by using DSC". In: Journal of thermal analysis and calorimetry 86.2 (2006), pp. 505-509.

[120] Y Özonur et al. "Microencapsulation of coco fatty acid mixture for thermal energy storage with phase change material". In: International Journal of Energy Research 30.10 (2006), pp. 741-749.

[121] Emel Onder, Nihal Sarier, and Erhan Cimen. "Encapsulation of phase change materials by complex coacervation to improve thermal performances of woven fabrics". In: Thermochimica Acta 467.1-2 (2008), pp. 63-72. DOI: $10.1016 /$ j.tca.2007.11.007

[122] L. Bayés-García et al. "Phase Change Materials (PCM) microcapsules with different shell compositions: Preparation, characterization and thermal stability". In: Solar Energy Materials and Solar Cells 94.7 (2010), pp. 1235-1240. DOI: 10.1016/j.solmat.2010.03.014.

[123] Chloé Butstraen and Fabien Salan. "Preparation of microcapsules by complex coacervation of gum Arabic and chitosan". In: Carbohydrate Polymers 99 (2014), pp. 608-616. DOI: 10.1016/j. carbpol.2013.09.006.

[124] Younsook Shin, Dong-Il Yoo, and Kyunghee Son. "Development of thermoregulating textile materials with microencapsulated phase change materials (PCM). II. Preparation and application of PCM microcapsules". In: Journal of Applied Polymer Science 96.6 (2005), pp. 2005-2010. DOI: $10.1002 /$ app. 21438 
[125] Fuyun Jiang, Xiaodong Wang, and Dezhen Wu. "Design and synthesis of magnetic microcapsules based on n-eicosane core and $\mathrm{Fe} 3 \mathrm{O} 4 / \mathrm{SiO} 2$ hybrid shell for dual-functional phase change materials". In: Applied Energy 134 (2014), pp. 456-468. DoI: 10.1016/j.apenergy.2014.08.061.

[126] Chang-Bo Wu et al. "Preparation of microencapsulated medium temperature phase change material of Tris(hydroxymethyl)methyl aminomethane@SiO2 with excellent cycling performance". In: Applied Energy 154 (2015), pp. 361-368. DOI: 10.1016/j.apenergy.2015.05.029

[127] Lei Cao, Fang Tang, and Guiyin Fang. "Synthesis and characterization of microencapsulated paraffin with titanium dioxide shell as shape-stabilized thermal energy storage materials in buildings". In: Energy and Buildings 72 (2014), pp. 31-37. DOI: 10.1016/j.enbuild.2013.12.028.

[128] Lei Cao, Fang Tang, and Guiyin Fang. "Preparation and characteristics of microencapsulated palmitic acid with TiO2 shell as shape-stabilized thermal energy storage materials". In: Solar Energy Materials and Solar Cells 123 (2014), pp. 183-188. DOI: 10.1016/j . solmat.2014.01.023.

[129] Zhi Chen et al. "Preparation and characteristics of microencapsulated stearic acid as composite thermal energy storage material in buildings". In: Energy and Buildings 62 (2013), pp. 469-474. DOI: $10.1016 / \mathrm{j}$.enbuild.2013.03.025

[130] Zhi Chen et al. "Synthesis and Characterization of Microencapsulated Paraffin Microcapsules as Shape-Stabilized Thermal Energy Storage Materials". In: Nanoscale and Microscale Thermophysical Engineering 17.2 (2013), pp. 112-123. DOI: 10.1080/15567265.2012.761305.

[131] L.-Y. Wang, P.-S. Tsai, and Y.-M. Yang. "Preparation of silica microspheres encapsulating phasechange material by sol-gel method in O/W emulsion". In: Journal of Microencapsulation 23.1 (2006), pp. 3-14. DOI: $10.1080 / 02652040500286045$.

[132] Guiyin Fang, Zhi Chen, and Hui Li. "Synthesis and properties of microencapsulated paraffin composites with $\mathrm{SiO} 2$ shell as thermal energy storage materials". In: Chemical Engineering Journal 163.1-2 (2010), pp. 154-159. DOI: $10.1016 /$ j.cej.2010.07.054

[133] Huanzhi Zhang, Xiaodong Wang, and Dezhen Wu. "Silica encapsulation of n-octadecane via sol-gel process: A novel microencapsulated phase-change material with enhanced thermal conductivity and performance". In: Journal of Colloid and Interface Science 343.1 (2010), pp. 246-255. DOI: $10.1016 / \mathrm{j} \cdot \mathrm{jcis} .2009 .11 .036$

[134] Luxiao Chai, Xiaodong Wang, and Dezhen Wu. "Development of bifunctional microencapsulated phase change materials with crystalline titanium dioxide shell for latent-heat storage and photocatalytic effectiveness". In: Applied Energy 138 (2015), pp. 661-674.

[135] Yan Hong et al. "Enhancing heat capacity of colloidal suspension using nanoscale encapsulated phase-change materials for heat transfer". In: ACS applied materials $\&$ interfaces 2.6 (2010), pp. $1685-1691$.

[136] Min Li, Zhishen Wu, and Jinmiao Tan. "Properties of form-stable paraffin/silicon dioxide/expanded graphite phase change composites prepared by sol-gel method". In: Applied Energy 92 (2012), pp. 456-461. DOI: $10.1016 / \mathrm{j}$.apenergy .2011.11.018. 
[137] Chih Chung Chang et al. "Preparation of phase change materials microcapsules by using PMMA network-silica hybrid shell via sol-gel process". In: Journal of Applied Polymer Science 112.3 (2009), pp. 1850-1857. DOI: 10.1002/app.29742.

[138] Yung-Chieh Tan et al. "Controlled microfluidic encapsulation of cells, proteins, and microbeads in lipid vesicles". In: Journal of the American Chemical Society 128.17 (2006), pp. 5656-5658.

[139] Bing Jie Sun et al. "Microfluidic melt emulsification for encapsulation and release of actives". In: ACS applied materials \& interfaces 2.12 (2010), pp. 3411-3416.

[140] Zhenjin Fu et al. "Elastic silicone encapsulation of n-hexadecyl bromide by microfluidic approach as novel microencapsulated phase change materials". In: Thermochimica Acta 590 (2014), pp. 2429. DOI: $10.1016 /$ j.tca.2014.06.008

[141] Ignacio G Loscertales et al. "Micro/nano encapsulation via electrified coaxial liquid jets". In: Science 295.5560 (2002), pp. 1695-1698.

[142] Meghdad Kamali Moghaddam, Sayed Majid Mortazavi, and Taghi Khayamian. "Preparation of calcium alginate microcapsules containing n-nonadecane by a melt coaxial electrospray method". In: Journal of Electrostatics 73 (2015), pp. 56-64. DOI: 10.1016/j.elstat.2014.10.013.

[143] Talita A. Comunian et al. "Fabrication of solid lipid microcapsules containing ascorbic acid using a microfluidic technique". In: Food Chemistry 152 (2014), pp. 271-275. DOI: 10.1016/j.foodchem. 2013.11.149.

[144] Neus Vilanova et al. "Fabrication of novel silicone capsules with tunable mechanical properties by microfluidic techniques". In: ACS applied materials \& interfaces 5.11 (2013), pp. 5247-5252.

[145] Congwang Ye et al. "Ceramic microparticles and capsules via microfluidic processing of a preceramic polymer". In: Journal of The Royal Society Interface 7.Suppl 4 (2010), S461-S473.

[146] Huanzhi Zhang and Xiaodong Wang. "Synthesis and properties of microencapsulated n-octadecane with polyurea shells containing different soft segments for heat energy storage and thermal regulation". In: Solar Energy Materials and Solar Cells 93.8 (2009), pp. 1366-1376. DOI: 10.1016/j . solmat.2009.02.021

[147] Sangphil Park et al. "Magnetic nanoparticle-embedded PCM nanocapsules based on paraffin core and polyurea shell". In: Colloids and Surfaces A: Physicochemical and Engineering Aspects 450 (2014), pp. 46-51. DOI: 10.1016/j.colsurfa.2014.03.005.

[148] Lin Pan et al. "Preparation, characterization and thermal properties of micro-encapsulated phase change materials". In: Solar Energy Materials and Solar Cells 98 (2012), pp. 66-70. DOI: 10.1016/ j.solmat.2011.09.020.

[149] Anna M. Szczotok et al. "Predicting microcapsules morphology and encapsulation efficiency by combining the spreading coefficient theory and polar surface energy component". In: Colloids and Surfaces A: Physicochemical and Engineering Aspects 554 (2018), pp. 49-59. DOI: 10.1016/j. colsurfa.2018.06.022. 
[150] Jessica Giro-Paloma et al. "Types, methods, techniques, and applications for microencapsulated phase change materials (MPCM): A review". In: Renewable and Sustainable Energy Reviews 53 (2016), pp. 1059-1075. DOI: $10.1016 /$ j.rser.2015.09.040

[151] K. Landfester. "Miniemulsions for Nanoparticle Synthesis". In: Topics in Current Chemistry. Springer Berlin Heidelberg, 2003, pp. 75-123. DOI: 10.1007/3-540-36412-9_4.

[152] Johanna Galindo-Alvarez et al. "Miniemulsion polymerization templates: A systematic comparison between low energy emulsification (Near-PIT) and ultrasound emulsification methods". In: Colloids and Surfaces A: Physicochemical and Engineering Aspects 374.1-3 (2011), pp. 134-141. DOI: $10.1016 / j \cdot c o l s u r f a .2010 .11 .019$.

[153] Hua Wang, Mozhen Wang, and Xuewu Ge. "Graft copolymers of polyurethane with various vinyl monomers via radiation-induced miniemulsion polymerization: Influential factors to grafting efficiency and particle morphology". In: Radiation Physics and Chemistry 78.2 (2009), pp. 112-118. DOI: $10.1016 / \mathrm{j}$.radphyschem.2008.08.005.

[154] Shahriar Sajjadi and Fatemeh Jahanzad. "Comparative study of monomer droplet nucleation in the seeded batch and semibatch miniemulsion polymerisation of styrene". In: European Polymer Journal 39.4 (2003), pp. 785-794. DOI: 10.1016/s0014-3057(02)00288-4.

[155] Ahmet Sarı et al. "Micro/nanoencapsulated n-nonadecane with poly(methyl methacrylate) shell for thermal energy storage". In: Energy Conversion and Management 86 (2014), pp. 614-621. DOI: 10.1016/j.enconman.2014.05.092.

[156] Zhong-Hua Chen et al. "Preparation, characterization and thermal properties of nanocapsules containing phase change material n-dodecanol by miniemulsion polymerization with polymerizable emulsifier". In: Applied Energy 91.1 (2012), pp. 7-12. DOI: 10.1016/j . apenergy.2011.08.041.

[157] G.H. Zhang, S.A.F. Bon, and C.Y. Zhao. "Synthesis, characterization and thermal properties of novel nanoencapsulated phase change materials for thermal energy storage”. In: Solar Energy 86.5 (2012), pp. 1149-1154. DOI: 10.1016/j.solener.2012.01.003.

[158] Xuezhen Wang et al. "Nano-encapsulated PCM via Pickering Emulsification". In: Scientific Reports 5.1 (2015). DOI: $10.1038 /$ srep13357.

[159] Yutang Fang et al. "Preparation and characterization of novel nanoencapsulated phase change materials". In: Energy Conversion and Management 49.12 (2008), pp. 3704-3707. DOI: 10.1016/ j.enconman.2008.06.027.

[160] Guiyin Fang et al. "Preparation and characterization of nano-encapsulated n-tetradecane as phase change material for thermal energy storage". In: Chemical Engineering Journal 153.1-3 (2009), pp. $217-221$. DOI: $10.1016 /$ j.cej.2009.06.019.

[161] Fengxia Gao, Xiaodong Wang, and Dezhen Wu. "Design and fabrication of bifunctional microcapsules for solar thermal energy storage and solar photocatalysis by encapsulating paraffin phase change material into cuprous oxide". In: Solar Energy Materials and Solar Cells 168 (2017), pp. 146-164. DOI: $10.1016 /$ j.solmat.2017.04.026 
[162] K Hirech. "Microencapsulation of an insecticide by interfacial polymerisation". In: Powder Technology 130.1-3 (2003), pp. 324-330. DOI: 10.1016/s0032-5910(02)00211-5

[163] F. Salan et al. "Microencapsulation of a cooling agent by interfacial polymerization: Influence of the parameters of encapsulation on poly(urethane-urea) microparticles characteristics". In: Journal of Membrane Science 370.1-2 (2011), pp. 23-33. DOI: 10.1016/j.memsci.2010.11.033.

[164] Chen Liang et al. "Microencapsulation of butyl stearate as a phase change material by interfacial polycondensation in a polyurea system". In: Energy Conversion and Management 50.3 (2009), pp. 723-729. DOI: $10.1016 / \mathrm{j}$.enconman.2008.09.044.

[165] Guang Long Zou et al. "Preparation and characterization of microencapsulated hexadecane used for thermal energy storage". In: (2004).

[166] Jeong-Sook Cho, Aehwa Kwon, and Chang-Gi Cho. "Microencapsulation of octadecane as a phasechange material by interfacial polymerization in an emulsion system". In: Colloid and polymer science 280.3 (2002), pp. 260-266.

[167] Periyasamy Siddhan, Manjeet Jassal, and Ashwini K Agrawal. "Core content and stability of n-octadecane-containing polyurea microencapsules produced by interfacial polymerization". In: Journal of applied polymer science 106.2 (2007), pp. 786-792.

[168] Jun-Feng Su, Li-Xin Wang, and Li Ren. "Synthesis of polyurethane microPCMs containing noctadecane by interfacial polycondensation: Influence of styrene-maleic anhydride as a surfactant". In: Colloids and Surfaces A: Physicochemical and Engineering Aspects 299.1-3 (2007), pp. 268275. DOI: $10.1016 / \mathrm{j}$.colsurfa.2006.11.051.

[169] Y.-H. Tseng et al. "Preparation of microencapsulated phase-change materials (MCPCMs) by means of interfacial polycondensation". In: Journal of Microencapsulation 22.1 (2005), pp. 3746. DOI: $10.1080 / 02652040400026558$

[170] Huanzhi Zhang et al. "Fabrication of microencapsulated phase change materials based on noctadecane core and silica shell through interfacial polycondensation". In: Colloids and Surfaces A: Physicochemical and Engineering Aspects 389.1-3 (2011), pp. 104-117. DOI: 10.1016/j.colsurfa. 2011.08 .043

[171] Benxia Li et al. "Fabrication and Properties of Microencapsulated Paraffin@SiO2 Phase Change Composite for Thermal Energy Storage". In: ACS Sustainable Chemistry \& Engineering 1.3 (2013), pp. 374-380. DOI: $10.1021 /$ sc300082m

[172] Shuen Liang et al. "Nanoencapsulation of n-octadecane phase change material with silica shell through interfacial hydrolysis and polycondensation in miniemulsion". In: Energy 93 (2015), pp. 1684-1692. DOI: $10.1016 / \mathrm{j}$.energy.2015.10.024.

[173] SK Yadav, AK Suresh, and Kartic C Khilar. "Microencapsulation in polyurea shell by interfacial polycondensation". In: AIChE Journal 36.3 (1990), pp. 431-438. 
[174] S Yadav. "Release rates from semi-crystalline polymer microcapsules formed by interfacial polycondensation". In: Journal of Membrane Science 125.2 (1997), pp. 213-218. Dor: 10.1016/s03767388(96) 00171-8.

[175] K Hong and S Park. "Preparation of polyurethane microcapsules with different soft segments and their characteristics". In: Reactive and Functional Polymers 42.3 (1999), pp. 193-200. DOI: $10.1016 / \mathrm{s} 1381-5148(98) 00068-6$.

[176] K. Hong and S. Park. "Preparation of polyurea microcapsules containing ovalbumin". In: Materials Chemistry and Physics 64.1 (2000), pp. 20-24. DOI: 10.1016/s0254-0584(99)00241-2.

[177] Junghye Kim and Gilsoo Cho. "Thermal Storage/Release, Durability, and Temperature Sensing Properties of Thermostatic Fabrics Treated with Octadecane-Containing Microcapsules". In: Textile Research Journal 72.12 (2002), pp. 1093-1098. DOI: 10.1177/004051750207201209.

[178] Jun-Feng Su et al. "Preparation and characterization of polyurethane microcapsules containingnoctadecane with styrene-maleic anhydride as a surfactant by interfacial polycondensation". In: Journal of Applied Polymer Science 102.5 (2006), pp. 4996-5006. DOI: 10.1002/app.25001.

[179] Zou Guanglong et al. "Microencapsulation of n-hexadecane as a phase change material in polyurea". In: Acta Phys Chim Sin 20.1 (2004), pp. 90-93.

[180] Xiao-Zheng Lan et al. "Microencapsulation of n-Eicosane as Energy Storage Material". In: Chinese Journal of Chemistry 22.5 (2004), pp. 411-414.

[181] Ju Wei et al. "Preparation and characterization of novel polyamide paraffin MEPCM by interfacial polymerization technique". In: Journal of Applied Polymer Science 127.6 (2013), pp. 4588-4593.

[182] Jin Huang et al. "Preparation, characterization, and thermal properties of the microencapsulation of a hydrated salt as phase change energy storage materials". In: Thermochimica Acta 557 (2013), pp. 1-6. DOI: $10.1016 /$ j.tca.2013.01.019.

[183] Xiaolin Qiu et al. "Preparation and characterization of microencapsulated n-octadecane as phase change material with different n-butyl methacrylate-based copolymer shells". In: Solar Energy Materials and Solar Cells 128 (2014), pp. 102-111. DOI: 10.1016/j.solmat.2014.05.020.

[184] Xiaofen Tang et al. "Fabrication and characterization of microencapsulated phase change material with low supercooling for thermal energy storage". In: Energy 68 (2014), pp. 160-166. DOI: 10. 1016/j.energy.2014.03.002.

[185] Luz Sánchez-Silva et al. "Microencapsulation of PCMs with a styrene-methyl methacrylate copolymer shell by suspension-like polymerisation". In: Chemical Engineering Journal 157.1 (2010), pp. 216-222. DOI: $10.1016 /$ j.cej.2009.12.013.

[186] Luz Sánchez et al. "Microencapsulation of PCMs with a polystyrene shell". In: Colloid and Polymer Science 285.12 (2007), pp. 1377-1385. DOI: $10.1007 /$ s00396-007-1696-7.

[187] Luz Sánchez et al. "Influence of operation conditions on the microencapsulation of PCMs by means of suspension-like polymerization". In: Colloid and Polymer Science 286.8-9 (2008), pp. 1019-1027. DOI: $10.1007 / \mathrm{s} 00396-008-1864-4$. 
[188] Ana M. Borreguero et al. "Improvement of the thermal behaviour of gypsum blocks by the incorporation of microcapsules containing PCMS obtained by suspension polymerization with an optimal core/coating mass ratio". In: Applied Thermal Engineering 30.10 (2010), pp. 1164-1169. DOI: $10.1016 / \mathrm{j}$.applthermaleng.2010.01.032.

[189] Ming You et al. "Polyurethane foam containing microencapsulated phase-change materials with styrene-divinybenzene co-polymer shells". In: Journal of Materials Science 44.12 (2009), pp. 31413147. DOI: $10.1007 / \mathrm{s} 10853-009-3418-7$

[190] Ming You et al. "Microencapsulated n-Octadecane with styrene-divinybenzene co-polymer shells". In: Journal of Polymer Research 18.1 (2010), pp. 49-58. DOI: 10.1007/s10965-010-9390-8

[191] Wei Li et al. "Morphology, structure and thermal stability of microencapsulated phase change material with copolymer shell". In: Energy 36.2 (2011), pp. 785-791. DoI: $10.1016 / \mathrm{j}$. energy . 2010.12.041.

[192] Preeyaporn Chaiyasat, Md. Zahidul Islam, and Amorn Chaiyasat. "Preparation of poly(divinylbenzene) microencapsulated octadecane by microsuspension polymerization: oil droplets generated by phase inversion emulsification". In: RSC Advances 3.26 (2013), p. 10202. DOI: 10.1039/c3ra40802g.

[193] Xiaolin Qiu et al. "Fabrication and characterization of microencapsulated n-octadecane with different crosslinked methylmethacrylate-based polymer shells". In: Solar Energy Materials and Solar Cells 98 (2012), pp. 283-293. DOI: 10.1016/j.solmat.2011.11.018.

[194] Fangli Cheng et al. "Preparation and characterization of phase-change material nanocapsules with amphiphilic polyurethane synthesized by 3-allyloxy-1,2-propanediol". In: Journal of Applied Polymer Science 130.3 (2013), pp. 1879-1889. DOI: 10.1002/app.39302.

[195] Yanhong Ma et al. "Preparation and thermal reliabilities of microencapsulated phase change materials with binary cores and acrylate-based polymer shells". In: Thermochimica Acta 588 (2014), pp. 38-46. DOI: $10.1016 /$ j.tca.2014.04.023

[196] Luz Sa nchez et al. "Applying an Experimental Design to Improve the Characteristics of Microcapsules Containing Phase Change Materials for Fabric Uses". In: Industrial \& Engineering Chemistry Research 47.23 (2008), pp. 9783-9790. DOI: 10.1021/ie801107e.

[197] Luz Sánchez-Silva, Juan F. Rodríguez, and Paula Sánchez. "Influence of different suspension stabilizers on the preparation of Rubitherm RT31 microcapsules". In: Colloids and Surfaces A: Physicochemical and Engineering Aspects 390.1-3 (2011), pp. 62-66. DOI: 10.1016/j.colsurfa.2011. 09.004

[198] AM Borreguero et al. "Development of microcapsules containing phase change materials for refrigeration". In: 9th international conference on phase-change materials and slurries for refrigeration and air conditioning. Vol. 5. 2010, pp. 29-36. 
[199] Sude Ma et al. "UV irradiation-initiated MMA polymerization to prepare microcapsules containing phase change paraffin". In: Solar Energy Materials and Solar Cells 94.10 (2010), pp. 1643-1647. DOI: $10.1016 /$ j.solmat.2010.05.021

[200] J. Giro-Paloma, Y. Konuklu, and A.I. Fernández. "Preparation and exhaustive characterization of paraffin or palmitic acid microcapsules as novel phase change material". In: Solar Energy 112 (2015), pp. 300-309. DOI: 10.1016/j.solener.2014.12.008

[201] Ahmet Sarı et al. "Microencapsulated n-octacosane as phase change material for thermal energy storage". In: Solar Energy 83.10 (2009), pp. 1757-1763.

[202] Ahmet Sarı, Cemil Alkan, and Ali Karaipekli. "Preparation, characterization and thermal properties of PMMA/n-heptadecane microcapsules as novel solid-liquid microPCM for thermal energy storage". In: Applied Energy 87.5 (2010), pp. 1529-1534. DOI: 10.1016/j . apenergy . 2009.10.011.

[203] Cemil Alkan et al. "Preparation, characterization, and thermal properties of microencapsulated phase change material for thermal energy storage". In: Solar Energy Materials and Solar Cells 93.1 (2009), pp. 143-147. DOI: 10.1016/j.solmat.2008.09.009

[204] Cemil Alkan, Ahmet Sarı, and Ali Karaipekli. "Preparation, thermal properties and thermal reliability of microencapsulated n-eicosane as novel phase change material for thermal energy storage". In: Energy Conversion and Management 52.1 (2011), pp. 687-692. DOI: $10.1016 /$ j.enconman . 2010.07 .047

[205] Sennur Alay, Cemil Alkan, and Fethiye Gde. "Synthesis and characterization of poly(methyl methacrylate)/n-hexadecane microcapsules using different cross-linkers and their application to some fabrics". In: Thermochimica Acta 518.1-2 (2011), pp. 1-8. DOI: 10.1016/j.tca.2011.01. 014 .

[206] Sennur Alay, Fethiye Gde, and Cemil Alkan. "Preparation and characterization of poly(methylmethacrylatecoglycidyl methacrylate)/n-hexadecane nanocapsules as a fiber additive for thermal energy storage". In: Fibers and Polymers 11.8 (2010), pp. 1089-1093. DOI: 10.1007/s12221-010-1089-2.

[207] Kyung-Hyun Baek, Jun-Young Lee, and Jung-Hyun Kim. "Core/Shell Structured PCM Nanocapsules Obtained by Resin Fortified Emulsion Process". In: Journal of Dispersion Science and Technology 28.7 (2007), pp. 1059-1065. DOI: 10.1080/01932690701524281.

[208] Ahmet Sarı et al. "Micro/nano-encapsulated n-heptadecane with polystyrene shell for latent heat thermal energy storage". In: Solar Energy Materials and Solar Cells 126 (2014), pp. 42-50. DOI: $10.1016 /$ j.solmat. 2014.03 .023 .

[209] Ahmet Sarı, Cemil Alkan, and Cahit Bilgin. "Micro/nano encapsulation of some paraffin eutectic mixtures with poly(methyl methacrylate) shell: Preparation, characterization and latent heat thermal energy storage properties". In: Applied Energy 136 (2014), pp. 217-227. DOI: 10.1016/ j.apenergy 2014.09 .047 
[210] Ahmet Sarı et al. "Micro/nano encapsulated n-tetracosane and n-octadecane eutectic mixture with polystyrene shell for low-temperature latent heat thermal energy storage applications". In: Solar Energy 115 (2015), pp. 195-203. DOI: 10.1016/j.solener.2015.02.035.

[211] Ahmet Sarı, Cemil Alkan, and Ayşegl Nazlı zcan. "Synthesis and characterization of micro/nano capsules of PMMA/capric-stearic acid eutectic mixture for low temperature-thermal energy storage in buildings". In: Energy and Buildings 90 (2015), pp. 106-113. DOI: $10.1016 / \mathrm{j}$.enbuild. 2015.01 .013

[212] Yingwu Luo and Xiangdong Zhou. "Nanoencapsulation of a hydrophobic compound by a miniemulsion polymerization process". In: Journal of Polymer Science Part A: Polymer Chemistry 42.9 (2004), pp. 2145-2154. DOI: 10.1002/pola.20065.

[213] Chunming Chen et al. "Fabrication and characterization of nanocapsules containing n-dodecanol by miniemulsion polymerization using interfacial redox initiation". In: Colloid and Polymer Science 290.4 (2011), pp. 307-314. DOI: 10.1007/s00396-011-2545-2.

[214] Ming Guang Li et al. "Effect of different amounts of surfactant on characteristics of nanoencapsulated phase-change materials". In: Polymer Bulletin 67.3 (2011), pp. 541-552. DOI: 10.1007/ s00289-011-0492-1.

[215] Mónica Fuensanta et al. "Thermal properties of a novel nanoencapsulated phase change material for thermal energy storage". In: Thermochimica Acta 565 (2013), pp. 95-101. DOI: 10.1016/j. tca.2013.04.028.

[216] Yutang Fang et al. "Preparation and thermal performance of polystyrene/n-tetradecane composite nanoencapsulated cold energy storage phase change materials". In: Energy conversion and management 76 (2013), pp. 430-436.

[217] Yutang Fang et al. "Preparation of nanoencapsulated phase change material as latent functionally thermal fluid". In: Journal of Physics D: Applied Physics 42.3 (2008), p. 035407.

[218] Yutang Fang et al. "Ultrasonic synthesis and characterization of polystyrene/n-dotriacontane composite nanoencapsulated phase change material for thermal energy storage". In: Applied Energy 132 (2014), pp. 551-556. DOI: 10.1016/j.apenergy.2014.06.056.

[219] K. Tumirah et al. "Nano-encapsulated organic phase change material based on copolymer nanocomposites for thermal energy storage". In: Energy 66 (2014), pp. 881-890. DoI: 10.1016/j.energy. 2014.01 .033

[220] W. Wu et al. "Jet impingement and spray cooling using slurry of nanoencapsulated phase change materials". In: International Journal of Heat and Mass Transfer 54.13-14 (2011), pp. 2715-2723. DOI: $10.1016 /$ j.ijheatmasstransfer.2011.03.022.

[221] Xiaofeng Hu, Zhanhua Huang, and Yanhua Zhang. "Preparation of CMC-modified melamine resin spherical nano-phase change energy storage materials". In: Carbohydrate Polymers 101 (2014), pp. 83-88. DOI: $10.1016 /$ j.carbpol.2013.08.091, 
[222] Guang-Hua NAN et al. "Preparation and Properties of Nanoencapsulated Phase Change Materials Containing Polyaniline”. In: Acta Physico-Chimica Sinica 30.2 (2014), pp. 338-344.

[223] Jun-Kyu Choi et al. "Preparation of microcapsules containing phase change materials as heat transfer media by in-situ polymerization". In: Journal of Industrial and Engineering Chemistry 7.6 (2001), pp. 358-362.

[224] Zhaoguo Jin et al. "Synthesis and properties of paraffin capsules as phase change materials". In: Polymer 49.12 (2008), pp. 2903-2910. DOI: 10.1016/j.polymer.2008.04.030.

[225] X.X. Zhang et al. "Fabrication and properties of microcapsules and nanocapsules containing noctadecane". In: Materials Chemistry and Physics 88.2-3 (2004), pp. 300-307. DOI: 10.1016/j . matchemphys.2004.06.043

[226] Wei Li et al. "Preparation and characterization of microencapsulated phase change material with low remnant formaldehyde content". In: Materials Chemistry and Physics 106.2-3 (2007), pp. 437442. DOI: $10.1016 / \mathrm{j}$.matchemphys.2007.06.030.

[227] K Hong and S Park. "Melamine resin microcapsules containing fragrant oil: synthesis and characterization". In: Materials Chemistry and Physics 58.2 (1999), pp. 128-131. DOI: 10.1016/s0254$0584(98) 00263-6$.

[228] Fabien Salan et al. "Development of Phase Change Materials in Clothing Part I: Formulation of Microencapsulated Phase Change". In: Textile Research Journal 80.3 (2009), pp. 195-205. DOI: $10.1177 / 0040517509093436$

[229] Huanzhi Zhang and Xiaodong Wang. "Fabrication and performances of microencapsulated phase change materials based on n-octadecane core and resorcinol-modified melamine-formaldehyde shell". In: Colloids and Surfaces A: Physicochemical and Engineering Aspects 332.2-3 (2009), pp. 129-138. DOI: $10.1016 / \mathrm{j}$.colsurfa.2008.09.013.

[230] Xing xiang Zhang et al. "Structure and thermal stability of microencapsulated phase-change materials". In: Colloid and Polymer Science 282.4 (2003), pp. 330-336. DOI: 10.1007/s00396-0030925-y.

[231] X. X. Zhang et al. "Expansion space and thermal stability of microencapsulatedn-octadecane". In: Journal of Applied Polymer Science 97.1 (2005), pp. 390-396. DOI: 10.1002/app.21760.

[232] Y.F. Fan et al. "Thermal stability and permeability of microencapsulated n-octadecane and cyclohexane". In: Thermochimica Acta 429.1 (2005), pp. 25-29. DOI: 10.1016/j.tca.2004.11.025.

[233] Xi Guo et al. "Incorporation of microencapsulated dodecanol into wood flour/high-density polyethylene composite as a phase change material for thermal energy storage". In: Materials $\&$ Design 89 (2016), pp. 1325-1334. DOI: $10.1016 /$ j.matdes.2015.10.068.

[234] Yeliz Konuklu et al. "Microencapsulation of a fatty acid with Poly(melamine-urea-formaldehyde)". In: Energy Conversion and Management 80 (2014), pp. 382-390. DOI:10.1016/j .enconman. 2014. 01.042 . 
[235] Igor Krupa et al. "Phase change materials based on high-density polyethylene filled with microencapsulated paraffin wax". In: Energy Conversion and Management 87 (2014), pp. 400-409. DOI: $10.1016 / j$.enconman.2014.06.061.

[236] Kunjie Yuan et al. "Novel slurry containing graphene oxide-grafted microencapsulated phase change material with enhanced thermo-physical properties and photo-thermal performance". In: Solar Energy Materials and Solar Cells 143 (2015), pp. 29-37. DOI: 10.1016/j.solmat.2015. 06.034 .

[237] Y.F. Fan et al. "Super-cooling prevention of microencapsulated phase change material". In: Thermochimica Acta 413.1-2 (2004), pp. 1-6. DOI: 10.1016/j.tca.2003.11.006

[238] Xing xiang Zhang et al. "Crystallization and prevention of supercooling of microencapsulated nalkanes". In: Journal of Colloid and Interface Science 281.2 (2005), pp. 299-306. DOI: 10.1016/ j.jcis.2004.08.046

[239] Younsook Shin, Dong-Il Yoo, and Kyunghee Son. "Development of thermoregulating textile materials with microencapsulated phase change materials (PCM). II. Preparation and application of PCM microcapsules". In: Journal of Applied Polymer Science 96.6 (2005).

[240] Younsook Shin, Dong-Il Yoo, and Kyunghee Son. "Development of thermoregulating textile materials with microencapsulated phase change materials (PCM). IV. Performance properties and hand of fabrics treated with PCM microcapsules". In: Journal of Applied Polymer Science 97.3 (2005), pp. 910-915.

[241] B. Boh, E. Knez, and M. Staresinic. "Microencapsulation of higher hydrocarbon phase change materials byin situpolymerization". In: Journal of Microencapsulation 22.7 (2005), pp. 715-735. DOI: $10.1080 / 02652040500162139$.

[242] Yu Rao et al. "Preparation and thermal properties of microencapsulated phase change material for enhancing fluid flow heat transfer". In: Heat Transfer-Asian Research 36.1 (2006), pp. 28-37. DOI: $10.1002 / \mathrm{htj} .20138$.

[243] Fabien Salan and Isabelle Vroman. "Influence of core materials on thermal properties of melamine-formaldehyde microcapsules". In: European Polymer Journal 44.3 (2008), pp. 849-860. DOI: 10 . $1016 / \mathrm{j}$. eurpolymj.2007.11.018.

[244] Yan Chao Yuan, Min Zhi Rong, and Ming Qiu Zhang. "Preparation and characterization of microencapsulated polythiol". In: Polymer 49.10 (2008), pp. 2531-2541. DOI: 10.1016/j.polymer. 2008.03 .044

[245] Fei Yu, Zhong-Hua Chen, and Xing-Rong Zeng. "Preparation, characterization, and thermal properties of microPCMs containing n-dodecanol by using different types of styrene-maleic anhydride as emulsifier". In: Colloid and Polymer Science 287.5 (2009), pp. 549-560. DoI: 10.1007/s00396009-2001-8. 
[246] See Hoon Lee et al. "Development of building materials by using micro-encapsulated phase change material". In: Korean Journal of Chemical Engineering 24.2 (2007), pp. 332-335. DOI: 10.1007/ s11814-007-5054-8.

[247] Dongsheng Fu et al. "Phase change materials of n-alkane-containing microcapsules: observation of coexistence of ordered and rotator phases". In: Physical Chemistry Chemical Physics 13.6 (2011), p. 2021. DOI: $10.1039 / \mathrm{c0cp} 01173 \mathrm{~h}$

[248] Mahyar Silakhori et al. "Accelerated Thermal Cycling Test of Microencapsulated Paraffin Wax/Polyaniline Made by Simple Preparation Method for Solar Thermal Energy Storage". In: Materials 6.5 (2013), pp. 1608-1620. DOI: $10.3390 / \mathrm{ma} 6051608$.

[249] Bingtao Tang, Meige Qiu, and Shufen Zhang. "Thermal conductivity enhancement of PEG/SiO2 composite PCM by in situ Cu doping". In: Solar Energy Materials and Solar Cells 105 (2012), pp. 242-248. DOI: $10.1016 /$ j.solmat.2012.06.012.

[250] Yafei Zhao et al. "Storing solar energy within Ag-Paraffin@Halloysite microspheres as a novel self-heating catalyst". In: Applied Energy 222 (2018), pp. 180-188. DOI: 10.1016/j . apenergy . 2018.04 .013 .

[251] Xiaochun Ma et al. "Synthesis and characterization of microencapsulated paraffin with TiO2 shell as thermal energy storage materials". In: Journal of Materials Science: Materials in Electronics 29.17 (2018), pp. 15241-15248. DOI: 10.1007/s10854-018-9666-z

[252] Qingsong Lian et al. "Facile Strategy in Designing Epoxy/Paraffin Multiple Phase Change Materials for Thermal Energy Storage Applications". In: ACS Sustainable Chemistry \& Engineering 6.3 (2018), pp. 3375-3384. DOI: 10.1021/acssuschemeng.7b03558.

[253] Lixia Geng et al. "Facile Synthesis and Thermal Properties of Nanoencapsulated n-Dodecanol with SiO2 Shell as Shape-Formed Thermal Energy Storage Material". In: Energy \& Fuels 30.7 (2016), pp. 6153-6160. DOI: 10.1021/acs.energyfuels.6b00929

[254] Yi-Tian Huang et al. "Carbon nanotube-enhanced double-walled phase-change microcapsules for thermal energy storage". In: Journal of Materials Chemistry A 5.16 (2017), pp. 7482-7493. DOI: $10.1039 / \mathrm{c} 6 \mathrm{ta0} 9712 \mathrm{j}$

[255] Li Zhang et al. "Graphene oxide-modified microencapsulated phase change materials with high encapsulation capacity and enhanced leakage-prevention performance". In: Applied Energy 197 (2017), pp. 354-363. DOI: 10.1016/j.apenergy.2017.04.041.

[256] P. A. Advincula et al. "Accommodating volume change and imparting thermal conductivity by encapsulation of phase change materials in carbon nanoparticles". In: Journal of Materials Chemistry A 6.6 (2018), pp. 2461-2467. DOI: 10.1039/c7ta09664j.

[257] Dimberu G. Atinafu et al. "Introduction of organic-organic eutectic PCM in mesoporous N-doped carbons for enhanced thermal conductivity and energy storage capacity". In: Applied Energy 211 (2018), pp. 1203-1215. DOI: 10.1016/j.apenergy.2017.12.025 
[258] Guanghui Leng et al. "Micro encapsulated \& form-stable phase change materials for high temperature thermal energy storage". In: Applied Energy 217 (2018), pp. 212-220. DOI: 10.1016/j . apenergy.2018.02.064.

[259] Jian ping Wang et al. "Preparation of Microcapsules Containing Two-Phase Core Materials". In: Langmuir 20.25 (2004), pp. 10845-10850. DOI: 10.1021/la0490902.

[260] Cemil Alkan and Ahmet Sari. "Fatty acid/poly(methyl methacrylate) (PMMA) blends as formstable phase change materials for latent heat thermal energy storage". In: Solar Energy 82.2 (2008), pp. 118-124. DOI: $10.1016 /$ j.solener.2007.07.001

[261] Wen Pan et al. "A novel synthesis of micrometer silica hollow sphere". In: Materials Research Bulletin 44.2 (2009), pp. 280-283. DOI: 10.1016/j.materresbull.2008.06.006

[262] G.H. Zhang and C.Y. Zhao. "Thermal and rheological properties of microencapsulated phase change materials". In: Renewable Energy 36.11 (2011), pp. 2959-2966. DOI: 10.1016/j.renene. 2011.04 .002

[263] Jessica Giro-Paloma et al. "Physico-chemical and mechanical properties of microencapsulated phase change material". In: Applied Energy 109 (2013), pp. 441-448. DOI: 10.1016/j . apenergy . 2012.11 .007

[264] Yanhong Ma et al. "The effect of different soft segments on the formation and properties of binary core microencapsulated phase change materials with polyurea/polyurethane double shell". In: Journal of Colloid and Interface Science 392 (2013), pp. 407-414. DOI: 10.1016/j·jcis.2012. 10.052 .

[265] Jessica Giro-Paloma et al. "Physicochemical and Thermal Study of a MPCM of PMMA Shell and Paraffin Wax as a Core". In: Energy Procedia 48 (2014), pp. 347-354. DoI: $10.1016 /$ j . egypro. 2014.02 .040 .

[266] Wenhong Li et al. "Preparation and characterization of novel MicroPCMs (microencapsulated phase-change materials) with hybrid shells via the polymerization of two alkoxy silanes". In: Energy 70 (2014), pp. 298-306. DOI: 10.1016/j.energy.2014.03.125

[267] Yi Wang et al. "Effects of fabricated technology on particle size distribution and thermal properties of stearic-eicosanoic acid/polymethylmethacrylate nanocapsules". In: Solar Energy Materials and Solar Cells 120 (2014), pp. 481-490. DOI: 10.1016/j.solmat.2013.09.028.

[268] Shiyu Yu, Xiaodong Wang, and Dezhen Wu. "Microencapsulation of n-octadecane phase change material with calcium carbonate shell for enhancement of thermal conductivity and serving durability: Synthesis, microstructure, and performance evaluation". In: Applied Energy 114 (2014), pp. 632-643. DOI: $10.1016 / \mathrm{j}$. apenergy.2013.10.029.

[269] Xiang Jiang et al. "Synthesis, characterization and thermal properties of paraffin microcapsules modified with nano-Al 2 O 3". In: Applied Energy 137 (2015), pp. 731-737. DOI: 10.1016/j . apenergy.2014.09.028, 
[270] Hanfei Zhang et al. "Microencapsulation of molten salt in stable silica shell via a water-limited sol-gel process for high temperature thermal energy storage". In: Applied Thermal Engineering 136 (2018), pp. 268-274. DOI: 10.1016/j.applthermaleng.2018.02.050.

[271] Xiao Zhong Qiu et al. "Synthesis and characterization of paraffin/TiO2 -P(MMA-co -BA) phase change material microcapsules for thermal energy storage". In: Journal of Applied Polymer Science 135.27 (2018), p. 46447. DOI: 10.1002/app.46447.

[272] Nurten Şahan and Halime Paksoy. "Developing microencapsulated 12-hydroxystearic acid (HSA) for phase change material use". In: International Journal of Energy Research 42.10 (2018), pp. 33513360. DOI: $10.1002 /$ er.4090.

[273] L. Sánchez-Silva et al. "Poly(urea-formaldehyde) microcapsules containing commercial paraffin: in situ polymerization study". In: Colloid and Polymer Science 296.9 (2018), pp. 1449-1457. DOI: $10.1007 / \mathrm{s} 00396-018-4365-0$.

[274] Zhengguo Zhang and Xiaoming Fang. "Study on paraffin/expanded graphite composite phase change thermal energy storage material". In: Energy Conversion and Management 47.3 (2006), pp. 303-310. DOI: $10.1016 /$ j .enconman.2005.03.004.

[275] Qingwen Song et al. "Thermal stability of composite phase change material microcapsules incorporated with silver nano-particles". In: Polymer 48.11 (2007), pp. 3317-3323. DOI: 10.1016/j. polymer.2007.03.045.

[276] Jun-Feng Su, Zhen Huang, and Li Ren. "High compact melamine-formaldehyde microPCMs containing n-octadecane fabricated by a two-step coacervation method". In: Colloid and Polymer Science 285.14 (2007), pp. 1581-1591. DOI: 10.1007/s00396-007-1729-2.

[277] Yimin Xuan, Yong Huang, and Qiang Li. "Experimental investigation on thermal conductivity and specific heat capacity of magnetic microencapsulated phase change material suspension". In: Chemical Physics Letters 479.4-6 (2009), pp. 264-269. DOI: 10.1016/j.cplett.2009.08.033.

[278] Witold Fortuniak et al. "Synthesis of a paraffin phase change material microencapsulated in a siloxane polymer". In: Colloid and Polymer Science 291.3 (2012), pp. 725-733. DOI: 10.1007/ s00396-012-2782-z.

[279] Fangyu Cao and Bao Yang. "Supercooling suppression of microencapsulated phase change materials by optimizing shell composition and structure". In: Applied Energy 113 (2014), pp. 1512-1518. DOI: $10.1016 / \mathrm{j}$. apenergy .2013.08.048.

[280] J. Porras-Saavedra et al. "Microstructural properties and distribution of components in microparticles obtained by spray-drying". In: Journal of Food Engineering 152 (2015), pp. 105-112. DOI: $10.1016 / j \cdot j$ foodeng.2014.11.014.

[281] Tingyu Wang et al. "Microencapsulation of phase change materials with binary cores and calcium carbonate shell for thermal energy storage". In: Applied Energy 171 (2016), pp. 113-119. DoI: $10.1016 / \mathrm{j}$. apenergy . 2016.03.037. 
[282] Jian Liu et al. "Preparation of graphite nanoparticles-modified phase change microcapsules and their dispersed slurry for direct absorption solar collectors". In: Solar Energy Materials and Solar Cells 159 (2017), pp. 159-166. DOI: 10.1016/j.solmat.2016.09.020.

[283] Xiaoye Geng et al. "Design and fabrication of reversible thermochromic microencapsulated phase change materials for thermal energy storage and its antibacterial activity". In: Energy 159 (2018), pp. 857-869. DOI: $10.1016 /$ j.energy .2018.06.218.

[284] Wenbin Yang et al. "Novel segregated-structure phase change materials composed of paraffin@graphene microencapsules with high latent heat and thermal conductivity". In: Journal of Materials Science 53.4 (2018), pp. 2566-2575. DOI: 10.1007/s10853-017-1693-2.

[285] Rui Yang, Hui Xu, and Yingping Zhang. "Preparation, physical property and thermal physical property of phase change microcapsule slurry and phase change emulsion". In: Solar Energy Materials and Solar Cells 80.4 (2003), pp. 405-416. DOI: 10.1016/j.solmat.2003.08.005.

[286] Xiaoyu Zhang, Xiaodong Wang, and Dezhen Wu. "Design and synthesis of multifunctional microencapsulated phase change materials with silver/silica double-layered shell for thermal energy storage, electrical conduction and antimicrobial effectiveness". In: Energy 111 (2016), pp. 498-512. DOI: $10.1016 / j$.energy.2016.06.017

[287] Noemí Arconada et al. "Macroencapsulation of sodium chloride as phase change materials for thermal energy storage". In: Solar Energy 167 (2018), pp. 1-9. DOI: 10.1016/j.solener.2018. 02.045 .

[288] Min Li, Jianpeng Liu, and Junbing Shi. "Synthesis and properties of phase change microcapsule with $\mathrm{SiO} 2$-TiO 2 hybrid shell". In: Solar Energy 167 (2018), pp. 158-164. DOI: 10.1016/j . solener.2018.04.016.

[289] Fabio A. P. Scacchetti, Eugénia Pinto, and Graça M. B. Soares. "Thermal and antimicrobial evaluation of cotton functionalized with a chitosan-zeolite composite and microcapsules of phasechange materials". In: Journal of Applied Polymer Science 135.15 (2017), p. 46135. DOI: 10.1002/ app.46135.

[290] Sena Demirbağ and Sennur Alay Aksoy. "Encapsulation of phase change materials by complex coacervation to improve thermal performances and flame retardant properties of the cotton fabrics". In: Fibers and Polymers 17.3 (2016), pp. 408-417. DOI: 10.1007/s12221-016-5113-z.

[291] Xianfeng Wang, Chunhong Li, and Tao Zhao. "Fabrication and characterization of poly(melamineformaldehyde)/silicon carbide hybrid microencapsulated phase change materials with enhanced thermal conductivity and light-heat performance". In: Solar Energy Materials and Solar Cells 183 (2018), pp. 82-91. DOI: 10.1016/j.solmat.2018.03.019.

[292] Xiang Huang, Yaxue Lin, and Guiyin Fang. "Thermal properties of polyvinyl butyral/graphene composites as encapsulation materials for solar cells". In: Solar Energy 161 (2018), pp. 187-193. DOI: $10.1016 / \mathrm{j}$. solener.2017.12.051 
[293] Chenzhen Liu et al. "Experimental research on flow and heat transfer characteristics of latent functional thermal fluid with microencapsulated phase change materials". In: International Journal of Heat and Mass Transfer 115 (2017), pp. 737-742. DOI: 10.1016/j . i jheatmasstransfer.2017. 07.107 .

[294] S.D. Sharma, D. Buddhi, and R.L. Sawhney. "Accelerated thermal cycle test of latent heat-storage materials". In: Solar Energy 66.6 (1999), pp. 483-490. DOI: 10.1016/s0038-092x(99)00045-6.

[295] Atul Sharma, S.D Sharma, and D Buddhi. "Accelerated thermal cycle test of acetamide, stearic acid and paraffin wax for solar thermal latent heat storage applications". In: Energy Conversion and Management 43.14 (2002), pp. 1923-1930. DOI: 10.1016/s0196-8904(01)00131-5.

[296] G.H. Zhang and C.Y. Zhao. "Thermal property investigation of aqueous suspensions of microencapsulated phase change material and carbon nanotubes as a novel heat transfer fluid". In: Renewable Energy 60 (2013), pp. 433-438. DOI: 10.1016/j.renene.2013.05.041.

[297] Zhaoliang Zheng et al. "Microencapsulated Phase Change Materials in Solar-Thermal Conversion Systems: Understanding Geometry-Dependent Heating Efficiency and System Reliability". In: ACS Nano 11.1 (2016), pp. 721-729. DOI: 10.1021/acsnano.6b07126.

[298] Yi Zhang et al. "Bi- and tetra-layered dipalmitoyl phosphatidylserine (DPPS) patterns produced by hydration of Langmuir-Blodgett monolayers and the subsequent enzymatic digestion". In: Colloids and Surfaces A: Physicochemical and Engineering Aspects 337.1-3 (2009), pp. 26-32. DOI: $10.1016 / \mathrm{j} \cdot$ colsurfa.2008.11.050

[299] Derya Kahraman Dğşc et al. "Microencapsulated n -alkane eutectics in polystyrene for solar thermal applications". In: Solar Energy 160 (2018), pp. 32-42. DOI: 10.1016/j . solener.2017.11. 072 .

[300] Mushtaq I. Hasan. "Numerical investigation of counter flow microchannel heat exchanger with MEPCM suspension". In: Applied Thermal Engineering 31.6-7 (2011), pp. 1068-1075. DOI: 10. 1016/j.applthermaleng.2010.11.032.

[301] Lingkun Liu et al. "Dynamic thermal characteristics analysis of microencapsulated phase change suspensions flowing through rectangular mini-channels for thermal energy storage". In: Energy and Buildings 134 (2017), pp. 37-51. DOI: 10.1016/j.enbuild.2016.11.021.

[302] Małgorzata Jurkowska and Ireneusz Szczygieł. "Review on properties of microencapsulated phase change materials slurries (mPCMS)". In: Applied Thermal Engineering 98 (2016), pp. 365-373. DOI: $10.1016 / \mathrm{j}$. applthermaleng.2015.12.051.

[303] Yifeng Jiang et al. "Novel Na 2 SO 4 -NaCl-ceramic composites as high temperature phase change materials for solar thermal power plants (Part I)". In: Solar Energy Materials and Solar Cells 178 (2018), pp. 74-83. DOI: 10.1016/j.solmat.2017.12.034.

[304] Yuan Lu et al. "Green nano-encapsulation technique for preparation of phase change nanofibers mats with core-sheath structure". In: Colloids and Surfaces A: Physicochemical and Engineering Aspects 555 (2018), pp. 501-506. DOI: 10.1016/j.colsurfa.2018.07.030 
[305] Imran Hussain S., Ameelia Roseline A., and Kalaiselvam S. "Bifunctional nanoencapsulated eutectic phase change material core with $\mathrm{SiO} 2 / \mathrm{SnO} 2$ nanosphere shell for thermal and electrical energy storage". In: Materials 6 Design 154 (2018), pp. 291-301. DOI: 10.1016/j .matdes.2018.05.046.

[306] Majid Naderi. "Surface Area". In: Progress in Filtration and Separation. Elsevier, 2015, pp. 585608. DOI: $10.1016 / \mathrm{b} 978-0-12-384746-1.00014-8$.

[307] Adriana C Toma and Thomas Pfohl. "Small-Angle X-ray Scattering (SAXS) and Wide-Angle X-ray Scattering (WAXS) of Supramolecular Assemblies". In: Supramolecular chemistry: from molecules to nanomaterials (2012).

[308] Doriano Lamba. "Wide-Angle X-Ray Scattering (WAXS)". In: Encyclopedia of Membranes. Springer Berlin Heidelberg, 2016, pp. 2040-2042. DOI: 10.1007/978-3-662-44324-8_1101.

[309] Atul Sharma et al. "Thermal cycle test of urea for latent heat storage applications". In: International Journal of Energy Research 25.5 (2001), pp. 465-468. DOI: 10.1002/er.692.

[310] Jia Zeng, Yimin Xuan, and Huiling Duan. "Tin-silica-silver composite nanoparticles for mediumto-high temperature volumetric absorption solar collectors". In: Solar Energy Materials and Solar Cells 157 (2016), pp. 930-936. DOI: 10.1016/j.solmat.2016.08.012.

[311] Vignesh Pethurajan et al. "Facile approach to improve solar thermal energy storage efficiency using encapsulated sugar alcohol based phase change material". In: Solar Energy Materials and Solar Cells 185 (2018), pp. 524-535. DOI: 10.1016/j.solmat.2018.06.007.

[312] Yanfeng Chen et al. "A novel CNT encapsulated phase change material with enhanced thermal conductivity and photo-thermal conversion performance". In: Solar Energy Materials and Solar Cells 184 (2018), pp. 82-90. DOI: $10.1016 /$ j.solmat.2018.04.034

[313] Zhaoliang Zheng et al. "Highly Stable and Conductive Microcapsules for Enhancement of Joule Heating Performance". In: ACS Nano 10.4 (2016), pp. 4695-4703. DOI: 10 . 1021 / acsnano . $6 \mathrm{~b} 01104$

[314] Zhenpu Liu et al. "Tailoring Carbon Nanotube Density for Modulating Electro-to-Heat Conversion in Phase Change Composites". In: Nano Letters 13.9 (2013), pp. 4028-4035. DOI: 10 . $1021 /$ nl401097d.

[315] Ziye Ling et al. "Review on thermal management systems using phase change materials for electronic components, Li-ion batteries and photovoltaic modules". In: Renewable and Sustainable Energy Reviews 31 (2014), pp. 427-438. DOI: 10.1016/j.rser.2013.12.017.

[316] Zhongzhu Qiu et al. "Micro-encapsulated phase change material (MPCM) slurries: Characterization and building applications". In: Renewable and Sustainable Energy Reviews 77 (2017), pp. 246262. DOI: $10.1016 /$ j.rser.2017.04.001.

[317] Lin Chen et al. "Characterization of thermal and hydrodynamic properties for microencapsulated phase change slurry (MPCS)". In: Energy Conversion and Management 79 (2014), pp. 317-333. DOI: $10.1016 / j$.enconman . 2013.12.026 
[318] C.J. Ho et al. "Water-based suspensions of Al2O3 nanoparticles and MEPCM particles on convection effectiveness in a circular tube". In: International Journal of Thermal Sciences 50.5 (2011), pp. 736-748. DOI: $10.1016 /$ j.ijthermalsci.2010.11.015.

[319] C.J. Ho, Wei-Chen Chen, and Wei-Mon Yan. "Experiment on thermal performance of waterbased suspensions of $\mathrm{Al} 2 \mathrm{O} 3$ nanoparticles and MEPCM particles in a minichannel heat sink". In: International Journal of Heat and Mass Transfer 69 (2014), pp. 276-284. DOI: 10.1016/j . ijheatmasstransfer.2013.10.034.

[320] Hamid Reza Seyf et al. "Three dimensional numerical study of heat-transfer enhancement by nanoencapsulated phase change material slurry in microtube heat sinks with tangential impingement". In: International Journal of Heat and Mass Transfer 56.1-2 (2013), pp. 561-573. DOI: 10.1016/ j.ijheatmasstransfer.2012.08.052

[321] M. Mohib Ur Rehman, Z. G. Qu, and R. P. Fu. "Three-dimensional numerical study of laminar confined slot jet impingement cooling using slurry of nano-encapsulated phase change material". In: Journal of Thermal Science 25.5 (2016), pp. 431-439. DOI: 10.1007/s11630-016-0881-8.

[322] Yeliz Konuklu et al. "Review on using microencapsulated phase change materials (PCM) in building applications". In: Energy and Buildings 106 (2015), pp. 134-155. DOI: $10.1016 /$ j.enbuild. 2015.07 .019 .

[323] L. Erlbeck et al. "Investigation of different materials for macroencapsulation of salt hydrate phase change materials for building purposes". In: Construction and Building Materials 180 (2018), pp. 512-518. DOI: $10.1016 / \mathrm{j}$.conbuildmat.2018.05.204

[324] Jessica Giro-Paloma et al. "Preparation and Characterization of Microencapsulated Phase Change Materials for Use in Building Applications". In: Materials 9.1 (2015), p. 11. DOI: 10.3390/ ma9010011.

[325] Matthew Aguayo et al. "The influence of microencapsulated phase change material (PCM) characteristics on the microstructure and strength of cementitious composites: Experiments and finite element simulations". In: Cement and Concrete Composites 73 (2016), pp. 29-41. DOI: 10.1016/ j.cemconcomp.2016.06.018.

[326] Vinh Duy Cao et al. "Microencapsulated phase change materials for enhancing the thermal performance of Portland cement concrete and geopolymer concrete for passive building applications". In: Energy Conversion and Management 133 (2017), pp. 56-66. DOI: 10.1016/j .enconman.2016. 11.061 .

[327] Zhenhua Wei et al. "The durability of cementitious composites containing microencapsulated phase change materials". In: Cement and Concrete Composites 81 (2017), pp. 66-76. DOI: 10.1016/j. cemconcomp.2017.04.010.

[328] Benjamin A. Young et al. "A general method for retrieving thermal deformation properties of microencapsulated phase change materials or other particulate inclusions in cementitious composites". In: Materials \& Design 126 (2017), pp. 259-267. DoI: 10.1016/j.matdes.2017.04.023. 
[329] Kaushik Biswas et al. "Combined experimental and numerical evaluation of a prototype nano-PCM enhanced wallboard". In: Applied Energy 131 (2014), pp. 517-529. Dor: 10.1016/j . apenergy . 2014.02 .047 .

[330] Camila Barreneche et al. "Comparison of three different devices available in Spain to test thermal properties of building materials including phase change materials". In: Applied Energy 109 (2013), pp. 421-427. DOI: $10.1016 / \mathrm{j}$. apenergy .2013.02.061.

[331] Huanzhi Zhang et al. "Preparation and thermal performance of gypsum boards incorporated with microencapsulated phase change materials for thermal regulation". In: Solar Energy Materials and Solar Cells 102 (2012), pp. 93-102. DOI: 10.1016/j.solmat.2012.03.020

[332] Cecilia Castellón et al. "Effect of microencapsulated phase change material in sandwich panels". In: Renewable Energy 35.10 (2010), pp. 2370-2374. DOI: 10.1016/j.renene.2010.03.030.

[333] Yeliz Konuklu and Halime O. Paksoy. "Phase Change Material Sandwich Panels for Managing Solar Gain in Buildings". In: Journal of Solar Energy Engineering 131.4 (2009), p. 041012. DOI: $10.1115 / 1.3197839$

[334] Gordon Nelson. "Application of microencapsulation in textiles". In: International Journal of Pharmaceutics 242.1-2 (2002), pp. 55-62. DOI: 10.1016/s0378-5173(02)00141-2.

[335] Sennur Alay, Fethiye Gde, and Cemil Alkan. "Synthesis and thermal properties of poly(n-butyl acrylate)/n-hexadecane microcapsules using different cross-linkers and their application to textile fabrics". In: Journal of Applied Polymer Science 120.5 (2011), pp. 2821-2829. DOI: 10.1002/app. 33266 .

[336] Meghdad Kamali Moghaddam and Sayed Majid Mortazavi. "Preparation, characterisation and thermal properties of calcium alginate/n-nonadecane microcapsules fabricated by electro-coextrusion for thermo-regulating textiles". In: Journal of Microencapsulation 32.8 (2015), pp. 737-744. DOI: $10.3109 / 02652048.2015 .1073388$

[337] Cemil Alkan, Sennur Alay Aksoy, and Ruhan Altun Anayurt. "Synthesis of poly(methyl methacrylateco-acrylic acid)/n-eicosane microcapsules for thermal comfort in textiles". In: Textile Research Journal 85.19 (2015), pp. 2051-2058. DOI: 10.1177/0040517514548751.

[338] Sennur Alay Aksoy et al. "Preparation and textile application of poly(methyl methacrylate-comethacrylic acid)/n-octadecane and n-eicosane microcapsules". In: The Journal of The Textile Institute 108.1 (2016), pp. 30-41. DOI: 10.1080/00405000.2015.1133128.

[339] Danmei Sun and Kashif Iqbal. "Synthesis of functional nanocapsules and their application to cotton fabric for thermal management". In: Cellulose 24.8 (2017), pp. 3525-3543. Dor: 10.1007/s10570017-1326-6.

[340] M. You et al. "Effects of MicroPCMs on the fabrication of MicroPCMs/polyurethane composite foams". In: Thermochimica Acta 472.1-2 (2008), pp. 20-24. DOI: 10.1016/j.tca.2008.03.006. 
[341] Ana M. Borreguero et al. "Characterization of rigid polyurethane foams containing microencapsulated Rubitherm®) RT27. Part I". In: Journal of Materials Science 45.16 (2010), pp. 4462-4469. DOI: $10.1007 / \mathrm{s} 10853-010-4529-\mathrm{x}$.

[342] Ana M. Borreguero et al. "Characterization of rigid polyurethane foams containing microencapsulated Rubitherm® RT27: catalyst effect. Part II". In: Journal of Materials Science 46.2 (2010), pp. 347-356. DOI: $10.1007 / \mathrm{s} 10853-010-4824-6$.

[343] Ana M. Borreguero et al. "Characterization of rigid polyurethane foams containing microencapsulted phase change materials: Microcapsules type effect". In: Journal of Applied Polymer Science 128.1 (2012), pp. 582-590. DOI: 10.1002/app.38226.

[344] Angel Serrano et al. "Reducing heat loss through the building envelope by using polyurethane foams containing thermoregulating microcapsules". In: Applied Thermal Engineering 103 (2016), pp. 226-232. DOI: $10.1016 /$ j.applthermaleng.2016.04.098.

[345] Xiaolin Qiu, Lixin Lu, and Zhenzhen Chen. "Preparation and characterization of flame retardant phase change materials by microencapsulated paraffin and diethyl ethylphosphonate with poly(methacrylic acid-co-ethyl methacrylate) shell". In: Journal of Applied Polymer Science 132.17 (2015), n/a-n/a. DOI: $10.1002 /$ app.41880

[346] Xiaolin Qiu et al. "Fabrication, thermal properties and thermal stabilities of microencapsulated n-alkane with poly(lauryl methacrylate) as shell". In: Thermochimica Acta 620 (2015), pp. 10-17. DOI: $10.1016 /$ j.tca.2015.10.001

[347] Xiaolin Qiu et al. "Fabrication, thermal property and thermal reliability of microencapsulated paraffin with ethyl methacrylate-based copolymer shell". In: Journal of Thermal Analysis and Calorimetry 124.3 (2016), pp. 1291-1299. DOI: 10.1007/s10973-016-5300-6

[348] Pengju Han et al. "Fabrication and characterization of a new enhanced hybrid shell microPCM for thermal energy storage". In: Energy Conversion and Management 126 (2016), pp. 673-685. DOI: $10.1016 /$ j.enconman.2016.08.052.

[349] D. M. Tobaldi et al. "Silver-Modified Nano-titania as an Antibacterial Agent and Photocatalyst". In: The Journal of Physical Chemistry C 118.9 (2014), pp. 4751-4766. DOI: 10.1021/jp411997k. 